\title{
Studies on the Ascaridia galli embryonal stages, potential maternal protection and immune response in chicken
}

Dissertation to obtain the Ph.D. degree in the International Ph.D. Program for Agricultural Sciences in Göttingen (IPAG) at the Faculty of Agricultural Sciences, Georg-August-University Göttingen

Shayan Rahimian 
Studies on the Ascaridia galli embryonal stages, potential maternal protection and immune response in chicken

Dissertation to obtain the Ph.D. degree in the International Ph.D. Program for Agricultural Sciences in Göttingen (IPAG) at the Faculty of Agricultural Sciences, Georg- August- University Göttingen

\section{Shayan Rahimian}

Born in Ramsar, Iran

Goettingen, Germany, November 2016 
D7

\section{Referee committee:}

\section{Prof. Dr. Dr. Matthias Gauly}

Faculty of Science and Technology, Universitätsplatz 5,39100, Freie Universität Bozen, Bolzano, Italy

\section{Prof. Dr. Christoph Knorr}

Department for Animal Sciences, University of Göttingen, Germany

Prof. Dr. Jürgen Hummel

Department for Animal Sciences, University of Göttingen, Germany

\section{Supervisors:}

Prof. Dr. Dr. Matthias Gauly

Faculty of Science and Technology, Universitätsplatz 5,39100, Freie Universität Bozen, Bolzano, Italy

Prof. Dr. Christoph Knorr

Department for Animal Sciences, University of Göttingen, Germany

Date of defense: 4.11 .2016 


\section{Dedicated to}

My first teacher in life "maman" and my kind dad "baba"

$$
\text { بيشكش به }
$$

نخستين استاد زندكى من "مامان" و بِر مهربان من "بابا" 


\section{Contents}

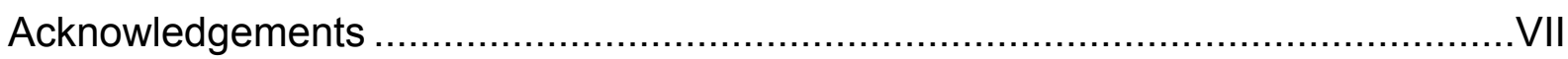

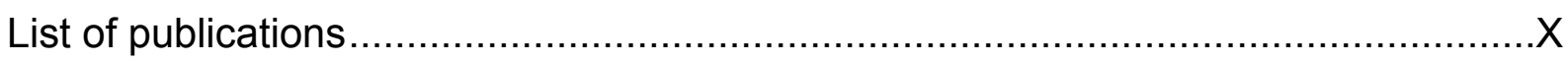

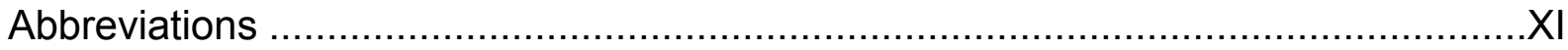

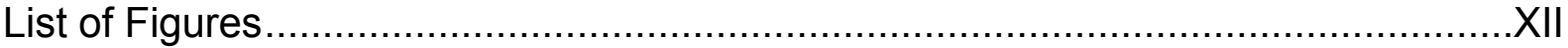

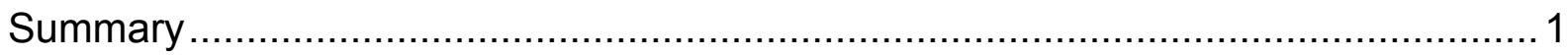

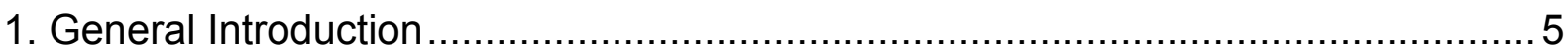

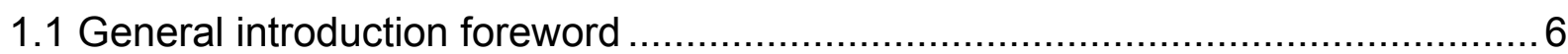

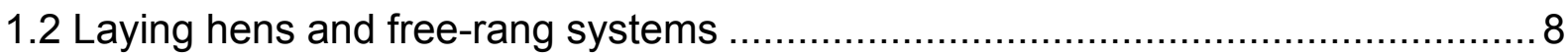

1.3 Nematodes and the importance of prevalent poultry nematodes …...................

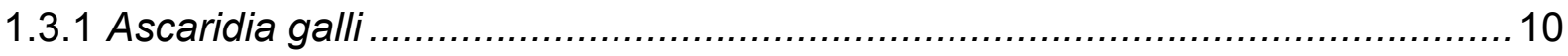

1.3.1.1 Embryonic development of A.galli eggs ........................................... 11

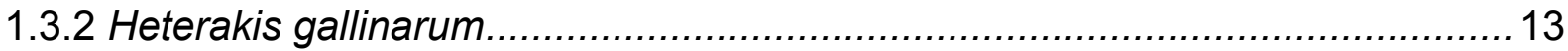

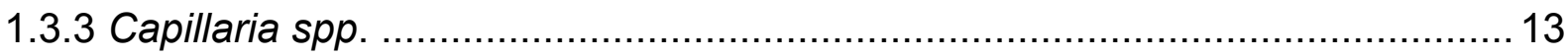

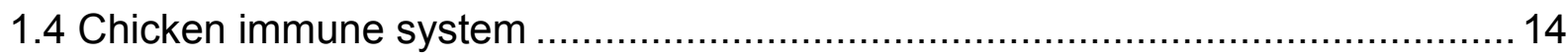

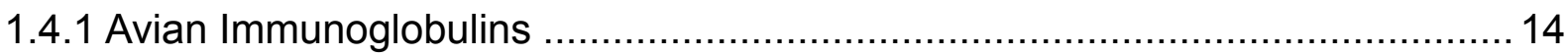

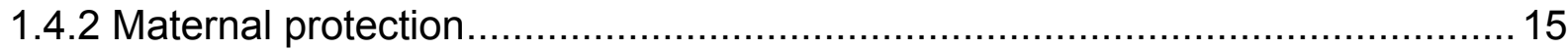

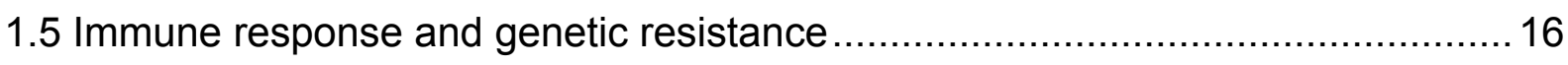

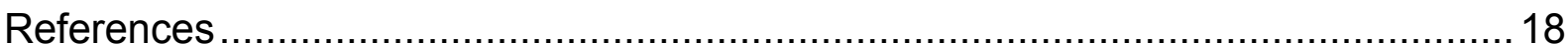


2. Paper 1: Embryonation ability of Ascaridia galli eggs isolated from worm uteri or host faeces

3. Paper 2: Maternal protection against Ascaridia galli?

4. Paper 3. Genetic variation for levels of total specific antibodies in naturally infected laying hens with gastrointestinal nematodes 44

5. General discussion. 67

5.1 General discussion foreword. 68

5.2 Ascaridia galli eggs originated from the same infrapopulation 68

5.2.1 In ovo embryonic development. 71

5.2.2 Different stages of in ovo embryonic development 72

5.3 Passive immunity induced by Ascaridia galli. 74

5.3.1 Infection dose on worm load and worm phenotypic association 74

5.3.2 Host gender on immune response and worm load 77

5.3.3 Maternal protection 77

5.4. Host genotype in immune response of free-range chicken 78

5.4.1. Chickens seroconversion 79

5.4.2. Phenotypic associations. 80

5.4.3. Possibility of infectivity diagnosis by antibody detection 81

5.5 General conclusion. 82 
References.

84

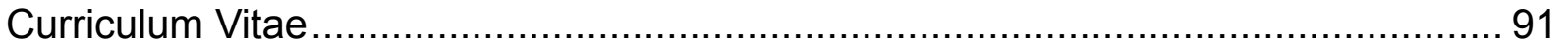




\section{Acknowledgments}

This milestone of my life took valuable time. Time to think, time to learn, time to get to know people and time to interact.

At Göttingen University I have had a good collegial place to do the above. Let me here collectively thank the Livestock production group for being so very helpful at times of need.

I am indebted to my supervisor Professor Dr. Dr. Matthias Gauly for his valuable support from the very beginning and guidance throughout the years. Prof. Gauly knew exactly how to push me forward. His sharp mind always detects difficulties in the steps ahead, as well as seeing the how to resolve these issues with pre-emptive measures. I owe much more to him than what is reflected in this thesis.

I also would like to thank Prof. Dr. Christoph Knorr and Prof. Dr. Jürgen Hummel for serving on my dissertation committee. Moreover, many thanks to Dr. Gürbüz Daş, with whom I enjoyed uncovering the puzzles of the nemaodes infection studies and publication challenges.

I would like to thank Dr. Uta König von Borstel for her kind concern and responsibilities as current head of our research group.

I gratefully acknowledge the financial support of the Erasmus Mundus program. I consider myself lucky to have received this grant for most of my PhD study period. Without this support, developing this thesis over the years would have been very difficult. 
Special thanks go to Professor Dr. Wolfgang Holtzt for his kindness and supportive nature and our endless political talks. The light of his office during the dark evenings was heartwarming.

The Livestock production research group would not function as a group without the great help and support of the administrative and technical staff. Many thanks to Dr. Christian Lamberz, Mr. Burchard Möllers, Ms. Döring and Ms. Thinggaard, who have helped me more than once finding a way through the mysterious labyrinths of the administrative university procedures and other issues.

Many thanks to Ms. Eli Stüwe, Ms. Birgit Sohnrey, Mr Erwin Tönges, Mr. Dieter Daniel and the animal caretakers for their kind help during laboratory and field work. I want to single out Ms. Birgit Sohnrey, Ms. Eli Stüwe and Ms. Andrea Aembrecht who have been struggling to talk Deutsch with me.

Over the last few years I have collaborated with many colleagues at the University of Göttingen, many of which I would now describe as friend. I would like to thank Dr. Johannes W.R Martini, Dr. Saber Qanbari, Dr. Mahmood Gholami and Ershad Tavakkol who have been a constant source of inspiration, motivation and friendship for me. Without their guidance I was not able to move forward through ' $R$ ' difficulties. I am grateful to Johannes Martini for the joyful company at the gym, which helped me to deal with the stresses of research. I am also very much indebted to my friends outside of the faculty at Göttingen University, who have supported me in many ways and who kept my life fun. Special thanks go to Reza Hosseinpourpia, Mohammad L. Mohammadi, Sarah Samavati, Juan Carlos Orozco Rey, Tahereh Ajam, Rashin Mofidian and Johannes Otte for helping me through difficult times and taking care of endless social gatherings that helped me stay positive. 
Lastly, my deepest gratitude goes to my close family for their unflagging support throughout my life. None of this would have been possible without the encouragement and understanding of my parents, my sisters Shaghayegh and Shabnam, my dear nephew Ahura and my brother-in-law Ebrahim.

Shayan Rahimian

Göttingen, September 2016 


\section{List of Publications}

This thesis is based on the following publications:

Paper 1: Shayan Rahimian, Matthias Gauly, Gürbüz Daş (2016): Embryonation ability of Ascaridia galli eggs isolated from worm uteri or host faeces. Veterinary Parasitology, Volume 215, Pages 29-34. DOI: 10.1016/j.vetpar.2015.10.026

Paper 2: Shayan Rahimian, Gürbüz Daş, Matthias Gauly (2016): Maternal protection against Ascaridia galli? Veterinary Parasitology. Veterinary Parasitology, Volume 233, Pages 43-47. DOI: 10.1016/j.vetpar.2016.11.014

Paper 3: Shayan Rahimian, Gürbüz Daş, Uta. König von Borstel, Matthias Gauly: Genetic variation for levels of total specific antibodies in naturally infected laying hens with gastrointestinal nematodes (In preparation) 


\section{Abbreviations and Acronnyms}

$\mathrm{Ab}$

Antibody

ELISA Enzyme Linked Immunosorbent Assay

EPG Number of parasite eggs per gram of faeces

EU European Union

FEC Faecal egg counts

GALT Chicken gut associated lymphoid tissue

Ig Immunoglobulin

mab+ Maternal antibody positive

mab- Maternal antibody negative

Tepg Total number of parasites eggs per gram of faeces

TMB ELISA substrate solution

TsAb Total specific antibody concentration

TWb Total worm burden

LB Lohmann Brown

LSL Lohmann Selected Leghorn

RT Room temperature

rG Genetic correlation

$\mu \mathrm{l} \quad$ Microliter

$\mathrm{nm} \quad$ Nanometer 


\section{List of figures}

Figure 1: Morphological characteristics of Ascaridia galli eggs at different developmental stages

Figure 2: Percentages of damaged eggs during the incubation period 70

Figure 3: Specific antibody responses from two different sources of

isolated eggs 71

Figure 4: Correlation between number of worms from both genders and worm characteristics 76 


\section{Summary}

Regarding to a lack of experimental infection models and different maturation ability of Ascaridia galli egg sources (Worm uteri and faeces) in a first study (Paper 1), A.galli eggs isolated from two different sources were investigated for different embryonic development capacities. The second study (Paper 2) showed no protective maternal immunity against $A$. galli in chicken. The objective was to investigate whether maternal antibody positive chicks are more resistant to A. galli infection than maternal antibody negative chicks. Free-range chickens are exposed to a high risk of nematode infections. Genetic selection for increased immunity could be an important tool to reduce problems due to infectious diseases - estimating the number of parasite eggs for an infectivity diagnosis can be unreliable in a free-range system. Thus the objectives of a third study (Paper 3 ) were to estimate genetic resistance to naturally acquired immune systems and infectivity diagnosis by estimating the total specific antibody responses against most prevalent nematodes in the free-range laying hen system.

The first experiment (Paper 1) was performed to investigate the embryonation ability of A. galli eggs, isolated from two different sources originating from 12 worm infrapopulations both from faeces of the living host (faecal eggs) and directly from worm uteri after host necropsy (uterine eggs). The isolated eggs from each infrapopulation and source were incubated in Petri dishes $(n=24)$ containing a potassium-dichromate $(0.1 \%)$ medium for 28 days at room temperature. In ovo larval development was evaluated every second day by examining morphological characteristics of 200 eggs/ Petri dish starting from the day of egg isolation (d0). A total of 72,000 eggs were classified into undeveloped, early development, vermiform 
or fully embryonated stages. Isolation procedures caused similar damage to uterine and faecal eggs $(2.2 \%$ and $0.5 \%$, respectively; $\mathrm{P}=0.180)$. The first sign of in ovo embryonic development in faecal eggs (7\%) was observed during the 24-hour period when faeces were collected. On d28, a higher percentage of uterine eggs remained undeveloped when compared with faecal eggs $(58.6 \%$ vs $11.0 \%$; $P<0.001)$. Although a higher $(\mathrm{P}<0.001)$ percentage of faecal eggs entered both the early developmental and vermiform stages, which took place primarily within the first two weeks of incubation, there was no time-shift between the development of faecal and uterine eggs. Starting from $\mathrm{d} 10$, higher $(P<0.05)$ percentages of faecal eggs completed embryonation compared with uterine equivalents.

The second experiment (Paper 2) was demonstrating whether chicks descending from nematode-infected hens are more resistant against Ascaridia galli, a prevalent gastrointestinal nematode, infection than infected offspring from nematode-free mothers. One-day-old chick offspring $(\mathrm{N}=153)$ from infected (mab+; maternal antibody+) or uninfected control dams (mab-) were experimentally infected with $A$. galli at two different concentrations (100 or 1000 eggs/chick). Female chickens exhibited significantly $(P<0.05)$ higher specific antibody concentrations $(2.355 \pm$ 0.211). The worm burdens of the chicks were determined at 6 weeks after infection. There was a high correlation $(r=0.89, \mathrm{P}<0.001)$ between $A$. galli-specific antibody concentrations in dam plasma and egg yolk. Dam and chick infection doses interaction had a significant effect $(\mathrm{P}<0.05)$ on worm burden and the highest infection rate $(21.2 \pm 2.95)$ occurring in mab+ chicks challenged with +1000 A. galli eggs. In chicks, lower doses of infection caused a difference in worm burden between the mab +/ - groups. Chick infection dose had a significant effect on female/ male 
harvested worms. There was also an interaction effect between maternal infection and chick infection with respect to worm weight.

The final study (Paper 3) was conducted on two genotypes of Brown hens (LB classic and LB plus) under practical free-range farm condition. Aims of this study were to describe genetic resistance to immune systems and infectivity diagnosis by estimating total specific antibody concentration ( $T s A b)$ against the most prevalent nematodes in free-range chicken systems. Chickens (17 weeks old) of two Lohmann brown genotypes (LB plus/ LB Classic) were examined for a laying period of one and a half years. Individually obtained plasma of the genotypes, LB plus $(n=200)$ and LB classic $(n=200)$ were used for detecting TsAb via the ELISA test before necropsy. Some birds were subjected to post-mortem parasitological examinations at 79 weeks (LB plus, $n=162$ ) or 88 weeks (LB classic, $n=139$ ) of age. There was a significant $(P<0.05)$ difference in total worm burden $(T W b)$ and TsAb in relation to the genetic background of the chickens in their response to naturally acquired nematode infections. Positive phenotypic correlations $(r=0.1, P=0.014)$ of $T s A b$ with the total epg (Tepg) before necropsy and no significant correlation $(r=-0.13, P=0.1)$ with TWb at necropsy were moderated. Slightly fluctuating increases of TsAb by age (weeks) were observed.

It is concluded that isolated A.galli eggs from both sources reached a plateau of embryonation by the end of the second week of incubation, with faecal eggs having more than a two-fold higher embryonation ability. Cumulative mortality was higher in uterine eggs $(14.3 \%)$ when compared to faecal eggs $(0.2 \%)$. Although lower worm burden in mab- chicks with resistant tendency against A.galli pathogen in maternal antibody positive (mab+) offspring was demonstrated, no protective immunity against A. galli infection was observed. In this free-range chicken system, the LB classic 
genotype was more susceptible to gastrointestinal nematodes than the LB plus genotype with higher total antibody responses before necropsy and lower total antibody responses at necropsy. Estimating total specific antibody responses is meaningful for infectivity diagnosis in a free-range chicken system. 
1. General introduction 


\subsection{General introduction foreword}

For thousands of years, poultry has supplied meat and eggs as one of the main sources of animal protein for humans. Although pork is the most widely eaten meat in the world, accounting for over $36 \%$ of the world meat intake, it is in fact followed by poultry with a difference of about $1 \%$ less (FAO, 2014). Approximately $80 \%$ of the world poultry population is kept as free-range (FAO, 2000). Consumer demand (Gauly et al., 2002; Wijga et al., 2009), European regulations for laying hens (Anonymous, 1999), prohibited cage systems for laying hens in the EU since 2012 (CEC, 1999), and improving the behavioural importance of laying hens (Schou et al., 2003) are main reasons to increase outdoor access poultry farms. In the free-range system, high re-emergence of nematode infections in chickens, mainly due to close contact with their faeces, which ensures the completion of the parasite life cycle via the effective faecal-oral transmission route (Kaufmann et al., 2011b; Permin et al., 1999; Wongrak et al., 2014). Thus, the prevalence of nematodes has increased and higher risks of parasite infections have been showed with highest prevalence of Heterakis gallinarum, Ascaridia galli and Capillaria spp. species respectively within Germany (Kaufmann et al., 2011b; Wongrak et al., 2014; Wongrak et al., 2015). In Sweden $H$. gallinarum is not as prevalent as in Germany (Höglund and Jansson, 2011; Jansson et al., 2010). Female nematodes only lay mature eggs (Kim et al., 2012) and all isolated eggs from worm uteri are not mature or able to complete embryonation (Tiersch et al., 2013). Low reported establishment rates and worm burdens (Daş et al., 2010; Ferdushy et al., 2013; Marcos-Atxutegi et al., 2009) in experimental $A$. galli infection studies show the lack of a proper experimental infection model relying on the use of eggs isolated either directly from worm uteri (uterine eggs) or from host faeces (faecal eggs). A. galli infection stimulates a strong 
immune response in the host (Marcos-Atxutegi et al., 2009). Development immunity is caused by parasitic infections and demands a costly process requiring high metabolic inputs (Colditz, 2008). Transferred maternal antibodies via egg yolk (passive immunity) are the primary means of protection against infection in very young chickens (Ahmed and Akhter, 2003; Brambell, 1970; Gharaibeh et al., 2008; Hamal et al., 2006; Heller et al., 1990; Jungherr and Terrell, 1948; Kowalczyk et al., 1985; Mockett et al., 1987; Mondal and Naqi, 2001). Host genetic factors influence the immunoglobulin responses of most common gastrointestinal nematodes of swine and chicken (Kringel et al., 2015; Norup et al., 2013). Genetic selection for increased immunity proved an important tool to reduce problems due to infection diseases in chickens (Pinard et al., 1992). In addition, selection experiments for high and low antibody responses in chickens and diagnosis investigating antibody levels have been reported (Campos-da-Silva et al., 2015; Martin et al., 1990; Zhao et al., 2012). In the free-range system, infectivity estimating by parasite eggs is not precise because of combination of different nematode species (Wongrak et al., 2014), phenotypic similarity of some nematodes ( $H$. gallinarum and $A$. galli eggs) eggs (Thienpoint, 1986) as well as the sensitivity of the epg method (Cringoli et al., 2010; Das et al., 2011b; Michael and Bundy, 1989).

Although disinfection and pharmaceuticals are expensive options with which to control parasites (Gauly et al., 2001), synthetic anthelmentics still remain the most essential part of parasite control against $A$. galli. Currently, only benzimidazoles are available for the treatments of nematodes in laying hens in EU members (Tarbiat et al., 2016). Anthelmintic usage is crucial due to financial cost (Wijga et al., 2009), anthelmintic resistance (Johnston et al., 2012), left-over residues in food products (Johnston et al., 2012), and the upcoming limitations on the use of antibiotics. Thus, 
it is very important to investigate alternative methods that can lead to increases in host resistant to infectious diseases concerning the effective control of nematodes.

\subsection{Laying hens and free-rang systems}

There are clear links between good animal welfare and improved production. Diseases, morbidity and mortality all lead to loss of production, which can be addressed through improvements in welfare (Appleby M.C. and Hughes B.O., 1991). Hens in battery cages spend their lives in artificial space designed to maximise production activity (Widowski, 2002). The directive prohibits the use of battery cages from the $1^{\text {st }}$ of January 2012 (CEC, 1999). Conventional cages have decreased dramatically since 2008 , and in $2009,20 \%$ of farms were using conventional cages system beside their free-range system. From 2009 to 2013 the deep litter system did not increase a great deal, from $60 \%$ to $63.8 \%$, and an increase $(27.8 \%)$ was also very low $(7.8 \%)$ for free-range system in 2013 . In 2013 just $9.9 \%$ of poultry systems were cage based (Wongrak, 2014). Free-range chickens must not only have access to outdoor runs and day light, but must also have indoor housing at night (Shimmura et al., 2010; Stevenson, 2012). Chickens in appropriate free-range farming systems are considered to be more healthy, having stronger immune systems and welfare

improvement than those in cage systems (Shimmura et al., 2010). Despite a Swedish study not able to find a significant infectivity difference between the organic, conventional and non-cage systems (Höglund and Jansson, 2011; Jansson et al., 2010), chickens kept in free-range systems are subjected to an increased risk of some parasites (Wongrak et al., 2014). 


\subsection{Nematodes and the importance of prevalent poultry nematodes}

Nematodes (endoparasites) belong to the phylum Nemathelminthes, class Nematoda, the most common helminth species in poultry with a cylindrical and elongated shape. All nematode worms have an alimentary tract with separate sexes. The life cycle may be direct or indirect including an intermediate host (Permin and Hansen, 1998b). Species with a direct life cycle are more frequent under intensive farming conditions where constant temperatures and humidity are ideal for larval development. Species with indirect life cycles are particularly abundant in traditional farms with birds kept outdoors, especially in humid and humus-rich soils that are favorable for earthworm development. Thus, Ascaid infections occur in non-caged chickens worldwide (Permin and Hansen, 1998a). The body of a nematode has unique characteristics, such as a carbohydrate-rich surface coat (Fetterer and Rhoads, 1993) and by moulting several times throughout their development cycle they change their antigenic and cuticular surface (Blaxter et al., 1992), which play dominant role that how parasites are perceived by a host's innate defense system. Many problems caused by nematodes have been investigated in this studies, such as reduced growth, nematodes working as a major transport host of the aetiological agent of blackhead, Histomonas meleagridis by $\mathrm{H}$. gallinarum infection (Das et al., 2011a; McDougald, 2005), reduced weight gain, diarrhea due to C. Spp infection (Wakelin, 1965) and reduced egg production, growth, weight loss, increasing susceptibility to secondary infections and founded worms in table eggs for A.galli infection (Chadfield et al., 2001; Dahl et al., 2002; Daş et al., 2010; Höglund and Jansson, 2011; Permin et al., 2006; Skallerup et al., 2005) has been investigated as major problems caused by mentioned prevalent nematodes. 


\subsubsection{Ascaridia galli}

Ascaridia galli, a most pathogenic and one of the largest ascarids of poultry has a direct life cycle, including a faecal oral route of transmission of eggs (Jansson et al., 2010; Ramadan and Abou Znada, 1991; Skallerup et al., 2005). The life cycle of $A$. galli involves two principal populations: free living infective stage (L2 or L3) in the form of a resistant egg in the environment (Ackert, 1931; Araujo and Bressan, 1977; Ferdushy et al., 2012; Herd and McNaught, 1975; Luna-Olivares et al., 2012) and a histotrophic or mucosal phase. The latter starts on the first day after infection via ingestion of the infected egg. The larvae hatches in less than one hour in the anterior third of the intestine (Moran and Mizelle, 1957). Larvae then begins to penetrate in the jejunal mucosa (Luna-Olivares et al., 2012) - sexually mature parasites live in the gastrointestinal tract (lumen of small intestine). The prepatent periods (time between infection and shedding of the first eggs) of $A$. galli may have a duration of between two to seven weeks. Adult female worms are between 6 to $11.6 \mathrm{~cm}$ in length and adult male worms between 4.2 to $7.6 \mathrm{~cm}$. The gender of $A$. galli worms can differentiate between anterior and posterior ends (Taylor et al., 2015) and eggs are oval in shape with 45-57 $\mu \mathrm{m}$ width and 73-92 $\mu \mathrm{m}$ length (Ackert, 1931). Eggs of A.galli are known to be highly resistant and easily obtainable (Barrett, 1976; Katakam et al., 2014). Thick-shelled $A$. galli eggs can survive and remain infective for long periods of time in the soil (Hauck and Hafez, 2013). These eggs have three inner layers and consist of the inner lipid layer, middle chitinous layer and outer vitelline layer formed endogenously form the fertilised oocytes. Moreover, there is one outer uterine layer formed exogenously from the uterus of female worms (Wharton, 1980). 


\subsubsection{Embryonic development of A.galli eggs}

Embryonic development of $A$. galli eggs is mainly dependent on oxygen (Ackert, 1931), temperature and humidity (Permin and Hansen, 1998b; Tarbiat et al., 2015) with the varied length of embryonic development between 1 to 8 weeks depending on various environmental conditions (Onyirioha, 2011; Ramadan and Abou Znada, 1991; Tarbiat et al., 2015). Microscopic in ovo embryonic development examinations are feasible due to different embryonic stage criteria (Figure 1 a-i). Infertile eggs either have poorly defined structures, contraction, rupture or no monitored larvae movement. Fertile eggs start development by dividing them into large blastomeres from two to eight or 11 cells as cleavage or when at the early-morula stage. This stage continues to morula or late-morula stage by dividing into smaller blastomeres before blastula or the initial stage of differentiation, which is cleared by a spherical layer of cells surrounding a fluid-filled cavity. The formation takes place as follows: the balstula changes to the tadpole or gastrula stage and forms a kidney shape invagination on one side of the embryo. Afterwards, the embryo will turn into larval shape. Finally, a slender, coiled and motile larva develops, followed by the formation of the head and tail, completing the embryo which is embryonated stage (Caceres et al., 1987; Cruz et al., 2012; Ramadan and Abou Znada, 1991). 


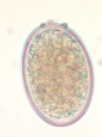

a

b

C

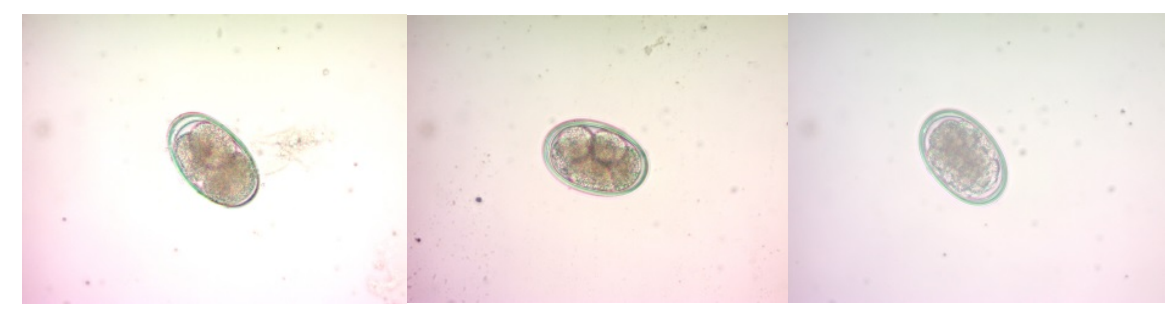

d

e

$\mathbf{f}$

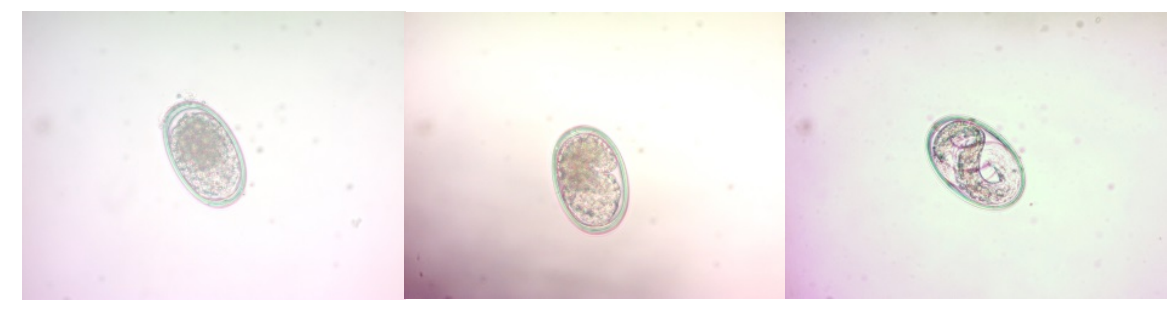

g

h $\quad$ i

Figure 1. Morphological characteristics of Ascaridia galli eggs at different developmental stages.

Undeveloped eggs: infertile (a) or fertile (b); early development (c-f): egg cells at division stages from cleavage to morula; vermiform $(g, h)$ : initial stage of differentiation (blastula: g) and tadpole or a motile mass (gastrula: h); embryonated (i): a slender, coiled and motile larva develops, followed by a head and tail, completing the formation. 


\subsubsection{Heterakis gallinarum}

Heterakis gallinarum has a direct life cycle including a faecal oral route for the transmission of eggs (Jansson et al., 2010) and can infect chickens indirectly via the ingestion of infected earthworms as well. The free living infective stage of $H$. gallinarum eggs is less than two weeks. After digestion through host larvae, hatching in a small intestine and passing down to the caeca. Worms of $H$. gallinarum are white and reside in the lumen of caeca, much smaller than $A$. galli worms in size (seven to $13 \mathrm{~mm}$ and 10 to $15 \mathrm{~mm}$ in length of male and female worms respectively). Compared to $A$. galli, $H$. gallinarum hardly ever causes clinical issues but it can be a transport host as explained before with nematodes (Morishita et al., 2008).

\subsubsection{Capillaria spp.}

This nematode is similar to $H$. gallinarum in that it may have a direct or indirect life cycle. In ovo embryonic development of eggs deposited by faeces is between nine to 14 days for direct and between 14 to 21 days for indirect cycles in earthworms respectively - the prepatent period is around three weeks. Hair-like worms are very thin and difficult to detect in intestinal content compared to some of the other nematodes described. Male worms are between six to $35 \mathrm{~mm}$ in length and female between 6 to $80 \mathrm{~mm}$, depending on the different species of Capillaria spp. nematode. Different species of Capillaria spp. are located throughout the intestinal tract (small intestine or caeca) or in crops (Permin and Hansen, 1998b). 


\subsection{Chicken immune system}

Both mammals and birds transfer maternal antibodies to their offspring and respond to pathogens with two broad arms of the immune response, innate and adaptive. Birds are different in terms of their lung ventilation system (Davison, 2008), presence or absence of lymphoid organs, antibody response, diversity of antibodies and maternal transfer of antibodies with mammals (Koch, 1991). Basically, the immune system of a bird has two types of defense system: innate (non-specific) and adaptive (specific) immunity. Natural antibodies, as part of an innate immune system present in the body play an important role in the first line of defense as part of the immune system, without a known antigenic stimulation of B cells (Parmentier et al., 2004; Siwek et al., 2006).

Adaptive immune responses consist of humoral (involving antibodies) and cellmediated (refers to $T$ lymphosites and macrophages) immunity. Chicken lymphocytes (cellular components of adaptive immunity) consist of B cells, which develop in the bursa of fabricius, making antibodies ( $\lg M, \lg Y$ and $\lg A)$ and $T$ cells that develop in the thymus. These lymphocytes have a homogenous set of antigenreceptors specific for a given antigen (Davison, 2008; Erf, 1997).

\subsubsection{Avian Immunoglobulins}

Glycoproteins, which have antibody (Ab) activity are immunoglobulins (Ig) (Marchalonis, 1977). The basic structure consists of four polypeptide chains, two heavy and two light. There are three main classes of avian immunoglobulins as the homologues of mammalian: $\lg \mathrm{M}, \lg \mathrm{A}$ and $\lg \mathrm{G}$ or immunoglobulin $\mathrm{Y}(\lg \mathrm{Y})$ as a major 
avian systemic antibody active in infections and has a longer heavy chain compared to the mammalian counterpart. There is no avian homologue for $\lg D$ and $\lg E$ isotype in avian. It seems likely that functions of mammalian $\lg E$ are performed by $\lg G(\lg Y)$ in avain (Davison et al., 2008). In chicken a spleen, IgM, IgG and IgA secreting cells detected 3 and 6 days post hatching respectively. All adult levels of Ig secreting cells were obtained 31 days after infection in the bone marrow even though they are not detectable after 50 days in the spleen or lungs (Lawrence et al., 1981). In chicken eggs, $\lg Y$ is a primary immunoglobulin isotype of the egg yolk (Leslie and Clem, 1969). No IgY was detected from the fresh egg albumin, appeared later from the fourth day of embryogenesis and persisted until 16 days afterwards (Kramer and Cho, 1970). IgA and IgM are mainly found in the albumen, as result of mucosal secretion in the oviduct (Rose et al., 1974). Here, the transfer of $\lg A$ and $\lg M$ antibodies from egg white to egg yolk occurs at a very low concentration (Kaspers et al., 1996).

\subsubsection{Maternal protection}

The transfer of maternal immunoglubulins to new born chicks is a two-step process that confess passive immunity. It is believed that oviductal secretions and yolk are the main paths of maternal immunoglubulin transfer from dam to offspring and that antibodies secreted to oviducts are produced from glandular cells of oviduct or plasma cell-like cells in the storma (Kimijima et al., 1990; Zheng et al., 2000). The first step is the transport of maternal lgY from dam plasma to maturing oocute in the ovarian follicle. The second step involves the uptake of a yolk IgY across a yolk sac endoderm by specific receptors across the cell with a release into the fetal 
circulation. The rate of transfer starts to increase from embryonic day 14 to 21 (Brambell, 1970; Kowalczyk et al., 1985). By injecting specific antibodies into the yolk sac and measuring the titre presented in the emebryonic cerculation at a later time, the antibody transfer from egg yolk to offspring is investigated (Brierley and Hemmings, 1956). Maternal dietary status may also influence the transmission of antibodies via the egg yolk sac in birds (Hoi-Leitner et al., 2001; Jackson et al., 1978).

Newly hatched chicks lack a fully developed immune system and immunization one day after hatching does not activate antibody production (Mast and Goddeeris, 1999). These are abruptly exposed after hatching to a wide range of environmental antigens. Thus, the post-hatching period is crucial and maternally derived antibodies can be an important part of the protective immune mechanisms of young chicks (Mockett et al., 1987). Maternal Ig transferred via egg yolks can protect chicks against bacterial toxins, bacteria, parasites and viruses after hatching (Fellah et al., 2008; Hamal et al., 2006). Maternally derived antibodies provide the primary form of humoral immune defense for offspring early in life (Brambell, 1970) and lasts a long time in the serum. For instance, transferred antibodies for the Infectious Bronchis Virus last for around two weeks in the serum is chicks (Jungherr and Terrell, 1948).

\subsection{Immune response and genetic resistance}

The genetic structure of animals and humans affects their susceptibility to helminth infections and immune response (Cuenco et al., 2009; Kringel et al., 2015; Nejsum et al., 2009). Some individuals show considerably more resistance than others and variation in the ability to resist infection with helminth has been documented. There 
are two different levels of resistance, natural and acquired resistance. In natural resistance the host fails to establish infection. When the host establishes an infection but then fails to complete development or eliminate the infection acquired resistance has occurred and it's heavily dependant on the adaptive immune response. Genetic resistance shows a significantly higher level of resistance compared to the mean response of the population involving many genes (Stear and Wakelin, 1998). The genetic background of chicken's influencing the $A$. galli infection has been studied a great deal (Gauly et al., 2002; Schou et al., 2003). Investigations into the genetic resistance to nematode burdens and antibody responses in chickens has concluded that this criteria is heritable (Bovenhuis et al., 2002; Gauly et al., 2008; Kaufmann et al., 2011a; Norup et al., 2013; Wijga et al., 2009). 


\section{References}

Ackert, James E. 1931. The Morphology and Life History of the Fowl Nematode Ascaridia lineata (Schneider). Parasitology 23: 360-379. doi: doi:10.1017/S0031182000013731

Ahmed, Zaheer and Saeed Akhter 2003. Role of maternal antibodies in protection against infectious bursal disease in commercial broilers. Int. J. Poult. Sci., 2: 251-255.

Anonymous 1999. Council directive 1999/74/EC laying down minimum standards for the protection of laying hens. Official Journal of the European Communities L: 00530057.

Appleby M.C. and Hughes B.O. 1991. Welfare of laying hens in cages and alternative system: environmental, physical and behavioral aspects. Worlds Poult Sci J 47: 19108.

Araujo, P. and C. R. Bressan 1977. [Observations on the second moult of the larvae of Ascaridia galli (author's transl)]. Ann Parasitol Hum Comp 52: 531-537.

Barrett, J. 1976. Studies on the induction of permeability in Ascaris lumbricoides eggs. Parasitology 73: 109-121.

Blaxter, M. L., A. P. Page, W. Rudin and R. M. Maizels 1992. Nematode surface coats: actively evading immunity. Parasitol Today 8: 243-247.

Bovenhuis, H., H. Bralten, M. G. Nieuwland and H. K. Parmentier 2002. Genetic parameters for antibody response of chickens to sheep red blood cells based on a selection experiment. Poult Sci 81: 309-315.

Brambell, F. W. R. 1970. Transmition of immunity in birds. In the transmition of Passive Immunity from Mother to Young. New York: Elsevier 18. (ed. A. Neuberger and E.L. Tatum): 20-41.

Brierley, Joan and W. A. Hemmings 1956. The Selective Transport of Antibodies from the Yolk Sac to the Circulation of the Chick. J. Embryol. exp. Morph. 4: 34-41. 
Caceres, A., A.M. Xet and G. Flores 1987. Simplified methodology for helminth eggs counts and viability in organic fertilizer. Second Meeting on Use of Human Waste in Agriculture and Aquaculture, 15-16 June, Adelboden, Switzerland.

Campos-da-Silva, D. R., J. S. da Paz, V. R. Fortunato, M. A. Beltrame, L. C. Valli and F. E. Pereira 2015. Natural infection of free-range chickens with the ascarid nematode Toxocara sp. Parasitol Res., 114: 4289-4293. doi: 10.1007/s00436-015-4669-7

CEC, . 1999. Laying down minimum standars for protection of laying hens. O.J.E.U.L 203: $53-57$.

Chadfield, M., A. Permin, P. Nansen and M. Bisgaard 2001. Investigation of the parasitic nematode Ascaridia galli (Shrank 1788) as a potential vector for Salmonella enterica dissemination in poultry. Parasitol Res., 87: 317-325.

Colditz, I. G. 2008. Six costs of immunity to gastrointestinal nematode infections. Parasite Immunol 30: 63-70. doi: 10.1111/j.1365-3024.2007.00964.x

Cringoli, G., L. Rinaldi, M. P. Maurelli and J. Utzinger 2010. FLOTAC: new multivalent techniques for qualitative and quantitative copromicroscopic diagnosis of parasites in animals and humans. Nat Protoc 5: 503-515. doi: 10.1038/nprot.2009.235

Cruz, Ligia M., Michael Allanson, Boo Kwa, Azliyati Azizan and Ricardo Izurieta 2012. Morphological Changes of Ascaris spp. Eggs During Their Development Outside the Host. J. Parasitol., 98: 63-68. doi: 10.1645/ge-2821.1

Cuenco, K. T., E. A. Ottesen, S. A. Williams, T. B. Nutman and C. Steel 2009. Heritable factors play a major role in determining host responses to Wuchereria bancrofti infection in an isolated South Pacific island population. J Infect Dis 200: 1271-1278. doi: $10.1086 / 605844$

Dahl, C., A. Permin, J. P. Christensen, M. Bisgaard, A. P. Muhairwa, K. M. D. Petersen, J. S. D. Poulsen and A. L. Jensen 2002. The effect of concurrent infections with Pasteurella multocida and Ascaridia galli on free range chickens. Vet Microbiol., 86: 313-324. doi: http://dx.doi.org/10.1016/S0378-1135(02)00015-9 
Das, G., H. Abel, J. Humburg, A. Schwarz, S. Rautenschlein, G. Breves and M. Gauly 2011a. Non-starch polysaccharides alter interactions between Heterakis gallinarum and Histomonas meleagridis. Vet Parasitol 176: 208-216. doi: 10.1016/j.vetpar.2010.11.004

Das, G., T. Savas, F. Kaufmann, A. Idris, H. Abel and M. Gauly 2011b. Precision, repeatability and representative ability of faecal egg counts in Heterakis gallinarum infected chickens. Vet Parasitol 183: 87-94.

Daş, Gürbüz, Falko Kaufmann, Hansjörg Abel and Matthias Gauly 2010. Effect of extra dietary lysine in Ascaridia galli-infected grower layers. Vet Parasitol., 170: 238-243. doi: http://dx.doi.org/10.1016/j.vetpar.2010.02.026

Davison, Fred 2008. 1 - THE IMPORTANCE OF THE AVIAN IMMUNE SYSTEM AND ITS UNIQUE FEATURES. In Avian Immunology, 1-I. London: Academic Press.

Davison, Fred, Katharine E. Magor and Bernd Kaspers 2008. 6 - STRUCTURE AND EVOLUTION OF AVIAN IMMUNOGLOBULINS. In Avian Immunology, 107-127. London: Academic Press.

Erf, G. F. 1997. Immune system function and developmnet in broilers. Center of Excellence for Poult. Sci., ed. Univ. Arkansas, Fayetteville.

FAO 2014. Animal Production and Health, Meat and Meat products, Sources of meat. FAO, FAOSTAT 2000. Statistical database of Food and Agriculture Organization of the United Nations Rome Italy.

Fellah, Julien S., Thierry Jaffredo and Dominique Dunon 2008. 3 - DEVELOPMENT OF THE AVIAN IMMUNE SYSTEM. In Avian Immunology, 51-V. London: Academic Press.

Ferdushy, T., L. A. Luna-Olivares, P. Nejsum, A. K. Roepstorff, S. M. Thamsborg and N. C. Kyvsgaard 2013. Population dynamics of Ascaridia galli following single infection in young chickens. Parasitology 140: 1078-1084. doi: doi:10.1017/S0031182013000401

Ferdushy, T., P. Nejsum, A. Roepstorff, S. M. Thamsborg and N. C. Kyvsgaard 2012. Ascaridia galli in chickens: intestinal localization and comparison of methods to 
isolate the larvae within the first week of infection. Parasitology research 111: 22732279. doi: $10.1007 / s 00436-012-3079-3$

Fetterer, R. H. and M. L. Rhoads 1993. Biochemistry of the nematode cuticle: relevance to parasitic nematodes of livestock. Vet Parasitol 46: 103-111.

Gauly, M., C. Bauer, C. Mertens and G. Erhardt 2001. Effect and repeatability of Ascaridia galli egg output in cockerels following a single low dose infection. Vet Parasitol 96: 301-307.

Gauly, M., C. Bauer, R. Preisinger and G. Erhardt 2002. Genetic differences of Ascaridia galli egg output in laying hens following a single dose infection. Vet Parasitol 103: 99-107.

Gauly, M., A. Kanan, H. Brandt, S. Weigend, E. Moors and G. Erhardt 2008. Genetic resistance to Heterakis gallinarum in two chicken layer lines following a single dose infection. Vet Parasitol 155: 74-79. doi: 10.1016/j.vetpar.2008.04.008

Gharaibeh, S., K. Mahmoud and M. Al-Natour 2008. Field Evaluation of Maternal Antibody Transfer to a Group of Pathogens in Meat-Type Chickens. Poult Sci 87: 1550-1555. doi: $10.3382 / p s .2008-00119$

Hamal, K. R., S. C. Burgess, I. Y. Pevzner and G. F. Erf 2006. Maternal antibody transfer from dams to their egg yolks, egg whites, and chicks in meat lines of chickens. Poult Sci 85: 1364-1372.

Hauck, R. and H. M. Hafez 2013. Experimental infections with the protozoan parasite Histomonas meleagridis: a review. Parasitology research 112: 19-34. doi: $10.1007 / \mathrm{s} 00436-012-3190-5$

Heller, E. D., H. Leitner, N. Drabkin and D. Melamed 1990. Passive immunisation of chicks against Escherichia coli. Avian pathology : journal of the W.V.P.A 19: 345-354. doi: $10.1080 / 03079459008418685$

Herd, R. P. and D. J. McNaught 1975. Arrested development and the histotropic phase of Ascaridia galli in the chicken. Int J Parasitol 5: 401-406. 
Höglund, Johan and Désirée S. Jansson 2011. Infection dynamics of Ascaridia galli in noncaged laying hens. Vet Parasitol 180: 267-273. doi:

http://dx.doi.org/10.1016/j.vetpar.2011.03.031

Hoi-Leitner, Maria, Marilo Romero-Pujante, Herbert Hoi and A. Pavlova 2001. Food Availability and Immune Capacity in Serin (Serinus serinus) Nestlings. Behav Ecol Sociobiol 49: 333-339.

Jackson, D. W., G. R. Law and C. F. Nockels 1978. Maternal vitamin E alters passively acquired immunity of chicks. Poult Sci 57: 70-73.

Jansson, D. S., A. Nyman, I. Vagsholm, D. Christensson, M. Goransson, O. Fossum and J. Hoglund 2010. Ascarid infections in laying hens kept in different housing systems. Avian pathology : journal of the W.V.P.A 39: 525-532. doi:

$10.1080 / 03079457.2010 .527923$

Johnston, Claire E., Catherine Hartley, Anne-Marie Salisbury and Paul Wigley 2012. Immunological changes at point-of-lay increase susceptibility to Salmonella enterica serovar enteritidis infection in vaccinated chickens. PLoS ONE 7: e48195. doi: 10.1371/journal.pone.0048195

Jungherr, E.L. and N.L. Terrell 1948. Naturally acquired passive immunity to infectious bronchitis in chicks. Am J Vet Res 9: 201-205.

Kaspers, B., H. Bondl and T. W. Gobel 1996. Transfer of IgA from albumen into the yolk sac during embryonic development in the chicken. Zentralbl Veterinarmed A 43: 225231.

Katakam, Kiran Kumar, Helena Mejer, Anders Dalsgaard, Niels Christian Kyvsgaard and Stig Milan Thamsborg 2014. Survival of Ascaris suum and Ascaridia galli eggs in liquid manure at different ammonia concentrations and temperatures. Vet Parasitol 204: 249-257. doi: http://dx.doi.org/10.1016/j.vetpar.2014.05.017

Kaufmann, Falko, Gürbüz Daş, Rudolf Preisinger, Matthias Schmutz, Sven König and Matthias Gauly 2011a. Genetic resistance to natural helminth infections in two 
chicken layer lines. Vet Parasitol 176: 250-257. doi:

http://dx.doi.org/10.1016/j.vetpar.2010.11.007

Kaufmann, Falko, Gürbüz Daş, Birgit Sohnrey and Matthias Gauly 2011b. Helminth infections in laying hens kept in organic free range systems in Germany. Livestock Science 141: 182-187. doi: http://dx.doi.org/10.1016/j.livsci.2011.05.015

Kim, Min-Ki, Kyoung-Ho Pyo, Young-Sang Hwang, Ki Hwan Park, In Gyun Hwang, Jong-Yil Chai and Eun-Hee Shin 2012. Effect of Temperature on Embryonation of Ascaris suum Eggs in an Environmental Chamber. The Korean Journal of Parasitology 50: 239-242. doi: 10.3347/kjp.2012.50.3.239

Kimijima, T., Y. Hashimoto, H. Kitagawa, Y. Kon and M. Sugimura 1990. Localization of immunoglobulins in the chicken oviduct. Nihon Juigaku Zasshi 52: 299-305.

Koch, G. 1991. The immune system in poultry. Tijdschr Diergeneeskd 116: 728-734.

Kowalczyk, K., J. Daiss, J. Halpern and T. F. Roth 1985. Quantitation of maternal-fetal IgG transport in the chicken. Immunology 54: 755-762.

Kramer, T. T. and H. C. Cho 1970. Transfer of immunoglobulins and antibodies in the hen's egg. Immunology 19: 157-167.

Kringel, Helene, Stig Milan Thamsborg, Heidi Huus Petersen, Harald Heinz Herbert Göring, Per Skallerup and Peter Nejsum 2015. Serum antibody responses in pigs trickleinfected with Ascaris and Trichuris: Heritabilities and associations with parasitological findings. Vet Parasitol 211: 306-311. doi: http://dx.doi.org/10.1016/j.vetpar.2015.06.008

Lawrence, E. C., F. Arnaud-Battandier, J. Grayson, I. R. Koski, N. J. Dooley, A. V. Muchmore and R. M. Blaese 1981. Ontogeny of humoral immune function in normal chickens: a comparison of immunoglobulin-secreting cells in bone marrow, spleen, lungs and intestine. Clinical and Experimental Immunology 43: 450-457.

Leslie, G. A. and L. W. Clem 1969. Phylogen of immunoglobulin structure and function. 3. Immunoglobulins of the chicken. J Exp Med 130: 1337-1352. 
Luna-Olivares, Luz Adilia, Tania Ferdushy, Niels Christian Kyvsgaard, Peter Nejsum, Stig Milan Thamsborg, Allan Roepstorff and Tine Moesgaard Iburg 2012. Localization of Ascaridia galli larvae in the jejunum of chickens 3 days post infection. Vet Parasitol 185: 186-193. doi: http://dx.doi.org/10.1016/j.vetpar.2011.10.025

Marchalonis, J.J. 1977. Immunity in Evolution. Harvard University Press, Boston, MA. Marcos-Atxutegi, C., B. Gandolfi, T. Arangüena, R. Sepúlveda, M. Arévalo and F. Simón 2009. Antibody and inflammatory responses in laying hens with experimental primary infections of Ascaridia galli. Vet Parasitol 161: 69-75. doi: http://dx.doi.org/10.1016/j.vetpar.2008.12.011

Martin, A., E. A. Dunnington, W. B. Gross, W. E. Briles, R. W. Briles and P. B. Siegel 1990. Production traits and alloantigen systems in lines of chickens selected for high or low antibody responses to sheep erythrocytes. Poult Sci 69: 871-878.

Mast, J. and B. M. Goddeeris 1999. Development of immunocompetence of broiler chickens. Vet Immunol Immunopathol 70: 245-256.

McDougald, L. R. 2005. Blackhead disease (histomoniasis) in poultry: a critical review. Avian Dis 49: 462-476. doi: $10.1637 / 7420-081005 r .1$

Michael, E. and D. A. Bundy 1989. Density dependence in establishment, growth and worm fecundity in intestinal helminthiasis: the population biology of Trichuris muris (Nematoda) infection in CBA/Ca mice. Parasitology 98: 451-458.

Mockett, A. P., J. K. Cook and M. B. Huggins 1987. Maternally-derived antibody to infectious bronchitis virus: Its detection in chick trachea and serum and its role in protection. Avian pathology : journal of the W.V.P.A 16: 407-416. doi: $10.1080 / 03079458708436391$

Mondal, S. P. and S. A. Naqi 2001. Maternal antibody to infectious bronchitis virus: its role in protection against infection and development of active immunity to vaccine. Vet Immunol Immunopathol 79: 31-40.

Moran, Joseph F. and John D. Mizelle 1957. Studies on Ascaridia galli (Schrank, 1758). The American Midland Naturalist 58: 170-181. doi: 10.2307/2422368 
Morishita, Teresa Y., Jordan C. Schaul and David G. Baker 2008. Parasites of Birds. In Flynn's Parasites of Laboratory Animals, 217-301: Blackwell Publishing Ltd.

Nejsum, P., A. Roepstorff, C. B. Jorgensen, M. Fredholm, H. H. Goring, T. J. Anderson and S. M. Thamsborg 2009. High heritability for Ascaris and Trichuris infection levels in pigs. Heredity (Edinb) 102: 357-364. doi: 10.1038/hdy.2008.131

Norup, Liselotte Rothmann, Tina S. Dalgaard, Janne Pleidrup, Anders Permin, Torben W. Schou, Gregers Jungersen, Dorte R. Fink and Helle R. Juul-Madsen 2013. Comparison of parasite-specific immunoglobulin levels in two chicken lines during sustained infection with Ascaridia galli. Vet Parasitol 191: 187-190. doi: http://dx.doi.org/10.1016/j.vetpar.2012.07.031

Onyirioha, J.N.N. 2011. Effects of varying temperatures on the ex-uterine development and incubation period of eggs of Ascaridia galli. new york science journal 4: 61-63.

Parmentier, Henk K., Aart Lammers, Jan J. Hoekman, Ger De Vries Reilingh, Ilja T. A. Zaanen and Huub F. J. Savelkoul 2004. Different levels of natural antibodies in chickens divergently selected for specific antibody responses. Dev Comp Immunol 28: 39-49. doi: http://dx.doi.org/10.1016/S0145-305X(03)00087-9

Permin, A., M. Bisgaard, F. Frandsen, M. Pearman, J. Kold and P. Nansen 1999. Prevalence of gastrointestinal helminths in different poultry production systems. British Poultry Science 40: 439-443. doi: 10.1080/00071669987179

Permin, A., J. P. Christensen and M. Bisgaard 2006. Consequences of concurrent Ascaridia galli and Escherichia coli infections in chickens. Acta Veterinaria Scandinavica 47: 43-54.

Permin, A. and J.W. Hansen 1998a. Ascaridia galli (Schrank, 1778). Heterakis spp. In FAO Animal Health Manual. Epidemiology, Diagnosis and Control of Poultry Parasites (pp. 25-30). Rome:Food and Agrivulture Organization of the United Nations.

Permin, A. and J.W. Hansen 1998b. Epidemiology, Diagnosis and Control of Poultry Parasites. FAO Handbook. Rome, Italy. Food and Agricultutre Organisation of the United Nations: pp 22-23. 
Pinard, M. H., J. A. van Arendonk, M. G. Nieuwland and A. J. van der Zijpp 1992. Divergent selection for immune responsiveness in chickens: estimation of realized heritability with an animal model. J Anim Sci 70: 2986-2993. doi: /1992.70102986x

Ramadan, H.H. and N.Y. Abou Znada 1991. Morphology and life history of Ascaridia galli in the domestic fowl that are raised in jeddah. J.K.A.U. Sci 4: 87-99.

Rose, M. E., E. Orlans and N. Buttress 1974. Immunoglobulin classes in the hen's egg: their segregation in yolk and white. Eur J Immunol 4: 521-523. doi: 10.1002/eji.1830040715

Schou, T., A. Permin, A. Roepstorff, P. Sorensen and J. Kjaer 2003. Comparative genetic resistance to Ascaridia galli infections of 4 different commercial layer-lines. British Poultry Science 44: 182-185. doi: 10.1080/0007166031000088335

Shimmura, T., S. Hirahara, T. Azuma, T. Suzuki, Y. Eguchi, K. Uetake and T. Tanaka 2010. Multi-factorial investigation of various housing systems for laying hens. British Poultry Science 51: 31-42. doi: 10.1080/00071660903421167

Siwek, M., B. Buitenhuis, S. Cornelissen, M. Nieuwland, E. F. Knol, R. Crooijmans, M. Groenen, H. Parmentier and J. van der Poel 2006. Detection of QTL for innate: nonspecific antibody levels binding LPS and LTA in two independent populations of laying hens. Dev Comp Immunol 30: 659-666. doi: 10.1016/j.dci.2005.09.004

Skallerup, P., L. A. Luna, M. V. Johansen and N. C. Kyvsgaard 2005. The impact of natural helminth infections and supplementary protein on growth performance of free-range chickens on smallholder farms in El Sauce, Nicaragua. Prev Vet Med 69: 229-244. doi: 10.1016/j.prevetmed.2005.02.003

Stear, M.J. and D. Wakelin 1998. Genetic resistance to parasitic infection. Rev. sci. tech. Off. int. Epiz., 17: 143-153.

Stevenson, Peter 2012. EUROPEAN UNION LEGIS LATION ON THE WELFARE OF FARM ANIMALS. Compassion in World Farming. 
Tarbiat, B., D. S. Jansson and J. Höglund 2015. Environmental tolerance of free-living stages of the poultry roundworm Ascaridia galli. Vet Parasitol. doi: http://dx.doi.org/10.1016/j.vetpar.2015.01.024

Tarbiat, B., D. S. Jansson, E. Tydén and J. Höglund 2016. Comparison between anthelmintic treatment strategies against Ascaridia galli in commercial laying hens. Vet Parasitol 226: 109-115. doi: http://dx.doi.org/10.1016/j.vetpar.2016.07.006

Taylor, M.A., R.L. Coop and R.L. Wall 2015. Parasites of Poultry and Gamebirds, in Veterinary Parasitology, Fourth Edition, John Wiley \& Sons, Inc., Hoboken, NJ, USA. doi: 10.1002/9781119073680.ch13.

Thienpoint, D., Rochette, F., Vanparis, O.F.J., 1986. Diagnosis Helminthiasis by Coprological Examination, 2nd. Janson Research Foundation, Beerse.

Tiersch, K. M., G. Das, G. V. Samson-Himmelstjerna and M. Gauly 2013. The role of culture media on embryonation and subsequent infectivity of Capillaria obsignata eggs. Parasitology research 112: 357-364. doi: 10.1007/s00436-012-3143-z

Wakelin, D. 1965. Experimental Studies on the Biology of Capillaria obsignata Madsen, 1945, a Nematode Parasite of the Domestic Fowl. J Helminthol 39: 399-412.

Wharton, D. 1980. Nematode egg-shells. Parasitology 81: 447-463.

Widowski, Tina 2002. Overview Of International Egg Production, Hen Housing and Animal Welfare Standards' in Welfare Issues and Housing for Laying Hens. International Developments and Perspectives; Primary Industries Standing Committee, Model Code of Practice for the Welfare of Animals- Poultry 4th Edition: paragraph 5.

Wijga, S., H. K. Parmentier, M. G. Nieuwland and H. Bovenhuis 2009. Genetic parameters for levels of natural antibodies in chicken lines divergently selected for specific antibody response. Poult Sci 88: 1805-1810. doi: 10.3382/ps.2009-00064

Wongrak, K., G. Das, E. Moors, B. Sohnrey and M. Gauly 2014. Establishment of gastrointestinal helminth infections in free-range chickens: a longitudinal on farm study. Berliner und Munchener tierarztliche Wochenschrift 127: 314-321. 
Wongrak, K., G. Das, U. K. von Borstel and M. Gauly 2015. Genetic variation for worm burdens in laying hens naturally infected with gastro-intestinal nematodes. British Poultry Science 56: 15-21. doi: 10.1080/00071668.2014.981147

Wongrak, Kalyakorn 2014. Epidemiological studies on gastro-intestinal nematode infections in chickens: on farm establishment, host genetics and fluctuations in nematode egg excretion. $\mathrm{PhD}$ thesis.

Zhao, G., B. Shen, Q. Xie, L. X. Xu, R. F. Yan, X. K. Song, I. A. Hassan and X. R. Li 2012. Detection of Toxoplasma gondii in free-range chickens in China based on circulating antigens and antibodies. Vet Parasitol 185: 72-77. doi: 10.1016/j.vetpar.2011.10.031

Zheng, W. M., J. Izaki, S. Furusawa and Y. Yoshimura 2000. Localization of immunoglobulin G gamma-chain mRNA-expressing cells in the oviduct of laying and diethylstilbestrol-treated immature hens. Gen Comp Endocrinol 120: 345-352. doi: 10.1006/gcen.2000.7573 


\title{
2. Paper 1: Embryonation ability of Ascaridia galli eggs isolated from worm uteri or host faeces
}

\author{
Shayan Rahimian ${ }^{\mathbf{a}}$, Matthias Gauly ${ }^{\mathrm{b}}$, Gürbüz Daş ${ }^{\mathrm{c} *}$ \\ aUniversity of Göttingen, Department of Animal Sciences, Albrecht-Thaer-Weg 3, \\ 37075, Göttingen, Germany \\ ${ }^{\mathbf{b}}$ Faculty of Science and Technology, Universitätsplatz 5,39100, Bolzano, Italy \\ 'Institute of Nutritional Physiology ‘Oskar Kellner', Leibniz Institute for Farm Animal \\ Biology, Wilhelm-Stahl-Allee 2 18196, Dummerstorf, Germany
}

Published in Veterinary Parasitology, Volume 215, Pages 29-34 doi:10.1016/j.vetpar.2015.10.026

\begin{abstract}
Experimental infection models for Ascaridia galli rely on the use of eggs isolated either directly from worm uteri or from host faeces. We investigated whether $A$. galli eggs isolated from the two sources differ in their embryonation ability. A. galli eggs originating from 12 worm infrapopulations were isolated both from faeces of the living host (faecal eggs) and directly from worm uteri after host necropsy (uterine eggs). The isolated eggs from each infrapopulation and source were incubated in Petri dishes $(n=24)$ containing a potassium-dichromate $(0.1 \%)$ medium for $28 \mathrm{~d}$ at room temperature. Starting from the day of egg isolation (d0), in ovo larval development
\end{abstract}


was evaluated every second day by examining morphological characteristics of 200 eggs/Petri dish. A total of 72,000 eggs were classified into undeveloped, early development, vermiform or fully embryonated stages. Isolation procedures caused similar damage to uterine and faecal eggs $(2.2 \%$ and $0.5 \%$, respectively; $P=0.180)$. The first sign of in ovo embryonic development in faecal eggs $(7 \%)$ was observed during the 24-hour period when faeces were collected. On d28, a higher percentage of uterine eggs remained undeveloped when compared with faecal eggs (58.6\% vs $11.0 \% ; P<0.001)$. Although a higher $(P<0.001)$ percentage of faecal eggs entered both the early developmental and vermiform stages, which took place primarily within the first two weeks of incubation, there was no time-shift between the development of faecal and uterine eggs. Starting from day 10 , higher $(P<0.05)$ percentages of faecal eggs completed embryonation compared with uterine equivalents. Eggs from both sources reached a plateau of embryonation by the end of 2 nd week of incubation, with faecal eggs having a greater than two-fold higher embryonation ability. Cumulative mortality was higher in uterine eggs (14.3\%) than in faecal eggs $(0.2 \%)$. We conclude that faecal eggs have a higher embryonation ability than uterine eggs possibly due to maturation differences. 
Research paper

\title{
Embryonation ability of Ascaridia galli eggs isolated from worm uteri or host faeces
}

\author{
Shayan Rahimian ${ }^{\mathrm{a}}$, Matthias Gauly ${ }^{\mathrm{b}}$, Gürbüz Daş ${ }^{\mathrm{c}, *}$ \\ a University of Gottingen, Department of Animal Sciences, Albrecht-Thaer-Weg 3, 37075 Gottingen, Germany \\ ${ }^{\mathrm{b}}$ Faculty of Science and Technology, Universitätsplatz 5, 39100 Bolzano, Italy \\ c Institute of Nutritional Physiology ‘Oskar Kellner', Leibniz Institute for Farm Animal Biology, Wilhelm-Stahl-Allee 218196 Dummerstorf, Germany
}

\section{A R T I C L E I N F O}

\section{Article history:}

Received 18 June 2015

Received in revised form 14 October 2015

Accepted 26 October 2015

\section{Keywords:}

Chicken

Egg development

Incubation

Infection model

Nematode

\begin{abstract}
A B S T R A C T
Experimental infection models for Ascaridia galli rely on the use of eggs isolated either directly from worm uteri or from host faeces. We investigated whether A. galli eggs isolated from the two sources differ in their embryonation ability. A. galli eggs originating from 12 worm infrapopulations were isolated both from faeces of the living host (faecal eggs) and directly from worm uteri after host necropsy (uterine eggs). The isolated eggs from each infrapopulation and source were incubated in Petri dishes $(n=24)$ containing a potassium-dichromate $(0.1 \%)$ medium for 28 days $(\mathrm{d})$ at room temperature. Starting from the day of egg isolation (d0), in ovo larval development was evaluated every second day by examining morphological characteristics of 200 eggs/petri dish. A total of 72,000 eggs were classified into undeveloped, early development, vermiform or fully embryonated stages.

Isolation procedures caused similar damage to uterine and faecal eggs $(2.2 \%$ and $0.5 \%$, respectively; $P=0.180$ ). The first sign of in ovo embryonic development in faecal eggs (7\%) was observed during the 24$\mathrm{h}$ period when faeces were collected. On $\mathrm{d} 28$, a higher percentage of uterine eggs remained undeveloped when compared with faecal eggs $(58.6 \%$ vs $11.0 \%$; $P<0.001)$. Although a higher $(P<0.001)$ percentage of faecal eggs entered both the early developmental and vermiform stages, which took place primarily within the first two weeks of incubation, there was no time-shift between the development of faecal and uterine eggs. Starting from day 10 , higher $(P<0.05)$ percentages of faecal eggs completed embryonation compared with uterine equivalents. Eggs from both sources reached a plateau of embryonation by the end of 2 nd week of incubation, with faecal eggs having a greater than two-fold higher embryonation ability. Cumulative mortality was higher in uterine eggs (14.3\%) than in faecal eggs $(0.2 \%)$. We conclude that faecal eggs have a higher embryonation ability than uterine eggs possibly due to maturation differences.
\end{abstract} (C) 2015 Elsevier B.V. All rights reserved.

\section{Introduction}

Poultry products are the most consumed source of animal protein by humans (Upton, 2007), and poultry production is subject to strict legislative regulations. European regulations for the protection and welfare of laying hens have banned conventional battery cages for laying hens (Anonymous, 1999). This practice has resulted in the re-emergence of nematode infections in chickens, mainly due to frequent contact with contaminated litter, which ensures the completion of the parasite life cycle by the effective faecal-oral transmission route in floor husbandry and free-range systems (Permin et al., 1999; Kaufmann et al., 2011b; Wongrak

\footnotetext{
* Corresponding author. Fax: +49 3820868693.

E-mail address: gdas@fbn-dummerstorf.de (G. Daş).
}

et al., 2014). Currently, the most prevalent chicken nematodes in European farms are Ascaridia galli, Heterakis gallinarum and Capillaria spp. (Kaufmann et al., 2011a; Wongrak et al., 2014). In addition to the direct adverse effects of $A$. galli infection on chicken performance (Ramadan and Abou Znada, 1991; Daş et al., 2010, 2012), it may favor secondary bacterial infections (e.g., salmonellosis and fowl cholera) (Eigaard et al., 2006). Since the re-emergence of these infections, there have been a considerable number of studies, including those with experimental infections, that have improved our understanding of nematode epidemiology and investigated possible control strategies. Experimental infection models for $H$. gallinarum and Capillaria obsignata are highly successful (i.e., high establishment rates are repeatedly achieved) (Das et al., 2011; Tiersch et al., 2013, 2014). Experimental A. galli infections, however, have often produced lower establishment rates and worm burdens (Marcos-Atxutegi et al., 2009; Daş et al., 2010) than those observed 
with natural infections (Permin et al., 1999; Kaufmann et al., 2011b; Wongrak et al., 2014), thus resulting in questionable infection levels when studying the effects of experimental factors of interest. In some cases, patency may not be achieved in any experimentally infected birds (Ferdushy et al., 2013). These results clearly indicate the lack of a proper $A$. galli experimental infection model.

A considerable proportion of recent $A$. galli studies have addressed issues that may contribute to improving experimental infection models including the choice of incubation media (Permin et al., 1997; Kaingu et al., 2013), incubation temperature and humidity (Onyirioha, 2011; Tarbiat et al., 2015), resistance of eggs to environmental conditions (Katakam et al., 2014), and hostrelated factors e.g., age at infection (Idi et al., 2004; Gauly et al., 2005), genotype (Kaufmann et al., 2011a) and nutrition (Daş et al., 2010, 2012). In most experimental A. galli infection studies, eggs isolated from worm uteri have been used, whereas only a few studies (Luna-Olivares et al., 2012; Ferdushy et al., 2013) have used eggs isolated from host faeces. Female worms only lay mature eggs (Kim et al., 2012), and all uterine eggs are not mature or able to complete embryonation (Tiersch et al., 2013). Therefore, we hypothesize that A. galli eggs isolated from worm uteri and host faeces may vary in their capacity for embryonic development, antigenic stimulation and subsequent infectivity. As a first step, the aim of this study was to investigate whether A. galli eggs isolated from two sources (worm uteri and faeces) differ in their capacity for embryonic development.

\section{Materials and methods}

\subsection{Chickens}

A total of 19 White Leghorn chickens (Lohmann Selected Leghorn) at five weeks of age were purchased from a commercial breeding company in Germany. As indicated by examining individual faecal samples with a modified McMaster method (MAFF, 1986), the birds were free from nematode infections on arrival and were placed in a clean/disinfected barn. After a two-week adaptation period, the birds were individually numbered with wing tags. Following infection (see Section 2.2), the birds were kept as one group for six weeks post-infection (p.i.) under floor husbandry conditions, where water and a commercial feed $(185 \mathrm{~g} \mathrm{CP} / \mathrm{kg}$ feed $)$ for growing hens were provided ad libitum.

\subsection{Experimental infection and worm infrapopulations}

The birds were infected orally with a single dose of 1000 embryonated A. galli eggs using a 5-cm esophageal cannula (Daş et al., 2010). The embryonated eggs had been isolated from worm uteri and incubated in $0.1 \%$ potassium dichromate $\left(\mathrm{K}_{2} \mathrm{Cr}_{2} \mathrm{O}_{7}\right)$ for 22 days at room temperature. A small quantity of medium was added occasionally to maintain a constant volume. After the prepatent period (approximately six weeks), the birds were transferred to individual cages for faeces collection. All faecal droppings from each bird were collected quantitatively within less than $24 \mathrm{~h}$ of captivity and thereafter the birds were immediately necropsied as described previously (Daş et al., 2010). Faecal samples were examined to estimate egg concentration (eggs per gram faeces, EPG). At necropsy, worms from each bird were harvested from the small intestines separately. Of 19 faecal samples, there was one egg-negative sample. This bird, which did not have any worms, was therefore excluded from the experiment. Chickens with only male worms $(n=2)$ or with a few female worms $(n=4)$ were also excluded so that 12 infrapopulations from which eggs were isolated from both faeces and worm uteri remained. The average infrapopulation size was then $6.5 \pm 3.4$ worms per bird.

\subsection{Egg isolation from faeces (faecal eggs) and worm uteri (uterine eggs)}

After individual fresh faeces $(<24 \mathrm{~h})$ samples were flushed with tap water and passed through a series of sieves with mesh aperture sizes of 500,250 and $90 \mu \mathrm{m}$, the eggs were collected on a $36-\mu \mathrm{m}$ sieve (Ferdushy et al., 2012; Katakam et al., 2014). Depending on the amount, each of several $50-\mathrm{ml}$ conical centrifuge tubes was filled with $5 \mathrm{ml}$ of the sieve content (egg suspension). The tubes were then filled up to $50 \mathrm{ml}$ with saturated $\mathrm{NaCl}$ as the flotation fluid (density $\geq 1.2 \mathrm{w} / \mathrm{v}$ ) and centrifuged at $1619 \times \mathrm{g}$ for $1 \mathrm{~min}$. After centrifugation, the supernatant containing eggs was passed through the 36- $\mu \mathrm{m}$ sieve with a large amount of tap water. All eggs from each infrapopulation were then collected in a petri dish. The egg concentration was finally adjusted to a maximum of $25 \mathrm{eggs} / \mu \mathrm{l}$ (Eriksen, 1990) in a potassium dichromate $(0.1 \%)$ medium.

All female worms from each bird were dissected with scissors and placed on a tea sieve in a mortar. Opened worms were then squeezed gently using a pestle rubbing on a plastic tea sieve. The eggs were then separated from the worm tissues by sieving and collected in water (Daş et al., 2010) after adjusting for an egg concentration to $25 \mathrm{eggs} / \mu \mathrm{l}$ (Eriksen, 1990) in a potassium dichromate $(0.1 \%)$ medium. Eggs were then stored at room temperature (overall average temperature $24.4^{\circ} \mathrm{C}$ with minimum and maximum values of 21.2 and $28.2^{\circ} \mathrm{C}$, respectively) for 28 days.

\subsection{Monitoring embryonic development and sample size}

Starting from the day of egg isolation (d0) onwards, the embryonation of eggs (in ovo larval development) was evaluated for each petri dish $(n=24)$ by examining morphological characteristics of eggs from two sub-populations. Each sub-population represented a sample and comprised 100 eggs. The examined intact eggs were classified into four developmental stages as described in Fig. 1. The proportion of damaged eggs was also quantified for each petri dish. From these two sub-populations, the average percentage of eggs falling into each developmental class was calculated and the percentage of eggs corresponding to each class was adjusted to the proportion of intact eggs. A micro-photographic documentation of the stages is shown in Fig. 1. Embryonic development of the eggs was monitored for 28 days of incubation at two-day intervals, which resulted in the examination of 72,000 eggs. The eggs were aerated manually by giving air into the medium with a pipet every second day on the examination days. The microscopic examination of eggs was performed at $100 \times$ magnification.

\subsection{Statistical analyses}

Each dependent variable (i.e., the percentage of eggs at a given developmental stage) was adjusted for damaged eggs. Data for each dependent variable were analyzed with repeated ANOVA measures. The statistical model included fixed effects of egg sources (faeces or worm uteri), examination days (1-15; every second day from $\mathrm{d} 0$ to $\mathrm{d} 28$ ) during the incubation period ( $28 \mathrm{~d}$ ) and the interaction between the egg source and the examination days. As shown in the following, the model included the effect of the infrapopulation as random:

$Y_{\mathrm{ijkl}}=\mu+S_{i}+D_{j}+(\mathrm{SD})_{\mathrm{ij}}+a_{\mathrm{k}}+\epsilon_{\mathrm{ijk} \mathrm{l}}$

where $Y_{\mathrm{ijkl}}$ is the observation, $\mu$ is the overall mean, $S_{i}$ is the effect of egg source $(i=1-2), D_{j}$ is the effect of the examination days $(j=1-15),(S D)_{i j}$ is the interaction between the egg sources and the days, $a_{\mathrm{k}}$ is the individual random infrapopulation effect, and $\epsilon_{\mathrm{ijkl}}$ is the residual random error. Tukey-Kramer adjusted post-hoc comparisons $(P<0.05)$ were used to partition effects of the factors 


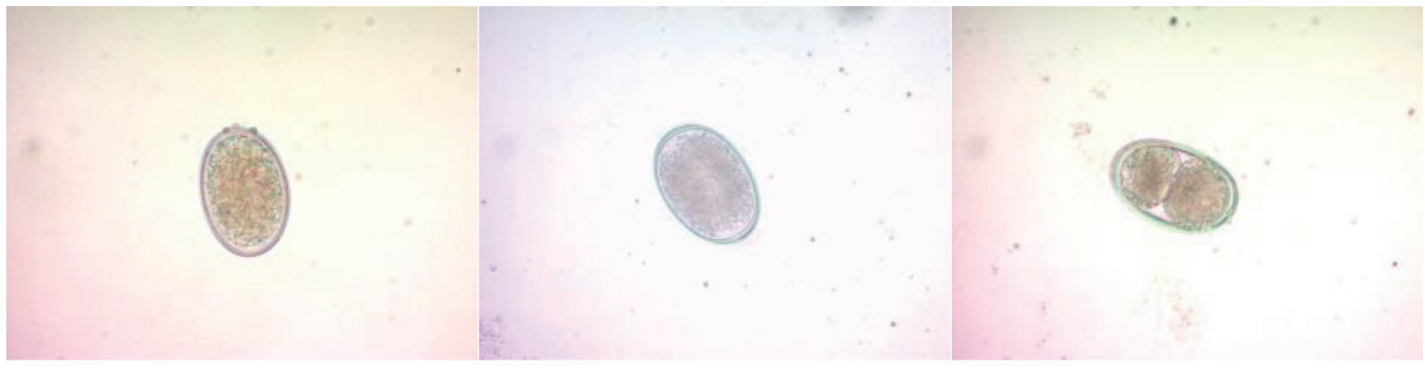

a

b

C

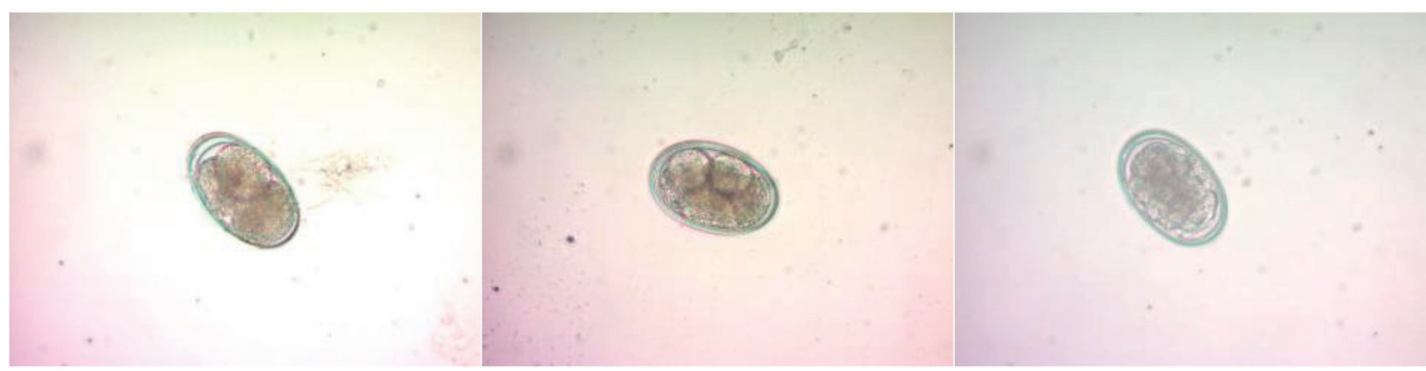

d

e

f

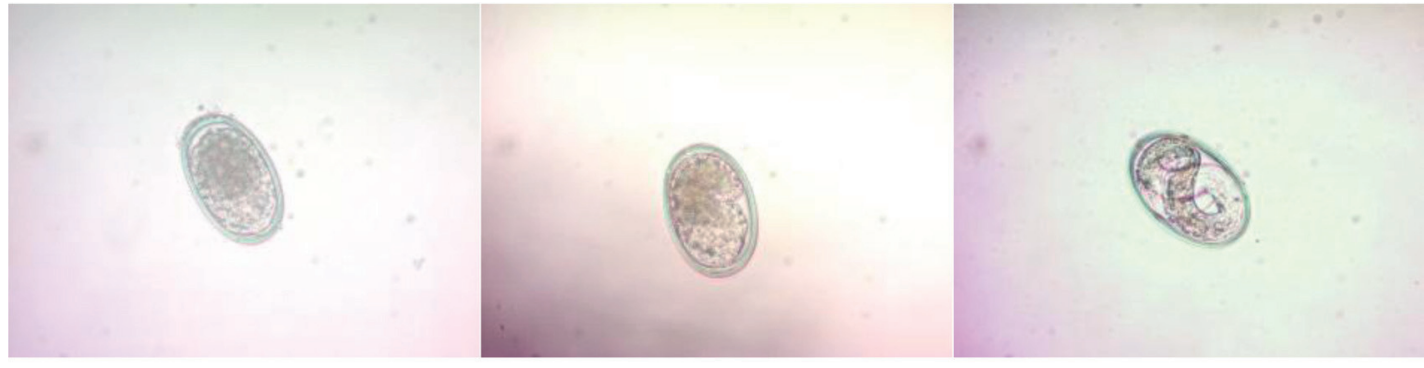

g

h

i

Fig. 1. Morphological characteristics of Ascaridia galli eggs at different developmental stages. Undeveloped eggs: infertile (a) or fertile (b); early development (c-f): eggs cell at division stages from cleavage to morula; vermiform ( $\mathrm{g}, \mathrm{h}$ ): initial stage of differentiation (blastula: $\mathrm{g}$ ) and tadpole or a motile mass (gastrula: $\mathrm{h}$ ); embryonated (i): a slender, coiled and motile larva is present, and head and tail formation is completed.

when needed. The results are presented as least-squares means (LSMEANS) with their standard errors (SE). All analyses were performed with SAS (SAS, 2014).

\section{Results}

The overall average percentages of damaged eggs were $0.5 \%$ and $2.2 \%$ in faecal and uterine eggs, respectively, with no significant difference $(P=0.180)$. The first sign of in ovo embryonic development in uterine eggs emerged in the second day of incubation. As shown in Fig. 2, approximately $7 \%$ of faecal eggs had already initiated embryonic development within $24 \mathrm{~h}$ when faeces were collected.

Starting from the second day (d2) of incubation onwards, higher $(P<0.001)$ percentages of uterine eggs were classified as undeveloped throughout the incubation period $(P<0.001)$. On $\mathrm{d} 2$, approximately three times higher $(P<0.05)$ numbers of uterine eggs were classified as undeveloped when compared with faecal eggs (Fig. 2A; 47.3\% and $11.6 \%$, respectively). There was a slight increase $(11.2 \%)$ in the percentage of undeveloped uterine eggs from $\mathrm{d} 2$ to $\mathrm{d} 28$, whereas the percentage of undeveloped faecal eggs showed almost no change with a decline of $0.5 \%$ in the same period of time (Fig. 2A). A total of $88.4 \%$ of the faecal eggs entered in embryonic development, whereas approximately $52.7 \%$ of uterine eggs initiated embryonation on the second day of the incubation period. Accordingly, during the first 8 days, $67.1 \%$ of faecal eggs were in early development, which was significantly higher $(P<0.05)$ than in uterine eggs $(35 \%)$. Independent of the egg source, developing eggs completed the early developmental stage within the first 8 days with no time-shift between faecal and uterine eggs (Fig. 2B). Most of the developing eggs went through the vermiform stage between the first two weeks of incubation, although faecal eggs represented a greater percentage than uterine eggs (Fig. 2C). Starting by the beginning of third week of the incubation, almost all developing eggs completed embryonation (Fig. 2D). Starting from day 10 of incubation, higher $(P<0.05)$ percentages of faecal eggs completed embryonation than did uterine ones. Eggs from both sources reached a plateau of embryonation by the end of second week of incubation, with faecal eggs having more than double the higher embryonation ability (Fig. 2D). The difference between the percentages of fully embryonated eggs from two different sources remained almost constant during the last two weeks of the incubation period. On the last day of incubation (d28), $88.2 \%$ and $38.4 \%$ of faecal and uterine eggs, respectively, were fully embryonated $(P<0.05)$. Apparent cumulative egg mortality (the difference between the percentages of fully embryonated 

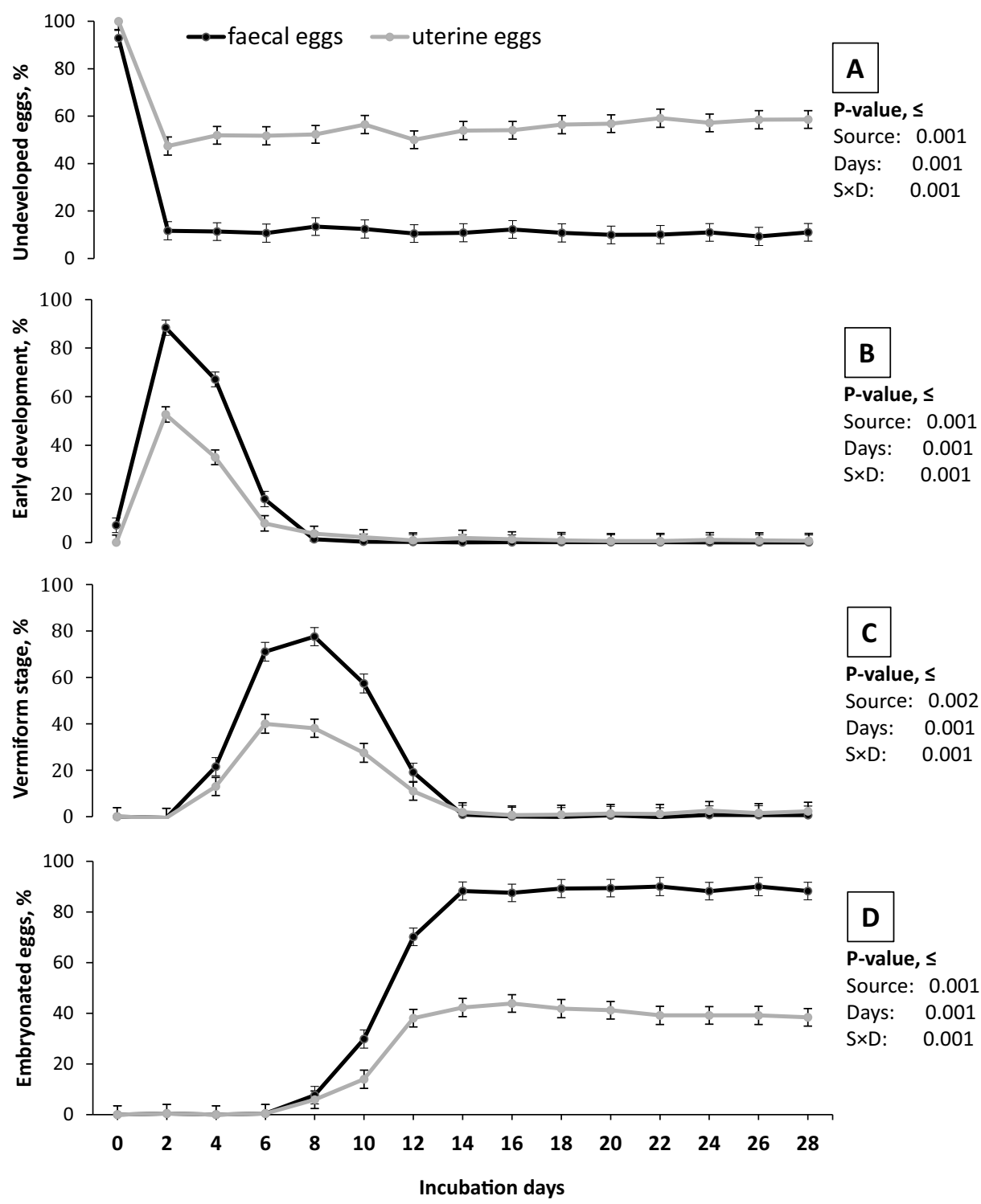

Fig. 2. Percentages* of uterine and faecal eggs classified as undeveloped (A), at early developmental stage (B), vermiform (C) and fully embryonated (D) at the end of the incubation period $\left({ }^{*}\right)$ Adjusted for damaged eggs; $N=12$ infrapopulation; sample size $=72,000$. The eggs examined every second day during the 28 -day incubation period.

Table 1

The percentages ${ }^{1}$ of Ascaridia galli eggs at different developmental stages after a four-week incubation period in relation to their source (faeces/worm uteri).

\begin{tabular}{|c|c|c|c|c|c|c|}
\hline \multirow[t]{2}{*}{ Developmental stage } & \multicolumn{2}{|c|}{ Egg source } & \multirow[b]{2}{*}{$\mathrm{SE}^{2}$} & \multicolumn{3}{|c|}{$P$-values, $\leq$} \\
\hline & Faeces & Worm uteri & & Source & Days & $\mathrm{S} \times \mathrm{D}$ \\
\hline Undeveloped & $11.0^{\mathrm{a}}$ & $58.6^{\mathrm{b}}$ & 4.39 & 0.001 & 0.001 & 0.001 \\
\hline Early development & 0.1 & 0.7 & 3.02 & 0.001 & 0.001 & 0.001 \\
\hline Vermiform & 0.7 & 2.3 & 3.87 & 0.002 & 0.001 & 0.001 \\
\hline Embryonated & $88.2^{\mathrm{a}}$ & $38.4^{\mathrm{b}}$ & 3.55 & 0.001 & 0.001 & 0.001 \\
\hline
\end{tabular}

Different superscripts (a,b) on the same line indicate a significant difference (Tukey $P<0.05$ ).

1 Adjusted for damaged eggs; $N=12$ infrapopulation; sample size $=72,000$ eggs examined every second day during the 28-day incubation period.

2 The most conservative (the largest) standard error of LSMEANS.

eggs on $\mathrm{d} 28$ and embryonating/viable eggs on $\mathrm{d} 2$ ) was higher in uterine eggs ( $14.3 \%)$ than in faecal eggs $(0.2 \%)$. Table 1 summarizes the percentages of eggs at different developmental stages after 28 days of incubation.

\section{Discussion}

In this study, the embryonic development of faecal and uterine A. galli eggs originating from the same infrapopulations was investigated. The use of eggs from the same worm infrapopulations for the two sources eliminated potentially confounding effects of natural variation among the embryonation ability of eggs originating from different infrapopulations. It has been demonstrated that the vast majority of the faecal eggs $(\approx 90 \%)$ are able to complete embryonation, whereas less than $40 \%$ of uterine eggs completed embryonation. Notably, the percentages of damaged eggs caused by mechanical grinding during isolation processes were low and similar between faecal and uterine eggs $(0.5 \%$ and $2.2 \%$, respectively), which is much lower than that of $C$. obsignata eggs (Tiersch et al., 2013), and confirms the robust morphological structure of $A$. galli eggs. The intact $A$. galli eggs have three layers with a permeable vitelline membrane, a resistant thick shell and a thin albuminous outer layer (Ackert, 1931; Cruthers et al., 1974) and are highly resistant to the external environmental conditions (Tarbiat et al., 2015), whereas damaged nematode eggs have no potential to initiate embryonic development (Johnston and Dennis, 2012). Because 
there was no difference in the proportion of damaged eggs, the differences in embryonation ability of the faecal and uterine eggs must be attributed to factors other than egg integrity. Higher embryonation ability of the faecal eggs is in line with the results reported for $C$. obsignata eggs whose development was evaluated in the first twothirds of uterus (proximal to vulva) in intact worms where adverse effects of mechanical grinding during isolation can be excluded (Tiersch et al., 2014). Eggs in the last part of uteri can be considered as fully developed and capable of embryonation because their size correspond well to those found in freshly deposited faeces (Graybill, 1924). Almost $60 \%$ of uterine eggs did not even initiate embryonation and remained undeveloped throughout the study period. This result is in close agreement with the result for $C$. obsignata eggs, with $95 \%$ embryonated faecal eggs compared with $32.6 \%$ uterine eggs (Norton and Joyner, 1965) and is probably due to the high proportion of undeveloped/immature eggs in worm uteri (Graybill, 1924; Püllen et al., 2008). In our study, starting from the second day of incubation, a higher percentage of undeveloped eggs were found in uterine eggs.

Under natural environmental conditions faecal eggs will complete an in ovo larval development (embryonation) to reach infectivity (Permin et al., 1998). This duration may vary from 1 to 8 weeks depending on different environmental factors (Ackert, 1931; Ramadan and Abou Znada, 1991; Onyirioha, 2011; Tarbiat et al., 2015). Cruz et al. (2012) reported in ovo developing embryos with 2 or more cells after $48 \mathrm{~h}$ of incubation in faecal Ascaris suum eggs, whereas our observations demonstrated a higher speed of development (7\%) within $24 \mathrm{~h}$ of collecting faeces. Despite the large differences in embryonation ability between faecal and uterine eggs, there was no time-shift between developmental stages independent of the source of eggs. The developing eggs (faecal/uterine) completed early development, vermiform stage and embryonation in 8,14 and 14 days, respectively. Todd et al. (1952) monitored fully embryonated eggs for 14 days at room temperature. In addition, $25 \%$ of uterine eggs completed embryonation in 15 days at fluctuating $\left(18-25^{\circ} \mathrm{C}\right)$ temperature (Onyirioha, 2011). These results are in close agreement to our result. In addition Katakam et al., 2014 monitored early development stage eggs from 1 to 6 days which is similar to our results and investigated embryonated faecal eggs after 30 days at $20^{\circ} \mathrm{C}$. The prolonged time required for embryonation may be because of the lower and constant temperature during their study.

The percentage of viable eggs on $\mathrm{d} 2$ represented the highest embryonation potential for both uterine and faecal eggs. Therefore, we estimated the apparent cumulative mortality as the difference between percentages of developing/viable eggs on $\mathrm{d} 2$ and fully embryonated eggs on the last day of incubation (d28). Mortality was higher in uterine eggs $(14.3 \%)$ than in faecal eggs $(0.2 \%)$. Because the percentage of uterine eggs classified as undeveloped increased by $11.2 \%$ from the 2 nd to 28 th day of incubation, the vast majority of egg deaths must have occurred at the very early stages of embryonic development. This notion is supported by the observation that embryonic death at very early developmental stages results in darkened and relatively easily recognizable dead eggs, whereas death at later stages may remain unnoticed unless they decompose. Thus, mortality for uterine eggs may have been even higher than the present estimate. Because egg integrity was not influenced by the isolation procedures, egg mortality may mainly be associated with egg maturation, which is expected to be lower for uterine eggs.

In most previous infection studies, uterine eggs were used as the infection material (Todd et al., 1952; Tongson and McCraw, 1967; Dahl et al., 2002; Gauly et al., 2005; Permin et al., 2006; Onyirioha, 2011). Using embryonated uterine eggs as the infection material is challenging due to the relatively long prepatent period of $A$. galli (Herd and McNaught, 1975), worm expulsion by the host animal
(Dahl et al., 2002), the presence of immature eggs in worm uteri (Graybill, 1924; Püllen et al., 2008; Tiersch et al., 2013), the probability of losing or damaging eggs during isolation (Tiersch et al., 2013) and, as shown in this study, the considerable percentage of eggs that do not survive during the incubation period. Furthermore, slaughtered chickens are needed to harvest uterine eggs. This is an ethically and economically important issue, and based on our results, we conclude that uterine eggs are less able to complete embryonation. Thus, in infection experiments, to supply the favorable doses with fully developed eggs, much higher numbers of uterine eggs are needed to compensate for the losses resulting from undeveloped/immature eggs and/or higher egg mortality. Moreover, uterine eggs may not be completely free from worm tissues and thus may induce an additional antigenic stimulation when given to birds. Alternatively, using eggs isolated from host faeces is not fully advantageous when used for mono-infections. Eggs of $H$. gallinarum, the caecal worm, are difficult to differentiate morphologically from those of $A$. galli (Thienpoint et al., 1986). Thus, eggs isolated from faeces of naturally infected animals cannot be considered safe infection material for mono-infections.

We conclude that $A$. galli eggs isolated from host faeces have a higher embryonation capacity than uterine eggs, possibly due to egg maturation. Future studies should focus on the antigenic stimulation and infectious capacity of eggs from both sources.

\section{Acknowledgements}

Authors would like to thank Ms. Birgit Sohnrey and Mrs. Erwin Tönges for their help in various technical issues during the study. The financial support to the first author from the Erasmus Mundus project is gratefully acknowledged.

\section{References}

Ackert, J.E., 1931. The morphology and life history of the fowl nematode Ascaridia lineata (Schneider). Parasitology 23, 360-379.

Anonymous, 1999. Council directive 1999/74/EC laying down minimum standards for the protection of laying hens. OJ C L, 0053-0057.

Cruthers, L.R., Weise, R.W., Hansen, M.F., 1974. Topography of Ascaridia galli eggs exposed to low-temperatures or cryoprotectants as shown by scanning electron-microscopy. J. Parasitol. 60, 632-635.

Cruz, L.M., Allanson, M., Kwa, B., Azizan, A., Izurieta, R., 2012. Morphological changes of Ascaris spp. eggs during their development outside the host. J. Parasitol. 98, 63-68.

Dahl, C., Permin, A., Christensen, J.P., Bisgaard, M., Muhairwa, A.P., Petersen, K.M.D., Poulsen, J.S.D., Jensen, A.L., 2002. The effect of concurrent infections with Pasteurella multocida and Ascaridia galli on free range chickens. Vet. Microbiol. $86,313-324$

Daş, G., Kaufmann, F., Abel, H., Gauly, M., 2010. Effect of extra dietary lysine in Ascaridia galli-infected grower layers. Vet. Parasitol. 170, 238-243.

Das, G., Savas, T., Kaufmann, F., Idris, A., Abel, H., Gauly, M., 2011. Precision, repeatability and representative ability of faecal egg counts in Heterakis gallinarum infected chickens. Vet. Parasitol. 183, 87-94.

Daş, G., Abel, H., Humburg, J., Schwarz, A., Rautenschlein, S., Breves, G., Gauly, M., 2012. The effects of dietary non-starch polysaccharides on Ascaridia galli infection in grower layers. Parasitology 139, 110-119.

Eigaard, N.M., Schou, T.W., Permin, A., Christensen, J.P., Ekstrom, C.T., Ambrosini, F, Cianci, D., Bisgaard, M., 2006. Infection and excretion of Salmonella enteritidis in two different chicken lines with concurrent Ascaridia galli infection. Avian Pathol. 35, 487-493.

Eriksen, L., 1990. Ascaris suum: influence of egg density on in vitro development from embryonated egg to infective stage. Acta Vet. Scand. 31, 489-491.

Ferdushy, T., Nejsum, P., Roepstorff, A., Thamsborg, S.M., Kyvsgaard, N.C., 2012. Ascaridia galli in chickens: intestinal localization and comparison of methods to isolate the larvae within the first week of infection. Parasitol. Res. 111, 2273-2279.

Ferdushy, T., Luna-Olivares, L.A., Nejsum, P., Roepstorff, A.K., Thamsborg, S.M., Kyvsgaard, N.C., 2013. Population dynamics of Ascaridia galli following single infection in young chickens. Parasitololy 140, 1078-1084.

Gauly, M., Homann, T., Erhardt, G., 2005. Age-related differences of Ascaridia galli egg output and worm burden in chickens following a single dose infection. Vet. Parasitol. 128, 141-148.

Graybill, H., 1924. Capillaria columbae (Rud.) from the chicken and turkey. J. Parasitol. 10, 205-207. 
Herd, R.P., McNaught, D.J., 1975. Arrested development and the histotropic phase of Ascaridia galli in the chicken. Int. J. Parasitol. 5, 401-406.

Idi, A., Permin, A., Murrell, K.D., 2004. Host age only partially affects resistance to primary and secondary infections with Ascaridia galli (Schrank, 1788) in chickens. Vet. Parasitol. 122, 221-231.

Johnston, W.L., Dennis, J.W., 2012. The eggshell in the C. elegans oocyte-to-embryo transition. Genesis 50, 333-349.

Kaingu, F., Kibor, A., Waihenya, R., Shivairo, R., Mungai, L., 2013. Efficacy of Aloe secundiflora crude extracts on Ascaridia galli in vitro. J. Sustainable Agric. 2. $49-53$.

Katakam, K.K., Mejer, H., Dalsgaard, A., Kyvsgaard, N.C., Thamsborg, S.M., 2014. Survival of Ascaris suum and Ascaridia galli eggs in liquid manure at differen ammonia concentrations and temperatures. Vet. Parasitol. 204, 249-257.

Kaufmann, F., Das, G., Preisinger, R., Schmutz, M., König, S., Gauly, M., 2011a. Genetic resistance to natural helminth infections in two chicken layer lines. Vet. Parasitol. 176, 250-257.

Kaufmann, F., Daş, G., Sohnrey, B., Gauly, M., 2011b. Helminth infections in laying hens kept in organic free range systems in Germany. Livest. Sci. 141, 182-187.

Kim, M.-K., Pyo, K.-H., Hwang, Y.-S., Park, K.H., Hwang, I.G., Chai, J.-Y., Shin, E.-H. 2012. Effect of temperature on embryonation of Ascaris suum eggs in an environmental chamber. Kor. J. Parasitol. 50, 239-242.

Luna-Olivares, L.A., Ferdushy, T., Kyvsgaard, N.C., Nejsum, P., Thamsborg, S.M., Roepstorff, A., Iburg, T.M., 2012. Localization of Ascaridia galli larvae in the jejunum of chickens 3 days post infection. Vet. Parasitol. 185, 186-193.

MAFF, 1986. Manual of veterinary parasitological laboratory techniques. Reference Book Ministry of Agriculture, Fisheries and Food, 418. HMSO, London, pp. 5.

Marcos-Atxutegi, C., Gandolfi, B., Arangüena, T., Sepúlveda, R., Arévalo, M., Simón, F., 2009. Antibody and inflammatory responses in laying hens with experimental primary infections of Ascaridia galli. Vet. Parasitol. 161, 69-75.

Norton, C.C., Joyner, L.P., 1965. Experiment chemotherapy of infection with Capillaria obsignata. J. Comp. Pathol. 75, 137-145.

Onyirioha, J.N.N., 2011. Effects of varying temperatures on the ex-uterine development and incubation period of eggs of Ascaridia galli. N. Y. Sci. J. 4, $61-63$.

Permin, A., Pearman, M., Nansen, P., Bisgaard, M., Frandsen, F., 1997. An investigation on different media for embryonation of Ascaridia galli eggs. Helminthologia 34, 75-79.

Permin, A., Nansen, P., Bisgaard, M., Frandsen, F., Pearman, M., 1998. Studies on Ascaridia galli in chickens kept at different stocking rates. Avian Pathol. 27, 382-389.
Permin, A., Bisgaard, M., Frandsen, F., Pearman, M., Kold, J., Nansen, P., 1999. Prevalence of gastrointestinal helminths in different poultry production systems. Br. Poult. Sci. 40, 439-443.

Permin, A., Christensen, J.P., Bisgaard, M., 2006. Consequences of concurrent Ascaridia galli and E. coli infections in chickens. Acta Vet. Scand. 47, 43-54.

Püllen, U., Moors, E., Gauly, M., 2008. The role of preparation technique: culture media and incubation time for embryonation of Heterakis gallinarum eggs. Deut. Tierarztl. Woch. 115, 30-33.

Ramadan, H.H., Abou Znada, N.Y., 1991. Morphology and life history of Ascaridia galli in the domestic fowl that are raised in Jeddah. J. K. A. U. Sci. 4, 87-99.

SAS OnlineDoc Version 9.1.3 Cary, NC, USA, 2014.

Tarbiat, B., Jansson, D.S., Höglund, J., 2015. Environmental tolerance of free-living stages of the poultry roundworm Ascaridia galli. Vet. Parasitol. 209, 101-107.

Thienpoint, D., Rochette, F., Vanparis, O.F.J., 1986. Diagnosis Helminthiasis by Coprological Examination, 2nd. Janson Research Foundation, Beerse.

Tiersch, K.M., Das, G., Samson-Himmelstjerna, G.V., Gauly, M., 2013. The role of culture media on embryonation and subsequent infectivity of Capillaria obsignata eggs. Parasitol. Res. 112, 357-364.

Tiersch, K.M., Das, G., von Samson-Himmelstjerna, G., Gauly, M., 2014. Artificial infection of chickens with Capillaria obsignata eggs embryonated in different media. Vet. Parasitol. 200, 139-146.

Todd, A.C., Crowdus, D.H., Wyant, Z.N., 1952. Experimental embryonation of the egg and development of Ascaridia galli in its chicken host. Exp. Parasitol. 1, $176-183$.

Tongson, M.S., McCraw, B.M., 1967. Experimental ascaridiasis: influence of chicken age and infective egg dose on structure of Ascaridia galli populations. Exp. Parasitol. 21, 160-172.

Upton, M., 2007. Scale and structure of the poultry sector and factors including changes: intercountry differences and expected trends. In: Thieme, O., Pilling, D. (Eds.), Poultry the 21st Century: Avian Influenza and Beyond, 9. Food and Agriculture Organization of the United Nations (FAO) Animal Production and Health Proceedings, pp. 23-24.

Wongrak, K., Das, G., Moors, E., Sohnrey, B., Gauly, M., 2014. Establishment of gastro-intestinal helminth infections in free-range chickens: a longitudinal on farm study. Berl. Munch. Tierarztl. Wochenschr. 127, 314-321. 


\section{Paper 2: Maternal protection against Ascaridia galli?}

Shayan Rahimian ${ }^{\mathbf{a} *}$, Matthias Gauly ${ }^{\mathbf{b}}$, Gürbüz Daş ${ }^{\mathbf{c}}$

aUniversity of Göttingen, Department of Animal Sciences, Albrecht-Thaer-Weg 3, 37075, Göttingen, Germany

${ }^{\mathbf{b}}$ Faculty of Science and Technology, Universitätsplatz 5,39100, Bolzano, Italy

'Institute of Nutritional Physiology 'Oskar Kellner', Leibniz Institute for Farm Animal Biology, Wilhelm-Stahl-Allee 2 18196, Dummerstorf, Germany

Published in Veterinary Parasitology, Volume 233, Pages 43-47 doi:10.1016/j.vetpar.2016.11.014

\section{Abstract}

Maternally derived antibodies can provide partial protection against certain bacterial and viral infections. We investigated whether chicks descending from nematodeinfected hens are more resistant against Ascaridia galli, a prevalent gastrointestinal nematode, than chicks from nematode-free mothers. One-day-old chicks $(N=153)$ from infected (mab+; maternal antibody+) or uninfected control dams (mab-) were experimentally infected with $A$. galli at two different levels (100 or 1000 eggs/chick). The worm burdens of the chicks were determined at 6 weeks post infection. There was a high correlation $(r=0.89)$ between $A$. galli-specific antibody concentrations in 
dam plasma and egg yolk. There was no difference between worm burdens of chicks descending from infected or uninfected dams $(P=0.892)$, indicating no maternally derived protection against $A$. galli. Chicks receiving the higher infection dose had higher worm burdens $(P<0.05)$. Although there was no difference $(P>0.05)$ between worm counts of female and male chicks infected with 100 eggs, females chicks infected with 100 eggs harboured longer and heavier female worms. We conclude that there is no protective maternal immunity against $A$. galli infection. 
Research paper

\title{
Maternal protection against Ascaridia galli?
}

\author{
Shayan Rahimian ${ }^{\mathrm{a}, *}$, Gürbüz Daş ${ }^{\mathrm{b}}$, Matthias Gauly ${ }^{\mathrm{c}}$ \\ a University of Göttingen, Department of Animal Sciences, Albrecht-Thaer-Weg 3, 37075, Göttingen, Germany \\ ${ }^{\mathrm{b}}$ Institute of Nutritional Physiology ‘Oskar Kellner', Leibniz Institute for Farm Animal Biology, Wilhelm-Stahl-Allee 2 18196, Dummerstorf, Germany \\ ${ }^{\mathrm{c}}$ Faculty of Science and Technology, Universitätsplatz 5,39100, Bolzano, Italy
}

\section{A R T I C L E I N F O}

\section{Article history:}

Received 16 May 2016

Received in revised form

13 November 2016

Accepted 15 November 2016

\section{Keywords:}

Chicken

Egg yolk

IgY

Nematode

Protective immunity

\begin{abstract}
A B S T R A C T
Maternally derived antibodies can provide partial protection against certain bacterial and viral infections. We investigated whether chicks descending from nematode-infected hens are more resistant against Ascaridia galli, a prevalent gastrointestinal nematode, than chicks from nematode-free mothers. Oneday-old chicks $(\mathrm{N}=153)$ from infected (mab+; maternal antibody $\left.{ }^{+}\right)$or uninfected control dams (mab-) were experimentally infected with A. galli at two different levels (100 or 1000 eggs/chick). The worm burdens of the chicks were determined at 6 weeks post infection. There was a high correlation $(r=0.89)$ between $A$. galli-specific antibody concentrations in dam plasma and egg yolk. There was no difference between worm burdens of chicks descending from infected or uninfected dams $(P=0.892)$, indicating no maternally derived protection against $A$. galli. Chicks receiving the higher infection dose had higher worm burdens $(P<0.05)$. Although there was no difference $(P>0.05)$ between worm counts of female and male chicks infected with 100 eggs, females chicks infected with 100 eggs harboured longer and heavier female worms. We conclude that there is no protective maternal immunity against A. galli infection.
\end{abstract}

(c) 2016 Elsevier B.V. All rights reserved.

\section{Introduction}

Many studies have shown that maternal antibodies are the primary means of protection against infection in very young chickens (Jungherr and Terrell, 1948; Kowalczyk et al., 1985; Mockett et al., 1987; Heller et al., 1990; Mondal and Naqi, 2001; Akhter, 2003; Hamal et al., 2006; Gharaibeh et al., 2008). Transferring maternally derived antibodies from an immune individual to a non-immune individual via egg yolk confers passive immunity in the recipient (Brambell, 1970). There are three principal classes of homologous antibodies, IgM, IgG (IgY) and IgA to the corresponding mammalian isotypes, and in birds, IgY is found predominantly in the egg yolks rather than the egg white (Leslie and Clem, 1969; Kincade and Cooper, 1973; Dahan et al., 1983; Sharma, 1997; Härtle et al., 2014).

The number of poultry farms with outdoor access, based on consumer demand (Gauly et al., 2002) and the European regulations for laying hens (Anonymous, 1999), has increased. Thus, the roundworm Ascaridia galli, is becoming one of the most abundant gastrointestinal nematodes (Permin et al., 1999; Chadfield et al., 2001; Idi et al., 2004; Pleidrup et al., 2014; Wongrak et al., 2014). A. galli has direct adverse effects on chicken performance (Ramadan

\footnotetext{
* Corresponding author.

E-mail address: srahimi@gwdg.de (S. Rahimian).
}

and Abou Znada, 1991; Daş et al., 2010; Das et al., 2012), and can lead to economic losses (Gauly et al., 2005; Daş et al., 2010; Andersen et al., 2013) and increase the susceptibility of chickens to secondary infections (Dahl et al., 2002; Permin et al., 2006). Disinfection and pharmaceuticals are expensive (Gauly et al., 2001). A. galli has been controlled mainly by synthetic anthelmintics (Tarbiat et al., 2016). Financial costs, potential anthelmintic underdosing (Bettridge et al., 2014), future anthelmintic resistance (Johnston et al., 2012) and potential anthelmintic residues in food products (Bovenhuis et al., 2002) have led to the need to develop an inexpensive and environmentally friendly method of protecting offspring against $A$. galli. Parasite collagen-based cuticles with carbohydraterich surface-coated bodies (Fetterer and Rhoads, 1993), as well as the ability to change antigenic surfaces by moulting several times throughout the development cycle (Blaxter et al., 1992), play a dominant role in how parasitic worms evade by the host innate immune system (De Veer et al., 2007). There are few studies describing naturally acquired immunity against $A$. galli (Bovenhuis et al., 2002).

Chickens experimentally infected with A. galli eggs develop both cellular and humoral immunity by secreting Th2-type cytokines and IgY, respectively (Degen et al., 2005; Marcos-Atxutegi et al., 2009; Schwarz et al., 2011). Maternal IgY antibodies can be transferred to progeny via the egg yolk (Marcos-Atxutegi et al., 2009); ovarian follicles, yolk sac membranes, and oviduct secretions are 
the main transfer paths (Kramer and Cho, 1970; Rose et al., 1974; Dohms et al., 1978; Loeken and Roth, 1983; Sharma, 1997; Grindstaff et al., 2003; West et al., 2004). A. galli infection can induce an humoral immune response in the host (Edgar, 1971), but this response may not be protective (Andersen et al., 2013; Norup et al., 2013). As far as we know, no studies have been conducted to identify passive immunity to A. galli in chickens. Thus, the aim of this study was to investigate whether maternal antibody positive (mab+) chicks are better able to resist $A$. galli infection than maternal antibody negative (mab-) chicks.

\section{Materials and methods}

\subsection{Experimental design and animals}

A. galli-free and A.galli-infected chickens ( $\mathrm{N}=20 ; 36 \mathrm{wk}$ old) of Lohmann Selected Leghorn (LSL) genotype were obtained from a research farm (University of Göttingen, Germany) and kept in two disinfected (INTERKOKASK, $p$-Chlor-m-kresol, 4\%) barns as control and infected groups, respectively. Nematode free and flubendazole treated cockerels (LSL, $18 \mathrm{wk}$ ) were placed in these barns for two weeks to mate (sex ratio: 1/10). Afterwards, all laid eggs were collected at regular intervals, and the positive fertility results for some of the randomly collected incubated eggs $(\mathrm{N}=37)$ demonstrated successful mating. All collected eggs were numbered $(\mathrm{N}=198)$ and incubated. Dams were necropsied, and individual blood and egg yolk samples were collected. A total of 153 newly hatched chicks (mab+, mab-) were challenged orally by infection (monoinfection) on day 1 with embryonated A. galli eggs, using a $5 \mathrm{~cm}$ until analysed. For analyses, the egg yolk and plasma samples were diluted 1:500 and 1:2500, respectively, with test buffer. Due to the tough texture of the yolk, additional mixing was undertaken via vortexing at room temperature to minimize any differences between the samples. Briefly, $100 \mu \mathrm{l}$ of plasma or egg yolk and standards (all diluted in the test buffer) was added to the coated wells. Dilution series of highly positive plasma samples were used. After incubation (wrapped and placed on a shaker $(500 \mathrm{rpm})$ ) for $2 \mathrm{~h}$ at RT, washed plates (wash buffer) were filled with $100 \mu \mathrm{l}$ of enzyme-conjugated anti-chicken IgY, wrapped again and incubated on the shaker $(500 \mathrm{rpm})$ for $30 \mathrm{~min}$ at RT. Afterwards, the plates were washed again, and $100 \mu$ l of substrate solution (TMB) was added, and the plates were incubated for an additional $15 \mathrm{~min}$ at RT in the dark. Colour development was stopped with a stop solution $(100 \mu \mathrm{l})$ and the plates were read at an absorbance of $450 \mathrm{~nm}$, with the absorbance at $650 \mathrm{~nm}$ serving as the reference wavelength. The standard curve described the relation between the concentrations of the standards and their absorbance value generated for each plate. Antibody binding was expressed relative to a standard chicken serum with high antibody activity ( 1 Unit per mL per definition).

\subsection{Statistical analysis}

The experiment was subjected to a factorial design. Plasma transferred antibody concentrations were calculated to investigate the occurrence of transferring antibodies via egg yolk. Data for each dependant variable (i.e., plasma antibody levels, worm burden, number of female and male worms, lengths and weights of worms of both genders) were analysed via factorial ANOVA, as shown in the following statistical model:

$$
\begin{aligned}
& \mathrm{Y}=1 \mu+\mathrm{B} 1 \times \text { mother_inf }+ \text { B2 } \times \text { chick_inf }+ \text { B3 } \times \text { sex }+ \text { B4 } \times \text { housing_in }+\left(\text { mother_inf } \times \text { chick_inf } \times \Upsilon_{\text {mother_inf } \times \text { chick_inf })}\right. \\
& +\left(\text { mother_inf } \times \operatorname{sex} \times \curlyvee_{\text {mother_inf }} \times \text { sex }\right)+\left(\text { mother_inf } \times \text { housing_in } \times \Upsilon_{\text {mother_inf } \times \text { housing_in }}\right)+\left(\text { chick_inf } \times \text { sex } \times \curlyvee_{\text {chick_inf } \times \text { sex }}\right) \\
& +\left(\text { chick_inf } \times \text { housing_in } \times \Upsilon_{\text {chick_inf } \times \text { housing_in }}\right)+\left(\operatorname{sex} \times \text { housing_in } \times \Upsilon_{\text {sex }} \times \text { housing_in }\right)
\end{aligned}
$$

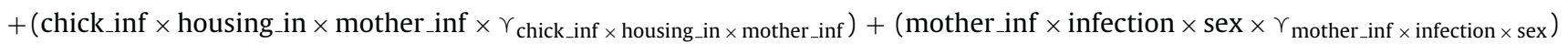

$$
\begin{aligned}
& +\left(\text { chick_inf } \times \text { housing_in } \times \text { mother_inf } \times \operatorname{sex} \times \Upsilon_{\text {chick_inf } \times \text { housing_in } \times \text { mother_inf } \times \text { sex }}\right)+\varepsilon
\end{aligned}
$$

oesophageal cannula (Daş et al., 2010). Half of the chicks were challenged with $+100 \mathrm{~A}$. galli eggs, and the remainder were infected with a 10 -fold higher infection dose $(+1000)$. At necropsy (6 wk post infection), blood was collected from all birds, and they were subjected to post-mortem parasitological examinations by sieving ( $100 \mu \mathrm{m}$ mesh aperture size) the whole small intestinal content. Worms visible with the naked eye were recovered, and microscopy was used to assess the presence of larvae not visible with the naked eye. The demographic characteristics of the infrapopulations were then determined.

\subsection{Infection material}

Fully embryonated uterine eggs that were incubated in $0.1 \%$ potassium dichromate $\left(\mathrm{K}_{2} \mathrm{Cr}_{2} \mathrm{O}_{7}\right)$ at room temperature were used for experimental infection(Rahimian et al., 2016).

\subsection{A. galli-specific antibody}

Plasma A. galli-specific antibodies raised against both soluble and solubilized worm body antigens were determined using antigen coated microtiter wells. Bound antibodies were measured by an enzyme-conjugated secondary antibody against chicken IgY as described by (Hennies et al., 2013). At necropsy blood was collected to obtain plasma. Egg yolks were separated and stored $-20^{\circ} \mathrm{C}$
Where $Y$ is the observation, 1 is the vector of size $n \times 1$ with each entry equal to one, $\mu$ is the fixed effect, and $\varepsilon$ is the residual random error. Tukey-Kramer adjusted post-hoc comparisons $(p<0.05)$ were employed to partition the effects of the factors when needed. Shapiro normality tests were used to test for normality of variation among the residuals, and the plots were visually inspected. Worm burden, number of female and male worms were analysed in a generalized linear model specifying a negative binomial distribution. Goodness of fit ( $p>0.05$ ) was considered for accuracy of the model. Logarithm transformation was used to normalize the data regarding antibody levels. The square root of male worm weight was used, and outliers in male worm length/weight were removed. Worm burden data that were analysed included outliers. All analyses were performed using the R package (Colditz, 2008).

\section{Results}

There was a strong correlation $(\mathrm{r}=0.89, \mathrm{P}<0.001)$ between $A$. galli-specific antibody concentration in plasma and egg yolks of infected dams (Fig. 1). The first, median and third quartiles for antibody titres for dam plasma and egg yolk were 23.55, 48.10, 98.55 and 20.7, 31.5, 53.6, respectively. There was no difference between worm burdens of chicks descending from infected or uninfected dams $(P=0.892)$. Chicks challenged with $+1000 \mathrm{~A}$. galli eggs harboured higher worms $(P \leq 0.001)$ than chicks challenged with +100 A.galli eggs (Table 1 ). The higher worm burdens 
Table 1

Responses of male and female chicks descending from A. galli-infected (Dams +1000) or uninfected dams (control) to an experimental A. galli infection with two different levels $(+100$ or +1000$)$.

${ }^{\mathrm{a}-\mathrm{c}}$ : Means within same column and a given factor with different superscript letters are significantly different $(\mathrm{P}<0.05)$.

\begin{tabular}{|c|c|c|c|c|c|c|c|c|c|}
\hline & & \multirow{2}{*}{$\begin{array}{l}\text { Total worm } \\
\text { burden } \\
\text { (\#/bird) }\end{array}$} & \multicolumn{2}{|l|}{ \# of Worms } & \multicolumn{2}{|c|}{ Worm weight (mg) } & \multicolumn{2}{|c|}{ Worm length $(\mathrm{cm})$} & \multirow{2}{*}{$\begin{array}{l}\text { Antibody } \\
\text { concentration } \\
(\mathrm{mU} / \mathrm{ml})^{*}\end{array}$} \\
\hline & & & o & $0^{7}$ & q & $0^{7}$ & q & $\sigma^{7}$ & \\
\hline Chicks' infection & $\begin{array}{l}(+100) \\
(+1000) \\
\text { P-values, } \leq\end{array}$ & $\begin{array}{l}5.6^{b} \pm 0.76 \\
19.2^{a} \pm 1.7 \\
0.001\end{array}$ & $\begin{array}{l}3.2^{\mathrm{b}} \pm 0.44 \\
11.8^{\mathrm{a}} \pm 1.05 \\
0.001\end{array}$ & $\begin{array}{l}2.5^{\mathrm{b}} \pm 0.37 \\
7.5^{\mathrm{a}} \pm 0.75 \\
0.001\end{array}$ & $\begin{array}{l}93.4^{\mathrm{b}} \pm 1 \\
85.2^{\mathrm{a}} \pm 1 \\
0.001\end{array}$ & $\begin{array}{l}39.9^{\mathrm{a}} \pm 0.7 \\
36.4^{\mathrm{b}} \pm 0.6 \\
0.0004\end{array}$ & $\begin{array}{l}8.7 \pm 0.06 \\
8.7 \pm 0.06 \\
0.536\end{array}$ & $\begin{array}{l}6.5 \pm 0.06 \\
6.5 \pm 0.06 \\
0.509\end{array}$ & $\begin{array}{l}1.992 \pm 0.208 \\
2.264 \pm 0.229 \\
0.171\end{array}$ \\
\hline Dams' infection & $\begin{array}{l}\text { (Control) } \\
(+1000) \\
\text { P-values, } \leq\end{array}$ & $\begin{array}{l}9.4 \pm 1.23 \\
12.2 \pm 1.65 \\
0.892\end{array}$ & $\begin{array}{l}5.6 \pm 0.75 \\
7.4 \pm 1.02 \\
0.119\end{array}$ & $\begin{array}{l}3.8 \pm 0.52 \\
5.0 \pm 0.7 \\
0.116\end{array}$ & $\begin{array}{l}90.6 \pm 1 \\
86.8 \pm 1 \\
0.053\end{array}$ & $\begin{array}{l}38.6 \pm 0.6 \\
37.3 \pm 0.8 \\
0.317\end{array}$ & $\begin{array}{l}8.7 \pm 0.06 \\
8.7 \pm 0.06 \\
0.489\end{array}$ & $\begin{array}{l}6.5 \pm 0.05 \\
6.5 \pm 0.07 \\
0.824\end{array}$ & $\begin{array}{l}2.277 \pm 0.214 \\
1.805 \pm 0.194 \\
0.117\end{array}$ \\
\hline Chick's Gender & $\begin{array}{l}\text { Chick_o } \\
\text { Chick_o" } \\
\text { P-values, } \leq\end{array}$ & $\begin{array}{l}10.2 \pm 1.48 \\
11.26 \pm 1.34 \\
0.316\end{array}$ & $\begin{array}{l}6.2 \pm 0.93 \\
6.7 \pm 0.81 \\
0.303\end{array}$ & $\begin{array}{l}4 \pm 0.59 \\
4.5 \pm 0.61 \\
0.911\end{array}$ & $\begin{array}{l}90.9^{\mathrm{a}} \pm 1.5 \\
86.4^{\mathrm{b}} \pm 1.6 \\
0.044\end{array}$ & $\begin{array}{l}38.2 \pm 0.7 \\
37.7 \pm 0.6 \\
0.926\end{array}$ & $\begin{array}{l}8.8 \pm 0.06 \\
8.6 \pm 0.07 \\
0.085\end{array}$ & $\begin{array}{l}6.5 \pm 0.06 \\
6.5 \pm 0.06 \\
0.959\end{array}$ & $\begin{array}{l}2.355^{\mathrm{a}} \pm 0.211 \\
1.689^{\mathrm{b}} \pm 0.190 \\
0.023\end{array}$ \\
\hline & $\begin{array}{l}\text { Dam_control: } \text { Chick_+100 } \\
\text { Dam_control: Chick_+1000 } \\
\text { Dam_+1000: } \text { Chick_+100 } \\
\text { Dam_+1000: Chick_+1000 } \\
\text { P-values, } \leq\end{array}$ & $\begin{array}{l}3.5 \pm 0.68 \\
17.5 \pm 1.88 \\
8.0 \pm 1.32 \\
21.2 \pm 2.95 \\
0.158\end{array}$ & $\begin{array}{l}2 \pm 0.37 \\
10.6 \pm 1.17 \\
4.5 \pm 0.75 \\
13 \pm 1.82 \\
0.416\end{array}$ & $\begin{array}{l}1.5^{\mathrm{c}} \pm 0.33 \\
7^{\mathrm{a}} \pm 0.83 \\
3.5^{\mathrm{b}} \pm 0.63 \\
8^{\mathrm{a}} \pm 1.30 \\
0.019\end{array}$ & $\begin{array}{l}92.2^{\mathrm{a}} \pm 1.9 \\
89.6^{\mathrm{a}} \pm 1.8 \\
94.5^{\mathrm{a}} \pm 2.2 \\
79.7^{\mathrm{b}} \pm 1.9 \\
0.001\end{array}$ & $\begin{array}{l}39.1^{\mathrm{a}} \pm 1.2 \\
38.3^{\mathrm{a}} \pm 0.7 \\
40.6^{\mathrm{a}} \pm 0.8 \\
34.2^{\mathrm{b}} \pm 1.1 \\
0.006\end{array}$ & $\begin{array}{l}8.7 \pm 0.10 \\
8.8 \pm 0.08 \\
8.8 \pm 0.11 \\
8.6 \pm 0.08 \\
0.062\end{array}$ & $\begin{array}{l}6.5 \pm 0.09 \\
6.6 \pm 0.07 \\
6.6 \pm 0.09 \\
6.4 \pm 0.09 \\
0.081\end{array}$ & $\begin{array}{l}2.258 \pm 0.299 \\
2.320 \pm 0.319 \\
1.679 \pm 0.279 \\
2.196 \pm 0.333 \\
0.164\end{array}$ \\
\hline Interaction & 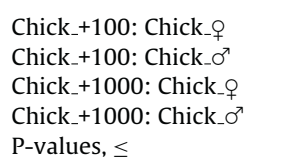 & $\begin{array}{l}5.1^{\mathrm{c}} \pm 1.17 \\
6.1^{\mathrm{c}} \pm 0.89 \\
18.5^{\mathrm{b}} \pm 2.62 \\
20^{\mathrm{a}} \pm 1.97 \\
0.001\end{array}$ & $\begin{array}{l}2.9^{\mathrm{c}} \pm 0.66 \\
3.5^{\mathrm{b}} \pm 0.51 \\
11.6^{\mathrm{a}} \pm 2.62 \\
12^{\mathrm{a}} \pm 1.18 \\
0.002\end{array}$ & $\begin{array}{l}2.3^{c} \pm 0.54 \\
2.7^{c} \pm 0.46 \\
7^{b} \pm 1.06 \\
8^{a} \pm 1.01 \\
0.001\end{array}$ & $\begin{array}{l}96.8^{\mathrm{a}} \pm 1.7 \\
89.8^{\mathrm{ab}} \pm 2.3 \\
86.6^{\mathrm{b}} \pm 1.9 \\
83.6^{\mathrm{b}} \pm 2.1 \\
0.005\end{array}$ & $\begin{array}{l}39.7 \pm 1.2 \\
40.1 \pm 0.6 \\
37 \pm 0.9 \\
35.7 \pm 1 \\
0.0594\end{array}$ & $\begin{array}{l}8.9 \mathrm{a} \pm 0.08 \\
8.6^{\mathrm{b}} \pm 0.12 \\
8.7^{\mathrm{ab}} \pm 0.08 \\
8.7^{\mathrm{ab}} \pm 0.08 \\
0.024\end{array}$ & $\begin{array}{l}6.5 \pm 0.11 \\
6.5 \pm 0.06 \\
6.5 \pm 0.07 \\
6.4 \pm 0.09 \\
0.795\end{array}$ & $\begin{array}{l}2.202 \pm 0.309 \\
1.728 \pm 0.261 \\
2.820 \pm 0.340 \\
1.589 \pm 0.244 \\
0.0784\end{array}$ \\
\hline
\end{tabular}

Concentration of A. galli specific antibodies in plasma samples of the chicks at necropsy (6 weeks p.i.).

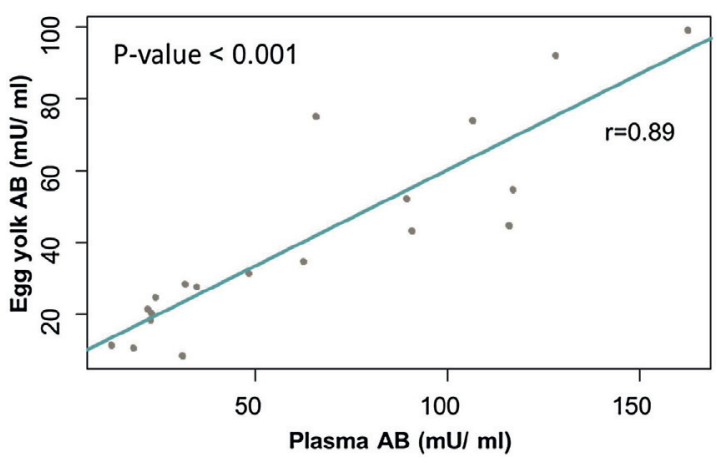

Fig. 1. Correlation between plasma and egg yolk A. galli specific antibody concentrations.

for male chicks in higher infection dose $(P \leq 0.001)$ were also noted in Table 1 . Regarding worm gender, chicks challenged with $+1000 \mathrm{~A}$. galli eggs hosted approximately three times more female $(11.8 \pm 1.05)$ and male $(7.5 \pm 0.75)$ worms than chicks infected with lower doses $(\mathrm{P} \leq 0.001)$. Heavier female $(93.4 \pm 1 \mathrm{mg}, \mathrm{P}<0.001)$ and male $(39.9 \pm 0.7 \mathrm{mg}, \mathrm{P}=0.0004)$ worms were harvested from chicks infected with lower doses than from chicks infected with higher dose. Mab+ chicks challenged with +100 A. galli eggs showed a tendency $(P<0.10)$ towards significance with respect to the effect of the interaction between maternal infection and chick infection on worm length, exhibiting longer female and male worms $8.8 \pm 0.11 \mathrm{~cm}, 6.6 \pm 0.09 \mathrm{~cm}$, respectively. Heavier female and male worms $(94.5 \pm 2.2 \mathrm{mg}, 40.6 \pm 0.8 \mathrm{mg})$ were noted in mab+ chicks challenged with +100 A. galli eggs $(P=0.0018,0.006)$ than from all other experimental groups. Independent from the infection dose $(P=0.023)$, average plasma antibody concentration was approximately 1.4 times higher in female chicks than in male chicks at necropsy. Heavier $(90.9 \pm 1.5 \mathrm{mg})$ and longer $(8.8 \pm 0.06 \mathrm{~cm})$ female worms were harvested from female chicks $(P=0.044,0.085)$ than from male chicks. Significant difference in the Interaction between chicks infection and gender on female worm weight and length $(P=0.005,0.024)$ were also noted in Table 1 . The heaviest $(96.8 \pm 1.7)$ and longest $(8.9 \pm 0.08)$ measured worms harvested from female chicks challenged with +100 eggs. There was no correlation $(r=0.07)$ between plasma antibody concentration and worm burdens of the chicks.

\section{Discussion}

This study investigated whether chicks descending from A. galliinfected hens would be more resistant against this parasite than chicks descending from uninfected control mothers.

It has been suggested that the age of the chicken has effect on resistance to A. galli (Idi et al., 2004; Gauly et al., 2005). By choosing 36 -week-old infected animals it was assumed that the dams would have already developed a reasonable immune response against the nematode, which would then be transferred to the offspring via egg yolk. Although the transfer of nematode specific antibodies from dam plasma to the egg yolk was shown, no protective role of the antibodies could be demonstrated. It has been shown that $\operatorname{IgG}$ is transferred from dams to offspring (Brambell, 1970) as a form of primary specific protection (Hamal et al., 2006). In our study, egg yolk was considered to be a source of protective antibodies (IgY) (Sharma, 1997). In the Hamal et al. (2006) study, the transfer of plasma antibodies against the Newcastle and bronchitis viruses to egg yolk and egg white in meat line chickens was shown. They reported that IgG is found mainly in egg yolk and that the presence of IgG in egg whites may be attributed to the transfer of egg yolk antibodies to egg whites. Similar to our results, they also showed differences in antibody titres between plasma and egg yolk (data not shown), which suggests that a portion of plasma antibodies is transferred to the egg yolk. Transfer of a portion of IgG antibodies to offspring and the stimulation of a strong immune response in the host was demonstrated in the study by Marcos-Atxutegi et al. (2009). Mondal and Naqi (2001) also investigated the transfer of maternal bronchitis virus antibodies to offspring. Our results suggest that the amount of antibody present in egg yolk is highly associated with dam antibody levels. 
After 6 weeks of study, all but 4 challenged chickens infected with +100 A. galli eggs harboured worms. We obtained significantly higher infection rates with higher infection doses. Chickens infected with +1000 A. galli eggs hosted 3.4 times more worms $(19.2 \pm 1.7)$ and 3.6 and 3 times more female $(11.8 \pm 1.05)$ and male $(7.5 \pm 0.75)$ worms, respectively. This result is similar to the study of Gauly et al. (2001) that found higher worm burdens and higher levels of harvested female worms at higher infection doses; however, similar results were not observed for male worms. Tongson and McCraw (1967) also showed higher worm burdens with higher infection doses. Ferdushy et al. (2012) investigated larva levels in conjunction with higher infection doses of A. galli eggs from +500 to +2000 , but not above +2000 . Harvested worms in all groups reached a size corresponding to their fertile stage (5.1-7.6 and 7.2-11.6 cm for males and females, respectively) (Ackert, 1931). There was a significant difference in worm weights, with heavier worms occurring at lower chick infection doses, which is different from the results obtained by Gauly et al. (2001) and may perhaps indicate impaired worm growth at higher infection intensities.

A. galli specific plasma antibody concentration was higher in female chicks than in male chicks, independent of dam/offspring infection levels. In general, female chicks hosted heavier female worms, and longer female worms were harvested from female chicks challenged with +100 A. galli eggs compared with male chicks. Bettridge et al. (2014) investigated higher antibody levels in female chickens with bacterial (Salmonella and Pasteurella) infections, which was also investigated in the Johnston et al. (2012) study. They reported that when birds reach sexual maturity, the lymphocyte population involved in cell-mediated immunity ( $T$ lymphocytes) decreases, whereas there is no corresponding change in humoral immunity (B lymphocytes), which shows that female chickens are more resistant to infection.

No significant correlations between specific offspring antibody plasma titres and worm burden were observed. Very weak correlations between plasma antibody concentrations and worm burden were observed in the study by (Marcos-Atxutegi et al., 2009). Kringel and Roepstorff (2007) investigated positive but poor associations between antibody level and $T$. suis worm burden in pigs. Inverse relationship between epg and antibody level has been investigated (Marcos-Atxutegi et al., 2009; Norup et al., 2013) and it is suggested the possibility of humoral immunity involved in protection by inverse relationship between epg and antibody level studied at (Norup et al., 2013) study. Because of the transfer of maternal antibodies and the correlation between egg yolk and plasma antibody concentrations, we expected lower infection rates in mab+ dams. However, the results indicated similar infection intensities chicks descending from infected or uninfected mothers, which suggest no protective role of maternally derived antibodies to $A$. galli in chickens. Thus it is concluded that there is no protective maternal immunity against A.galli infection.

\section{Acknowledgements}

Authors would like to thank Ms. Birgit Sohnrey and Mrs. Erwin Tönges for their help in various technical issues during the study. The financial support to the first author from the Erasmus Mundus project is gratefully acknowledged.

\section{References}

Ackert, J.E., 1931. The morphology and life history of the fowl nematode Ascaridia lineata (Schneider). Parasitology 23, 360-379.

Akhter, Z.A.S., 2003. Role of maternal antibodies in protection against infectious bursal disease in commercial broilers. Int. J. Poult. Sci. 2, 251-255.

Andersen, J.P., Norup, L.R., Dalgaard, T.S., Rothwell, L., Kaiser, P., Permin, A., Schou, T.W., Fink, D.R., Jungersen, G., Sorensen, P., Juul-Madsen, H.R., 2013. No protection in chickens immunized by the oral or intra-muscular immunization route with Ascaridia galli soluble antigen. Avian Pathol.: J. W.V.P.A 42, 276-282.

Anonymous, 1999. Council directive 1999/74/EC laying down minimum standards for the protection of laying hens. Off. J. Eur. Commun. L, 0053-0057.

Bettridge, J.M., Lynch, S.E., Brena, M.C., Melese, K., Dessie, T., Terfa, Z.G., Desta, T.T., Rushton, S., Hanotte, O., Kaiser, P., Wigley, P., Christley, R.M., 2014. Infection-interactions in Ethiopian village chickens. Prev. Vet. Med. 117, 358-366.

Blaxter, M.L., Page, A.P., Rudin, W., Maizels, R.M., 1992. Nematode surface coats: actively evading immunity. Parasitol. Today 8, 243-247.

Bovenhuis, H., Bralten, H., Nieuwland, M.G., Parmentier, H.K., 2002. Genetic parameters for antibody response of chickens to sheep red blood cells based on a selection experiment. Poult. Sci. 81, 309-315.

Brambell, F.W.R., 1970. Transmition of immunity in birds. In: Neuberger, A., Tatum, E.L. (Eds.), Transmition of Passive Immunity from Mother to Young. Elsevier, New York, NY 18, pp. 20-41.

Chadfield, M., Permin, A., Nansen, P., Bisgaard, M., 2001. Investigation of the parasitic nematode Ascaridia galli (Shrank 1788) as a potential vector for Salmonella enterica dissemination in poultry. Parasitol. Res. 87, 317-325.

Colditz, I.G., 2008. Six costs of immunity to gastrointestinal nematode infections. Parasite Immunol. 30, 63-70.

Daş, G., Kaufmann, F., Abel, H., Gauly, M., 2010. Effect of extra dietary lysine in Ascaridia galli-infected grower layers. Vet. Parasitol. 170, 238-243.

Dahan, A., Reynaud, C.A., Weill, J.C., 1983. Nucleotide sequence of the constant region of a chicken mu heavy chain immunoglobulin mRNA. Nucleic Acids Res. 11, 5381-5389.

Dahl, C., Permin, A., Christensen, J.P., Bisgaard, M., Muhairwa, A.P., Petersen, K.M.D., Poulsen, J.S.D., Jensen, A.L., 2002. The effect of concurrent infections with Pasteurella multocida and Ascaridia galli on free range chickens. Vet. Microbiol. $86,313-324$.

Das, G., Abel, H., Humburg, J., Schwarz, A., Rautenschlein, S., Breves, G., Gauly, M. 2012. The effects of dietary non-starch polysaccharides on Ascaridia galli infection in grower layers. Parasitology 139, 110-119.

De Veer, M.J., Kemp, J.M., Meeusen, E.N., 2007. The innate host defence against nematode parasites. Parasite Immunol. 29, 1-9.

Degen, W.G., Daal, N., Rothwell, L., Kaiser, P., Schijns, V.E., 2005. Th1/Th2 polarization by viral and helminth infection in birds. Vet. Microbiol. 105, 163-167.

Dohms, J.E., Saif, Y.M., Bacon, W.L., 1978. Metabolism and passive transfer of immunoglobulins in the turkey hen. Am. J. Vet. Res. 39, 1472-1481.

Edgar, R.N.B.a.S.A., 1971. Immunity development in chickens to the large intestinal roundworm, Ascaridia galli. Avian Dis. 15, 203-211.

Ferdushy, T., Nejsum, P., Roepstorff, A., Thamsborg, S.M., Kyvsgaard, N.C., 2012. Ascaridia galli in chickens: intestinal localization and comparison of methods to isolate the larvae within the first week of infection. Parasitol. Res. 111, 2273-2279.

Fetterer, R.H., Rhoads, M.L., 1993. Biochemistry of the nematode cuticle: relevance to parasitic nematodes of livestock. Vet. Parasitol. 46, 103-111.

Gauly, M., Bauer, C., Mertens, C., Erhardt, G., 2001. Effect and repeatability of Ascaridia galli egg output in cockerels following a single low dose infection. Vet. Parasitol. 96, 301-307.

Gauly, M., Bauer, C., Preisinger, R., Erhardt, G., 2002. Genetic differences of Ascaridia galli egg output in laying hens following a single dose infection. Vet. Parasitol. 103, 99-107.

Gauly, M., Homann, T., Erhardt, G., 2005. Age-related differences of Ascaridia galli egg output and worm burden in chickens following a single dose infection. Vet. Parasitol. 128, 141-148.

Gharaibeh, S., Mahmoud, K., Al-Natour, M., 2008. Field evaluation of maternal antibody transfer to a group of pathogens in meat-type chickens. Poult. Sci. 87, 1550-1555.

Grindstaff, J.L., Brodie, E.D., Ketterson, E.D., 2003. Immune function across generations: integrating mechanism and evolutionary process in maternal antibody transmission. Proc. R. Soc. Lond. B: Biol. Sci. 270, 2309-2319.

Härtle, S., Magor, K.E., Göbel, T.W., Davison, F., Kaspers, B., 2014. Chapter 6 structure and evolution of avian immunoglobulins. In: Avian Immunology, 2nd ed. Academic Press, Boston, pp. 103-120.

Hamal, K.R., Burgess, S.C., Pevzner, I.Y., Erf, G.F., 2006. Maternal antibody transfer from dams to their egg yolks, egg whites, and chicks in meat lines of chickens. Poult. Sci. 85, 1364-1372.

Heller, E.D., Leitner, H., Drabkin, N., Melamed, D., 1990. Passive immunisation of chicks against Escherichia coli. Avian Pathol. 19, 345-354.

Hennies, M., Das, G., Gauly, M., 2013. Measurement of Ascaridia galli infection by ELISA. In Measurement of Ascaridia galli infection by ELISA. In: International Symposium of the World Association of Veterinary Laboratory Diagnosticians (WAVLD) 16th, 10th OIE Seminar, 32nd Symposium of AVID, Berlin, Germany.

Idi, A., Permin, A., Murrell, K.D., 2004. Host age only partially affects resistance to primary and secondary infections with Ascaridia galli (Schrank, 1788) in chickens. Vet. Parasitol. 122, 221-231.

Johnston, C.E., Hartley, C., Salisbury, A.-M., Wigley, P., 2012. Immunological changes at point-of-lay increase susceptibility to Salmonella enterica serovar enteritidis infection in vaccinated chickens. PLoS One 7, e48195.

Jungherr, E.L., Terrell, N.L., 1948. Naturally acquired passive immunity to infectious bronchitis in chicks. Am. J. Vet. Res. 9, 201-205.

Kincade, P.W., Cooper, M.D., 1973. Immunoglobulin A: site and sequence of expression in developing chicks. Science 179, 398-400. 
Kowalczyk, K., Daiss, J., Halpern, J., Roth, T.F., 1985. Quantitation of maternal-fetal IgG transport in the chicken. Immunology 54, 755-762.

Kramer, T.T., Cho, H.C., 1970. Transfer of immunoglobulins and antibodies in the hen's egg. Immunology 19, 157-167.

Kringel, H., Roepstorff, A., 2007. Trichuris suis excretory/secretory antigen-specific antibodies in serum from single-inoculated pigs. Parasite Immunol. 29, 327-330.

Leslie, G.A., Clem, L.W., 1969. Phylogen of immunoglobulin structure and function. 3. Immunoglobulins of the chicken. J. Exp. Med. 130, 1337-1352.

Loeken, M.R., Roth, T.F., 1983. Analysis of maternal IgG subpopulations which are transported into the chicken oocyte. Immunology 49, 21-28.

Marcos-Atxutegi, C., Gandolfi, B., Arangüena, T., Sepúlveda, R., Arévalo, M., Simón, F., 2009. Antibody and inflammatory responses in laying hens with experimental primary infections of Ascaridia galli. Vet. Parasitol. 161, 69-75.

Mockett, A.P., Cook, J.K., Huggins, M.B., 1987. Maternally-derived antibody to infectious bronchitis virus: its detection in chick trachea and serum and its role in protection. Avian Pathol.: J. W.V.P.A 16, 407-416.

Mondal, S.P., Naqi, S.A., 2001. Maternal antibody to infectious bronchitis virus: its role in protection against infection and development of active immunity to vaccine. Vet. Immunol. Immunopathol. 79, 31-40.

Norup, L.R., Dalgaard, T.S., Pleidrup, J., Permin, A., Schou, T.W., Jungersen, G., Fink D.R., Juul-Madsen, H.R., 2013. Comparison of parasite-specific immunoglobulin levels in two chicken lines during sustained infection with Ascaridia galli. Vet. Parasitol. 191, 187-190.

Permin, A., Bisgaard, M., Frandsen, F., Pearman, M., Kold, J., Nansen, P., 1999. Prevalence of gastrointestinal helminths in different poultry production systems. Br. Poult. Sci. 40, 439-443.

Permin, A., Christensen, J.P., Bisgaard, M., 2006. Consequences of concurrent Ascaridia galli and Escherichia coli infections in chickens. Acta Vet. Scand. 47, 43-54.
Pleidrup, J., Dalgaard, T.S., Norup, L.R., Permin, A., Schou, T.W., Skovgaard, K., Vadekær, D.F., Jungersen, G., Sørensen, P., Juul-Madsen, H.R., 2014. Ascaridia galli infection influences the development of both humoral and cell-mediated immunity after Newcastle disease vaccination in chickens. Vaccine 32, 383-392.

Rahimian, S., Gauly, M., Daş, G., 2016. Embryonation ability of Ascaridia galli eggs isolated from worm uteri or host faeces. Vet. Parasitol. 215, 29-34.

Ramadan, H.H., Abou Znada, N.Y., 1991. Morphology and life history of Ascaridia galli in the domestic fowl that are raised in jeddah. J. King Abdulaziz Univ. Sci 4, 87-99.

Rose, M.E., Orlans, E., Buttress, N., 1974. Immunoglobulin classes in the hen's egg: their segregation in yolk and white. Eur. J. Immunol. 4, 521-523.

Schwarz, A., Gauly, M., Abel, H., Daș, G., Humburg, J., Rohn, K., Breves, G., Rautenschlein, S., 2011. Immunopathogenesis of Ascaridia galli infection in layer chicken. Dev. Comp. Immunol. 35, 774-784.

Sharma, J.M., 1997. The structure and function of the avian immune system. Acta Vet. Hung. 45, 229-238.

Tarbiat, B., Jansson, D.S., Tydén, E., Höglund, J., 2016. Comparison between anthelmintic treatment strategies against Ascaridia galli in commercial laying hens. Vet. Parasitol. 226, 109-115.

Tongson, M.S., McCraw, B.M., 1967. Experimental ascaridiasis: influence of chicken age and infective egg dose on structure of Ascaridia galli populations. Exp. Parasitol. 21, 160-172.

West Jr., A.P., Herr, A.B., Bjorkman, P.J., 2004. The chicken yolk sac IgY receptor, a functional equivalent of the mammalian MHC-related Fc receptor, is a phospholipase A2 receptor homolog. Immunity 20, 601-610.

Wongrak, K., Das, G., Moors, E., Sohnrey, B., Gauly, M., 2014. Establishment of gastro-intestinal helminth infections in free-range chickens: a longitudinal on farm study. Berl. Munch. Tierarztl. Wochenschr. 127, 314-321. 


\section{Paper 3. Genetic variation for levels of total specific antibodies in naturally infected laying hens with gastrointestinal nematodes}

Shayan Rahimian ${ }^{\mathbf{a}}$, Gürbüz Daş ${ }^{\mathbf{b}}$, Uta. König von Borstel ${ }^{\mathrm{a}}$, Matthias Gauly ${ }^{\mathrm{c}}$

aUniversity of Göttingen, Department of Animal Sciences, Albrecht-Thaer-Weg 3, 37075, Göttingen, Germany

'Institute of Nutritional Physiology ‘Oskar Kellner', Leibniz Institute for Farm Animal Biology, Wilhelm-Stahl-Allee 2 18196, Dummerstorf, Germany

${ }^{\mathrm{c}}$ Faculty of Science and Technology, Universitätsplatz 5,39100, Bolzano, Italy 
Abstract:

This study describes genetic resistance to a naturally acquired immune system and infectivity diagnosis by estimating total specific antibody concentrations (TsAb) against harvested nematodes in free-range laying hens system. Chickens (17 weeks old) of two Lohmann brown genotypes (LB plus/ LB Classic) were divergently examined for a laying period of one and a half years. Individually obtained plasma from the two genotypes, LB plus $(n=200)$ and LB classic $(n=200)$ were used to detect TsAb via the ELISA test before necropsy. Some of the birds were subjected to post-mortem parasitological examinations and TsAb at 79 weeks (LB plus, $n=162$ ) or 88 weeks (LB classic, $n=139$ ) of age at necropsy. There was a significant $(p<0.05)$ difference in the total worm burden (TWb) and TsAb when compared to the genetic background of chickens in their response to naturally acquired nematode infections. A positive correlation $(r=0.1)$ of TsAb before necropsy with a total epg (Tepg) and non-significant correlation ( $r=$ -0.13) with TWb at necropsy was found. Slightly fluctuated increases of TsAb before necropsy by age (weeks) was also apparent. It is concluded that the LB classic genotype was more susceptible to gastrointestinal nematodes with less TsAb at necropsy than the LB plus genotype. In addition, it was also found that estimating $T s A b$ is useful when diagnosing infectivity in a free-range chicken system.

Keywords: Antibody, Free-range, Genetics, Heritability, Laying hens 
Introduction:

Infection disease (Wijga et al., 2009) and the presence of roundworms in chickens is a well-known problem for the poultry industry (Ruff and Norton, 2008). Consumer demand (Gauly et al., 2002; Wijga et al., 2009), European regulations (Anonymous, 1999) and prohibited cage systems for laying hens in the EU since 2012 (CEC, 1999) are among the main reasons in the increase in outdoor access poultry farms. Free-range systems expose livestock to litter and parasites, increasing the risk of nematode infection (Wongrak et al., 2015). The higher risk of parasite infection come in the form of the following parasites: Heterkais gallinarum, Ascaridia galli and Capillaria spp. being the most prevalent species respectively (Kaufmann et al., 2011b; Wongrak et al., 2014). Infection of any of the above mentioned parasites can lead to serious problems, such as growth reduction (Das et al., 2011a) for $H$. gallinarum, reduced weight gain, diarrhea (Wakelin, 1965) for C. spp and reduced egg production, growth, weight gain, and increasing susceptibility to secondary infections from A.galli (Chadfield et al., 2001; Daş et al., 2010; Skallerup et al., 2005). In general, organic livestock production practices a rather limited use of anthelmintic remedies (CEC, 1999). However, within the EU an exception can be seen in the fight against nematodes (Tarbiat et al., 2016) which is crucial due to financial cost (Wijga et al., 2009), anthelmintic resistance (Johnston et al., 2012) and left-over residues (Johnston et al., 2012) in food products. It can be agreed that such remedies and the exploration of their use is crucial the future of a more sustainable approach to animal heath in agriculture, especially with ever increasing consumer awareness and demands for healthier and more transparent production systems. The chicken gut associated lymphoid tissue (GALT) plays a major role as a secondary 
lymphoid structure during intestinal infections (Pleidrup A et al., 2014). Development of immunity caused by parasitic infections is a costly process that can require high metabolic inputs (Colditz, 2008). Studies show that chickens infected with A.galli eggs develop both cellular and humoral immunity through a Th2-type cytokine pattern and IgG response (Degen et al., 2005; Marcos-Atxutegi et al., 2009; Schwarz et al., 2011). Natural antibodies are part of an innate immune system that are present in the body without known antigenic simulations of B cells (Siwek et al., 2006). Specific antibodies are part of the adaptive (humoral) immune system (Wijga et al., 2009). The high correlation between natural and specific antibodies was investigated by Wakelin (1965) and genetic selection for increased immunity due to infectious disease by (Pinard et al., 1993). Host genetic factors influence the immunoglobulin responses of most of the common gastrointestinal nematodes of swine (Kringel et al., 2015). Genetic selection for increased immunity was shown as an important tool to reduce problems due to infectious diseases in chickens (Pinard et al., 1992). Successful selection experiments for high and low antibody responses to the red blood cells of sheep in chicken have been reported (Martin et al., 1990). Low correlation between total epg (Tepg) and total worm burdens (TWb) in free-range chicken (Wongrak et al., 2014), phenotypic similarity of some nematode (H.gallinarum and A.galli) eggs (Thienpoint, 1986) and sensitivity of epg method (Cringoli et al., 2010; Das et al., 2011b; Michael and Bundy, 1989) are reasons to consider alternative ways to investigate infectivity in free-range chicken. Successful investigated antibody levels in free range chicken for Toxocara $s p$. and Toxoplasma gondii diagnosis has already been studied (Campos-da-Silva et al., 2015; Zhao et al., 2012). Investigations into the genotype for immunity responses 
and estimating infectivity by total specific antibody titer (TsAb) in free-range system may improve diagnosis and genetic resistance to infectious diseases. To our knowledge, little is known about genetic susceptibility to immune response in free-range chicken. Aims of this study were to see the possibilities of genetic improvement of natural immunity mechanisms and consider TsAb for infectivity tests in free-range chicken.

Material and methods:

\section{Experimental farm, animals and management}

The study follows the research of (Wongrak et al., 2014; Wongrak et al., 2015) on free-range chicken production with two mobile stalls in a 5 hectare area of Lower Saxony, Germany. As reported, the movement of the mobile stalls resulted in the livestock sharing the same pasture area at different times during a year. Water and feed access was provided ad libitum with outdoor access during the day time only. Artificial light with LED bulbs were used daily between 6.00 and 21.00 , which worked as natural lights - no anthelmintic treatment was used (Wongrak et al., 2015). A total of 230 LB classic and 230 LB plus chickens were used for the experiment. Pedigree information was known and documented and each animal was individually wing tagged. The two different genotypes were housed separately in two mobile stalls. Chickens were kept on the farm from 17 to 79 or to 88 weeks of age for LB plus and LB classic respectively. Post-mortem parasitological examinations were conducted afterwards. From July 2011 to one and a half years onward 20 chickens per genotype were bled directly from the wing vein to yield a volume of approximately $1 \mathrm{ml}$ of blood for ELISA tests at 
monthly intervals untill necropsy. Parasitological examinations were monitored by performing regular faecal egg counts (FEC) during laying periods. Faecal samples were analyzed for the total number of nematode eggs/gr of faeces (EPG) using a modified McMaster egg counting technique with a sensitivity of 50 EPG (Sloss MW et al., 1994). Some hens ( $n=162$, LB plus) and $(n=139$, LB classic) were necropsied at 79 and 88 weeks of age respectively due to organizational and economic factors. Post-mortem parasitological examinations were conducted by opening individual gastro-intestinal tracts from the oesphagus to the cloaca, including caeca, and washed with tap water into a $100 \mu m$ sieve. Blood samples were also taken for an ELISA test and the tracheas were examined macroscopically for the presence of Syngamus trachea. The morphology of the worms found was also examined (Wongrak et al., 2015).

\section{Total specific antibodies}

Total specific plasma antibodies concentrations (TsAb) raised against both soluble and solubilized worm body antigens were determined using antigen coated microtiter wells(96 well flat-bottomed microtitre antigen coated plates). Bound antibodies were measured by an enzyme-conjugated secondary antibody against chicken $\lg \mathrm{Y}$ as described by (Hennies et al., 2013). Centrifuged $(1,619 \mathrm{x}$ g) and frozen $\left(-20^{\circ} \mathrm{C}\right)$ plasma samples on the day of necropsy were thawed at room temperature (RT) for an ELISA test. The plasma sample was diluted with test buffer to 1:2500. $100 \mu \mathrm{l}$ of plasma and standards (all diluted in the test buffer) were allocated to the coated wells. A dilution series of highly positive plasma was used for maximum concentration. After two hours of incubation at room 
temperature (wrapped and placed on the shaker, washed plates (wash buffer) were filled with $100 \mu$ l of enzyme conjugated anti chicken IgY, which were then wrapped again and incubated on a shaker for $30 \mathrm{~min}$ at room temperature (RT). Afterwards, the plates were washed again and $100 \mu \mathrm{l}$ of substrate solution (TMB) were added and incubated for $15 \mathrm{~min}$ in the dark at RT. Color development was stopped with a stop solution $(100 \mu \mathrm{l})$ and the plates were read at an absorbance of $450 \mathrm{~nm}$, with the absorbance at $650 \mathrm{~nm}$ serving as the reference wavelength. The standard curve described the relation between the concentration of standards and their absorbance value was generated for each plate. Antibody binding was expressed relative to a standard chicken serum with high antibody activity (1 Unit per Ml per definition).

\section{Statistical Analysis}

The experiment was subjected to a factorial design. The correlation of TsAb to Tepg and TWb was investigated. Data for TsAb was only compared for a certain period of time (until 78 weeks of age, before necropsy) where by collected plasma samples of both on farm genotypes were available and analyzed via a two way ANOVA, as shown in the following statistical model:

$Y_{1}=1 \mu+B_{1} \times$ age $+B_{2} \times$ breed $+\left(\right.$ age $\times$ breed $\left.\times \gamma_{\text {age } \times \text { breed }}+\varepsilon\right)$

Data for other dependent variables (i.e., TsAb at necropsy, TWb, total number of female and male worms and three different species of worms), which was collected at necropsy was analysed through one way ANOVA, as shown in the following statistical model:

$Y_{2}=1 \mu+B \times$ breed $+\varepsilon$ 
Where $Y$ is the observation, 1 is the vector of size $n \times 1$ with each entry equal to one, $\mu$ is the fixed effect, and $\varepsilon$ is the residual random error. Tukey-Kramer adjusted post-hoc comparisons $(p<0.05)$ were employed to partition the effects of the factors when needed. Shapiro normality tests were used to test for normality of variation among the residuals - the plots were visually inspected. Logarithm transformation was used to get approximately normally distribution of data for TsAb before necropsy. Other dependent variables except TsAb at necropsy were analysed in a generalized linear model, specifying a negative binomial distribution. Goodness of fit ( $p>0.05)$ was considered for accuracy of the model. All analysis was performed using the R software package (Colditz, 2008).

Results:

Positive correlations were observed between TsAb titer (before necropsy) and Tepg $(r=0.1, P$-value $=0.014)$ and there is no significant association with $\operatorname{TWb}(r=$ -0.13, P-value=0.1) at necropsy (Fig. 1A, B). The total specific antibody titer (until 78 weeks of age, before necropsy) for LB plus and LB classic was significantly $(P=0.00628)$ different with $(58.779 \pm 15.31)$ and $(66.377 \pm 16.981)$ respectively for each of the genotypes. The specific antibody titer at necropsy was significantly $(P$-value $\leq 0.001)$ different for the two genotypes as well. The concentration was higher for LB plus $(150.128 \pm 9.918)$ when compared to LB classic $(84.547 \pm$ 4.764). Age of chicken (weeks) had a significant (P-value $\leq 0.001)$ effect on TsAb titer with fluctuation slightly increasing from week $17(12.663 \pm 2.271)$ to week 78 $(215.67 \pm 8.046)$, which is the maximum level of TsAb (Table 1, Fig. 2A). TWb was significantly $(P$-value $=0.00819)$ higher for LB classic $(239.9 \pm 21.5)$ compared to LB plus $(184.1 \pm 21.9)$. Expectedly, significantly higher means (male: $99.3 \pm 10.02$, P-value $\leq 0.001)$ and (female: $117.9 \pm 11.3$, P-value $\leq 0.001)$ 
of harvested worms were found in LB classic chickens. Also, species-specific nematode prevalence was different between two genotypes. Except Capillaria spp., other species were higher in LB classic (Table 1). Tepg and TsAb titer (before necropsy) is compared by weeks and shown in Figure 2B.

\begin{tabular}{|c|c|c|c|c|}
\hline & & LB plus & LB classic & P-values, $\leq$ \\
\hline $\begin{array}{l}\text { Total specific antibody concentration before } \\
\text { necropsy }(\mathrm{mU} / \mathrm{ml})\end{array}$ & & $58.779 \pm 15.31$ & $66.377 \pm 16.981$ & $0.00628^{* *}$ \\
\hline $\begin{array}{l}\text { Total specific antibody concentration at necropsy } \\
(\mathrm{mU} / \mathrm{ml})\end{array}$ & & $150.128 \pm 9.918$ & $84.547 \pm 4.764$ & $0.001^{* * *}$ \\
\hline Total worm burden (\#/bird) & & $184.1 \pm 21.9$ & $239.9 \pm 21.5$ & $0.00819^{* *}$ \\
\hline Total Cappilaria spp. (\#/bird) & & $20.73 \pm 2.0$ & $7.3 \pm 0.80$ & $0.001^{* * *}$ \\
\hline Total H. gallinarum (\#/bird) & & $142.5 \pm 21.42$ & $188.9 \pm 20.62$ & 0.0531 \\
\hline Total A.galli (\#/bird) & & $20.9 \pm 1.6$ & $45.8 \pm 3.9$ & $0.001^{* * *}$ \\
\hline \multirow{2}{*}{ \# worms } & $\widehat{\partial}$ & $55 \pm 5.1$ & $99.3 \pm 10.02$ & $0.001^{* * *}$ \\
\hline & q & $67.9 \pm 5.9$ & $117.9 \pm 11.3$ & $0.001^{* * *}$ \\
\hline \multirow{2}{*}{$\begin{array}{l}\text { Minimun and Maximun of total specific antibody } \\
\text { for both genotypes }(\mathrm{mU} / \mathrm{ml})\end{array}$} & & Age (week, 17) & Age (week, 78) & P-values, $\leq$ \\
\hline & & $12.663 \pm 2.271$ & $215.67 \pm 8.046$ & $0.001^{* * *}$ \\
\hline
\end{tabular}

Table1. Responses of the two different genotypes to gastrointestinal nematodes in free-range chickens

Legend: . $p<0.1^{*} p<.05 ;{ }^{* *} p<.01 ;{ }^{* *} p<.001$ 


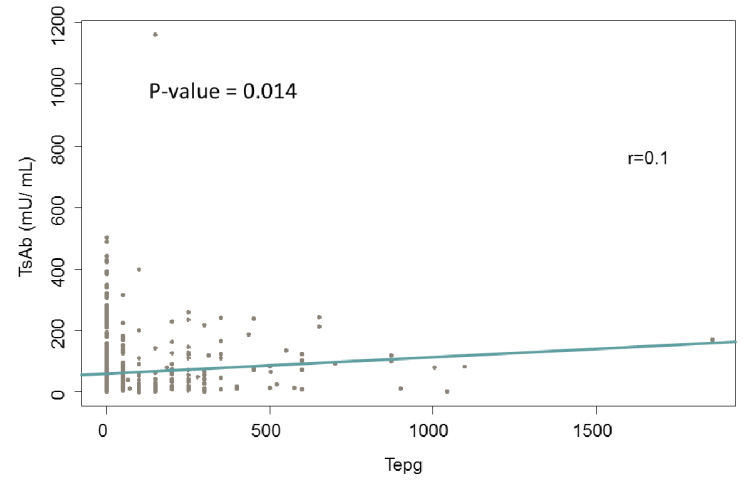

A.

Figure 1: Correlation between total number of parasites eggs per gram of faeces (Tepg) and total specific antodies (TsAb) concentration (A) and correlation between Total worm burden (TWb) and total specific antodies (TsAb) concentrations (B)
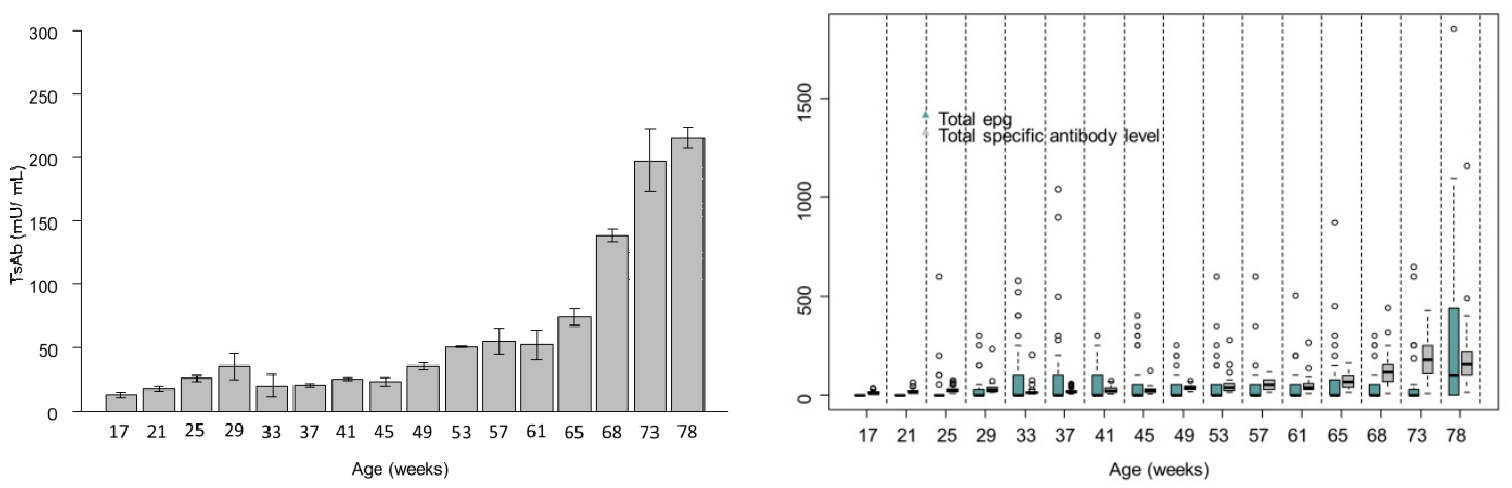

A.

B.

Figure 2: Total specific antibodies (TsAb) concentration in the both genotypes from week 17 to week 78 (A) Comparing the both genotypes total number of parasites eggs per gram of faeces (Tepg) and Total specific antibodies (TsAb) concentration from week 17 to week 78 
Discussion:

Improving the ability of birds to antigenic challenge responses by the genetic improvement of natural immunity mechanisms lead to the generation of more resistant poultry populations against a wide variety of pathogens. Brown chicken genotypes are genetically more resistant to parasites than white genotypes (Gauly et al., 2002; Sloss MW et al., 1994; Wakelin, 1965). The two examined (LB plus and LB classic) genotypes in this experiment share a very similar genetic background (Lohmann Tierzucht Gmbh, 2011).

The prepatent period (time between infection and shed of first eggs) of A.galli in young chicken is between 4 and 6 weeks (Anderson, 1992), with one week less for $H$. gallinarum (Fine, 1975). This period is three weeks for Cappilaria spp and depends on the species (Permin and Hansen, 1998). In Wongrak et al. (2015), the vast majority of chickens was reported as infected due to the presence of three nematode species on the day of necropsy. All of the factors influencing the establishment of the nematode infections on the studied farm have been described with detailed FEC and Infection data (Wongrak et al., 2014; Wongrak et al., 2015). Norup et al. (2013) investigated significant specific serum antibody titer difference in two lines of chickens during 80 weeks of the experimental A.galli infection. This could be attributed to the different genetic potential of genotypes, thus they may produce a stronger stimulation of IgY. It is also likely that different TWb of different species has an impact on TsAb. Higher significant prevalence of nematodes in the LB classic genotype, except less fecunded cappilaria spp., shows less resistance for the LB classic genotype. Based on results (Table 1), TsAb varied greatly between the two genotypes with higher TsAb for LB classic than the other genotype before necropsy. LB classic chickens 
were slaughtered later than LB plus (9 weeks), but TsAb at necropsy was significantly lower for LB classic. It should be considered that the number of LB classic chickens was lower than LB plus at necropsy. This study shows that the lower number of harvested worms from LB plus with higher TsAb at necropsy is equates to a negative association between $\mathrm{TWb}$ and $\mathrm{Ts} A \mathrm{Ab}$. This shows that older chickens with lower TsAb at necropsy were more susceptible to infection. Gauly et al. (2005) challenged birds at 6, 12, 18 and 24 weeks of age with A.gali eggs. The highest worm burden and faecal egg count was observed for the group infected at 18 weeks of age. They assume that the hormonal changes around the laying period make the bird immunocompromised, which may lower antibody production and make them more susceptible to infection. Ferdushy et al. (2014) also stimulated the drop in antibody level based on humoral changes in hens during the laying period. They showed a fluctuated antibody response for trickle challenged chickens by $100 \mathrm{~A}$.galli at 18 weeks of age with the first noticeable serum antibody 14 days after the first infection, fluctuating until 42 days pi and gradually decreasing afterwards. Our current results prove the hormonal changes investigated by the studies mentioned. Based on TWb at the start of the laying period, if TWb data was available at a different study period, it could be aligned to continuously estimate TsAb before necropsy. Kringel and Roepstorff (2007) investigated positive but poor associations between antibody levels and T.suis worm burden in pigs, which is not in agreement with our results (Fig. 1. B). Horning et al. (2003) also investigated the influence of helminth parasites on the vaccination of chicken against Newcastle disease in free-range chickens. They showed the seroconversion in all vaccinated chickens after 3 weeks, although this increase dropped to low levels at around 4 weeks. Here, the invers 
association was observed between $\mathrm{TWb}$ and TsAb by deworming chickens. Antibody titers rose in the chickens after being challenged by deworming. Significantly lower antibody titers for the all parasite infected animals as opposed to dewormed animals were observed. Moreover, a low correlation between total epg (Tepg) and total worm burdens (TWb) in free-range chickens was showed by (Wongrak et al., 2014), which is possibly due to a combination of nematode species and early infection time in the case of naturally acquired infections with mixed species.

It has been demonstrated that the capacity of the infected hens' immune system will increase against A.galli nematodes (Ackert et al., 1935; Idi et al., 2004), which is similar to our results for combined nematodes in free-range chickens. In the current study, the lowest TsAb observed from chickens occurred at 17 weeks of age. Wongrak et al. (2014) discussed very low Tepg for the first 3 months of the study at the beginning of laying period towards the final three months. This increasingly fluctuated until week 68 by continuing a rapid increase until week 78 . Based on the results (Fig. 3A), TsAb is lower at the beginning of the study and it fluctuates, increasing to week 68 towards the end of the project, which was also in line with the Tepg results. Kaufmann et al. (2011a) stimulated the obtained low FEC of two chicken lines in free range chickens after 6 months, developing host immunity to release higher antibodies, which is not in agreement with our study due to association between Tepg and TsAb (Fig. 1A) but in developing host immunity. Marcos-Atxutegi et al. (2009) investigated an inverse relationship between the antibody level and intensity of egg production by $A$. galli. Norup et al. (2013) furthered this and showed an inverse relationship between epg and antibody level. Through this inverse relationship, it was concluded that humoral 
immunity may be involved in protection but the high antibody titers neither prevent continued infection nor can they be associated with protection directly. The varied results reported could be due to the system studied (free-range) and because we used a combination of different nematode species. Kringel et al. (2015) investigated poor associations between specific antibody levels, egg excretion and the presence of macroscopic worms, which agree with our results. They concluded that the presence of specific antibodies in the serum is due to previous parasite exposure. However, it may not reflect the current infection status of the individual as antibodies can persist for a long time. In addition, a recent infection may be delayed in inducing the specific antibody response. Beside the low phenotypic correlation between Tepg and TWb, Wongrak et al. (2014) demonstrated the unreliability of parasite egg counts based on a combination of nematode parasites in a free-range system. Figure 3B shows that although at the beginning of study period chickens has antibody responses, Tepg was not reliable to estimate the infectivity. The progressive increase in TsAb over time is possibly due to a continuous infection that is readily available to them because of previous infections in the free-range system.

Kringel et al. (2015) showed that antibody detection may however be very useful for identifying pigs exposed to infection as FEC may underestimate the prevalence of infection. The accuracy of the epg technique is very much dependent on the freshness of the faecal samples and species of parasites being investigated (Cringoli et al., 2010). Chickens also have the ability to expel worm populations in Ascaridia galli infection (Permin et al., 1999), which can be another issue for importance when estimating infectivity by TsAb. As far as we know there 
is no published information about infection identification using TsAb in free-range chickens.

Hosts may have the same mechanisms to resist against reported nematodes, especially between $H$. gallinarum and $A$. galli (descended from the same family) and Ascaridiae. Higher contributions of $H$. gallinarum $(80 \%)$ in TWb are reported by (Wongrak et al., 2015), which may be the cause of higher heritability. Strong genetic correlation between A.galli and $H$. gallinarum $\left(r_{G}=0.88+0.34\right)$, as shown in their study, confirms the susceptibility of hosts to all nematodes. This study has investigated continuous TsAb before necropsy, an association between macroscopic worm load (infection levels) as well as TsAb at necropsy. We can conclude that the free-range system in this study has shown that repeated infection in free range chickens leads to a high rate of infection rather than complete protection against re-infection, as reported by (Höglund and Jansson, 2011; Idi et al., 2004) for partial and slowly developed immunity to A.galli nematode. The LB classic genotype is more susceptible to gastro-intestinal issues with lower TsAb concentration at necropsy, whereas the TsAb for the LB classic genotype was higher than LB plus before necropsy. Moreover, it seems possible to identify chicken lines that are less susceptible to gastrointestinal issues and infectivity diagnoses of chickens in free-range systems via immune response. 


\section{References}

Ackert, J.E., D.A. Porter and T.D. Beach 1935. Age resistanceof chickens to the nematodo Ascaridia lineada (Scheider). J. Parasitol 21: 205-213.

Anderson, R.C. 1992. Nematode Parasite of Vertebrates. Their Development and Transmission. CAB. International, Wallingford, UK, pp.578.

Anonymous 1999. Council directive 1999/74/EC laying down minimum standards for the protection of laying hens. Official Jornal of European Communities L: 0053-0057.

Campos-da-Silva, D. R., J. S. da Paz, V. R. Fortunato, M. A. Beltrame, L. C. Valli and F. E. Pereira 2015. Natural infection of free-range chickens with the ascarid nematode Toxocara sp. Parasitology research 114: 4289-4293. doi: 10.1007/s00436-015-4669-7

CEC, . 1999. Laying down minimum standars for protection of laying hens. O.J.E.U.L 203: 53-57.

Chadfield, M., A. Permin, P. Nansen and M. Bisgaard 2001. Investigation of the parasitic nematode Ascaridia galli (Shrank 1788) as a potential vector for Salmonella enterica dissemination in poultry. Parasitol Res 87: 317-325.

Colditz, I. G. 2008. Six costs of immunity to gastrointestinal nematode infections. Parasite Immunol 30: 63-70. doi: 10.1111/j.1365-3024.2007.00964.x

Cringoli, G., L. Rinaldi, M. P. Maurelli and J. Utzinger 2010. FLOTAC: new multivalent techniques for qualitative and quantitative copromicroscopic diagnosis of parasites in animals and humans. Nat Protoc 5: 503-515. doi: 10.1038/nprot.2009.235

Das, G., H. Abel, J. Humburg, A. Schwarz, S. Rautenschlein, G. Breves and M. Gauly 2011a. Non-starch polysaccharides alter interactions between 
Heterakis gallinarum and Histomonas meleagridis. Vet Parasitol 176: 208216. doi: 10.1016/j.vetpar.2010.11.004

Das, G., T. Savas, F. Kaufmann, A. Idris, H. Abel and M. Gauly 2011b. Precision, repeatability and representative ability of faecal egg counts in Heterakis gallinarum infected chickens. Vet Parasitol 183: 87-94.

Daş, Gürbüz, Falko Kaufmann, Hansjörg Abel and Matthias Gauly 2010. Effect of extra dietary lysine in Ascaridia galli-infected grower layers. Veterinary Parasitology 170: 238-243. doi:

\section{http://dx.doi.org/10.1016/j.vetpar.2010.02.026}

Degen, W. G., Nv Daal, L. Rothwell, P. Kaiser and V. E. Schijns 2005. Th1/Th2 polarization by viral and helminth infection in birds. Vet Microbiol 105: 163-167. doi: 10.1016/j.vetmic.2004.12.001

Ferdushy, T., T. W. Schou, L. R. Norup, T. S. Dalgaard, S. M. Thamsborg, P. Nejsum, A. Permin, H. R. Juul-Madsen and N. C. Kyvsgaard 2014. Acquisition of resistance after continuous infection with Ascaridia galli in chickens. Parasitology 141: 1603-1610. doi:

doi:10.1017/S0031182014000742

Fine, Paul E. M. 1975. Quantitative studies on the transmission of Parahistomonas wenrichi by ova of Heterakis gallinarum. Parasitology 70: 407-417.

Gauly, M., C. Bauer, R. Preisinger and G. Erhardt 2002. Genetic differences of Ascaridia galli egg output in laying hens following a single dose infection. Vet Parasitol 103: 99-107.

Gauly, M., T. Homann and G. Erhardt 2005. Age-related differences of Ascaridia galli egg output and worm burden in chickens following a single dose infection. 
Veterinary Parasitology 128: 141-148. doi:

http://dx.doi.org/10.1016/j.vetpar.2004.11.023

Hennies, M. , G. Das and M. Gauly 2013. Measurement of Ascaridia galli infection by ELISA. In Measurement of Ascaridia galli infection by ELISA. International symposium of the World Association of Veterinary Laboratory Diagnosticians (WAVLD) 16th, 10th OIE Seminar, 32nd Symposium of AVID. Berlin, Germany.

Höglund, Johan and Désirée S. Jansson 2011. Infection dynamics of Ascaridia galli in non-caged laying hens. Veterinary Parasitology 180: 267-273. doi: http://dx.doi.org/10.1016/j.vetpar.2011.03.031

Horning, G., S. Rasmussen, A. Permin and M. Bisgaard 2003. Investigations on the influence of helminth parasites on vaccination of chickens against Newcastle disease virus under village conditions. Trop Anim Health Prod 35: 415-424.

Idi, A., A. Permin and K. D. Murrell 2004. Host age only partially affects resistance to primary and secondary infections with Ascaridia galli (Schrank, 1788) in chickens. Vet Parasitol 122: 221-231. doi: 10.1016/j.vetpar.2004.04.006

Johnston, Claire E., Catherine Hartley, Anne-Marie Salisbury and Paul Wigley 2012. Immunological Changes at Point-of-Lay Increase Susceptibility to $<$ italic>Salmonella enterica</italic> Serovar Enteritidis Infection in Vaccinated Chickens. PLoS ONE 7: e48195. doi:

10.1371/journal.pone.0048195

Kaufmann, Falko, Gürbüz Daş, Rudolf Preisinger, Matthias Schmutz, Sven König and Matthias Gauly 2011a. Genetic resistance to natural helminth 
infections in two chicken layer lines. Veterinary Parasitology 176: 250257. doi: http://dx.doi.org/10.1016/j.vetpar.2010.11.007

Kaufmann, Falko, Gürbüz Daş, Birgit Sohnrey and Matthias Gauly 2011b. Helminth infections in laying hens kept in organic free range systems in Germany. Livestock Science 141: 182-187. doi: http://dx.doi.org/10.1016/j.livsci.2011.05.015

Kringel, H. and A. Roepstorff 2007. Trichuris suis excretory/secretory antigenspecific antibodies in serum from single-inoculated pigs. Parasite Immunol 29: 327-330. doi: 10.1111/j.1365-3024.2007.00943.x

Kringel, Helene, Stig Milan Thamsborg, Heidi Huus Petersen, Harald Heinz Herbert Göring, Per Skallerup and Peter Nejsum 2015. Serum antibody responses in pigs trickle-infected with Ascaris and Trichuris: Heritabilities and associations with parasitological findings. Veterinary Parasitology 211 : 306-311. doi: http://dx.doi.org/10.1016/j.vetpar.2015.06.008

Marcos-Atxutegi, C., B. Gandolfi, T. Arangüena, R. Sepúlveda, M. Arévalo and F. Simón 2009. Antibody and inflammatory responses in laying hens with experimental primary infections of Ascaridia galli. Veterinary Parasitology 161: 69-75. doi: http://dx.doi.org/10.1016/j.vetpar.2008.12.011

Martin, A., E. A. Dunnington, W. B. Gross, W. E. Briles, R. W. Briles and P. B. Siegel 1990. Production traits and alloantigen systems in lines of chickens selected for high or low antibody responses to sheep erythrocytes. Poult Sci 69: 871-878.

Michael, E. and D. A. Bundy 1989. Density dependence in establishment, growth and worm fecundity in intestinal helminthiasis: the population biology of 
Trichuris muris (Nematoda) infection in CBA/Ca mice. Parasitology $98 \mathrm{Pt}$ 3: 451-458.

Norup, Liselotte Rothmann, Tina S. Dalgaard, Janne Pleidrup, Anders Permin, Torben W. Schou, Gregers Jungersen, Dorte R. Fink and Helle R. JuulMadsen 2013. Comparison of parasite-specific immunoglobulin levels in two chicken lines during sustained infection with Ascaridia galli. Veterinary Parasitology 191: 187-190. doi:

http://dx.doi.org/10.1016/j.vetpar.2012.07.031

Permin, A. and J.W. Hansen 1998. Epidemiology, Diagnosis and Control of Poultry Parasites. FAO Handbook. Rome, Italy. Food and Agricultutre Organisation of the United Nations: pp 22-23.

Permin, A., H. Ranvig and P. Nansen 1999. Difference in parasite burdens between Danish Landrace chickens and Lohman Brown chickens infected with Ascaridia galli. In: Proceeding of the 17th International Conference of the World Association for the Advancement of Veterinary Parasitology Copenhagen: c.6.74.

Pinard, M. H., J. A. M. Van Arendonk, M. G. B. Nieuwland and A. J. Van der Zijpp 1993. Divergent selection for humoral immune responsiveness in chickens: distribution and effects of major histocompatibility complex types. Genetics, Selection, Evolution : GSE 25: 191-203. doi: $10.1186 / 1297-9686-25-2-191$

Pinard, M. H., J. A. van Arendonk, M. G. Nieuwland and A. J. van der Zijpp 1992. Divergent selection for immune responsiveness in chickens: estimation of realized heritability with an animal model. Journal of animal science 70 : 2986-2993. doi: /1992.70102986x 
Pleidrup A, Janne, Liselotte R. Norup, Tina S. Dalgaard, Pete Kaiser, Anders Permin, Torben W. Schou, Dorte Fink Vadekær, Gregers Jungersen, Poul Sørensen and Helle R. Juul-Madsen 2014. Cytokine gene expression profiles in chicken spleen and intestinal tissues during Ascaridia galli infection. Veterinary Parasitology 206: 317-321. doi: http://dx.doi.org/10.1016/j.vetpar.2014.10.016

Ruff, M.D. and R.A. Norton 2008. Nematodes and Acanthocephalans. In: Saif, Y.M. (Ed.), Disease of Poultry 12th edn. Wiley-Blackwell Publishing, San Fransisco, p. 1352

Schwarz, Anna, Matthias Gauly, Hansjörg Abel, Gürbüz Daş, Julia Humburg, Karl Rohn, Gerhard Breves and Silke Rautenschlein 2011. Immunopathogenesis of Ascaridia galli infection in layer chicken. Developmental \& Comparative Immunology 35: 774-784. doi: http://dx.doi.org/10.1016/j.dci.2011.02.012

Siwek, M., B. Buitenhuis, S. Cornelissen, M. Nieuwland, E. F. Knol, R. Crooijmans, M. Groenen, H. Parmentier and J. van der Poel 2006. Detection of QTL for innate: non-specific antibody levels binding LPS and LTA in two independent populations of laying hens. Dev Comp Immunol 30: 659-666. doi: 10.1016/j.dci.2005.09.004

Skallerup, P., L. A. Luna, M. V. Johansen and N. C. Kyvsgaard 2005. The impact of natural helminth infections and supplementary protein on growth performance of free-range chickens on smallholder farms in El Sauce, Nicaragua. Prev Vet Med 69: 229-244. doi:

10.1016/j.prevetmed.2005.02.003 
Sloss MW, Kemp RL and Zajac AM 1994. Fecal examination: dogs and cats. Veterinary clinical parasitology Sixth Ed.

Tarbiat, B., D. S. Jansson, E. Tydén and J. Höglund 2016. Comparison between anthelmintic treatment strategies against Ascaridia galli in commercial laying hens. Veterinary Parasitology 226: 109-115. doi: http://dx.doi.org/10.1016/j.vetpar.2016.07.006

Thienpoint, D., Rochette, F., Vanparis, O.F.J., 1986. Diagnosis Helminthiasis by Coprological Examination, 2nd. Janson Research Foundation, Beerse. Wakelin, D. 1965. Experimental Studies on the Biology of Capillaria obsignata Madsen, 1945, a Nematode Parasite of the Domestic Fowl. Journal of Helminthology 39: 399-412.

Wijga, S., H. K. Parmentier, M. G. Nieuwland and H. Bovenhuis 2009. Genetic parameters for levels of natural antibodies in chicken lines divergently selected for specific antibody response. Poult Sci 88: 1805-1810. doi: $10.3382 /$ ps.2009-00064

Wongrak, K., G. Das, E. Moors, B. Sohnrey and M. Gauly 2014. Establishment of gastro-intestinal helminth infections in free-range chickens: a longitudinal on farm study. Berl Munch Tierarztl Wochenschr 127: 314-321.

Wongrak, K., G. Das, U. K. von Borstel and M. Gauly 2015. Genetic variation for worm burdens in laying hens naturally infected with gastro-intestinal nematodes. British Poultry Science 56: 15-21. doi:

$10.1080 / 00071668.2014 .981147$

Zhao, G., B. Shen, Q. Xie, L. X. Xu, R. F. Yan, X. K. Song, I. A. Hassan and X. R. Li 2012. Detection of Toxoplasma gondii in free-range chickens in China 
based on circulating antigens and antibodies. Vet Parasitol 185: 72-77. doi: 10.1016/j.vetpar.2011.10.031 
5. General discussion 


\subsection{General discussion foreword}

Greater capacity (88.2\%) for faecal eggs from the same infrapopulation discussed the different embryonation ability of Ascaridia galli eggs originating from two different sources (faeces/ worm uteri) in the first study (Paper 1). The development of the faecal eggs began within 24 hours of collecting faeces in $7 \%$ of the eggs. Approximately $1 / 3$ of uterine eggs did not initiate embryonation. In the second study (Paper 2), a high correlation $(r=0.89, \mathrm{P}<0.001)$ between plasma and an egg yolk specific $A$. galli antibody was investigated. Protection role of a specific plasma $A$. galli antibody transferred to egg yolk was discussed. The gender of chicks that had a significant effect on the specific $A$. galli antibody released and harvested the most worms from maternal antibody positive chicks, challenged by a higher infection dose $(+1000)$, were shown. In the third study (Paper 3), a significant effect of the total specific antibody responses against the most prevalent nematode pathogens in two different breeds (LB Plus/ LB Classic) within the free-range system were discussed. The LB classic genotype was more susceptible to the most prevalent gastrointestinal nematode with a significantly $(P=0.00819)$ higher worm load and lower total specific antibodies than the LB plus genotype at necropsy.

\subsection{Ascaridia galli eggs originated from the same infrapopulation}

Uterine eggs were used as the infection material in most of the previous Ascaridia galli infection studies (Dahl et al., 2002; Gauly et al., 2005; K.H. Yusuf et al., 2016; Onyirioha, 2011; Permin et al., 2006; Todd et al., 1952; Tongson and McCraw, 1967). To harvest uterine eggs, slaughtered chickens are needed, which is ethically and 
economically a conflicting issue. Moreover, the pre-patent period (time between infection and first eggs shed) of A.galli is relatively long (Herd and McNaught, 1975). Chickens can expel worms (Dahl et al., 2002) and all eggs in the worm uteri are not yet mature (Graybill, 1924; Püllen U, 2007; Tiersch et al., 2013b). There is a high probability of losing or damaging eggs during isolation (Tiersch et al., 2013b). To supply the favorable doses with fully developed eggs, much higher numbers of uterine eggs are needed to compensate for the losses resulting from undeveloped/ immature eggs and/ or higher egg mortality. Thus, using uterine eggs as the infection material is challenging due to the mentioned disadvantage. Beside the advantages of using faceal eggs in opposite of mentioned uterine eggs characteristics faecal eggs cannot be considered safe infectious even though is less in comparison with uterine eggs. For mono-infections, morphological similarities between Heterakis gallinarum and A.galli eggs can be an important issue to consider (Das et al., 2011; Thienpoint, 1986).

Eggs in the last part of the uteri can be considered as fully developed and capable of embryonation, as their size corresponds well to those found in freshly deposited faeces (Graybill, 1924). In the first study (Paper 1), in order to isolate eggs from worms, entire worm (Daş et al., 2010; K.H. Yusuf et al., 2016) uteri were used that prepared the isolated eggs from all parts of the worm body, including immature eggs. Based on the presence of immature eggs, it was hypothesised that most isolated eggs from worm uteri can't reach the embryonated stage. In the current study it's shown that almost $60 \%$ of uterine eggs did not even initiate embryonation and remained undeveloped throughout the study period. Thus, based on the results, we conclude that uterine eggs are less able to complete embryonation than faecal eggs. 
The intact $A$. galli eggs have three inner layers with a permeable vitelline membrane, a resistant thick shell and a thin albuminous outer layer (Ackert, 1931; Hansen, 1974; Hauck and Hafez, 2013) and are highly resistant to the external environmental conditions (Tarbiat et al., 2015). Damaged nematode eggs, however, have no potential to initiate embryonic development (Johnston and Dennis, 2012). Isolating eggs from worm uteri needs mechanical crashing/ grinding and it was hypothesised that uterine eggs might get damage more severely than faecal eggs, which have no mechanical damaging methods to isolate. Although Tiersch et al. (2013a) showed high damaged uterine eggs for $C$. obsignata eggs, the current study shows no significant difference $(P=0.179)$ between isolated eggs from worm uteri or faeces (Figure 2). Notably, the percentages of damaged eggs caused by mechanical grinding during isolation processes were low and similar between faecal and uterine eggs, $0.5 \%$ and $2.2 \%$, respectively. This confirms the robust morphological structure of $A$. galli eggs. Because there was no difference in the proportion of damaged eggs, the differences in embryonation ability of the faecal and uterine eggs must be attributed to factors other than egg integrity (Graph not shown in the first study).

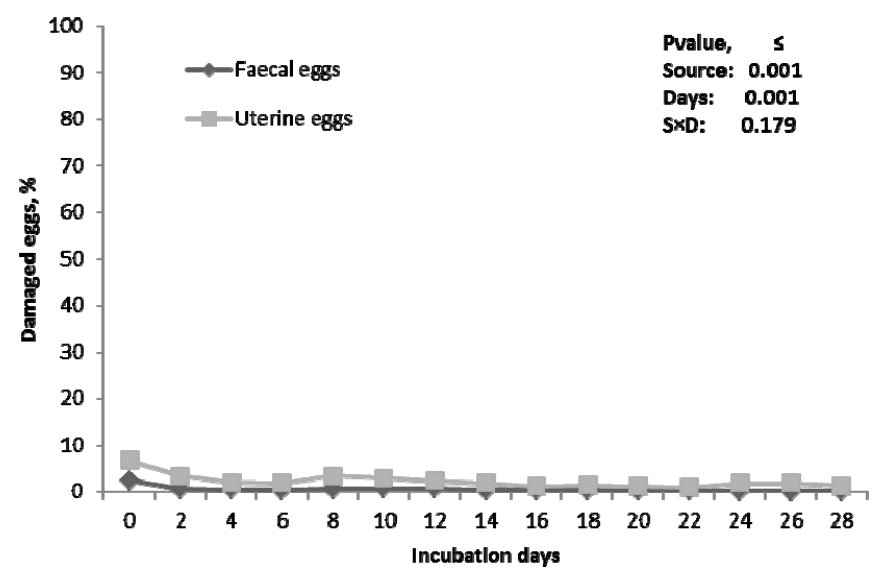

Figure 2: Percentages of damaged eggs during the incubation period 
Uterine eggs may not be completely free from worm tissue and may induce an additional antigenic stimulation when given to birds. This hypothesis was demonstrated by challenging 40 Lohman LSL chickens ( 8 weeks old) with +1000 isolated fully embryonated A. galli eggs from both sources (Faeces/ Uterus) of every infrapopulation. From beginning of the experiment blood samples were taken from Vena ulnaris of all chickens every 3 weeks ( 3 times). Plasma obtained was stored at $-20{ }^{\circ} \mathrm{C}$ for the ELISA test. Analysed data in Figure 3 shows differences in host antibody responses to $A$. galli eggs from two different sources. Hosts challenged by faecal eggs released less specific antibody levels than host challenged by uterine eggs (data not published in the first study).

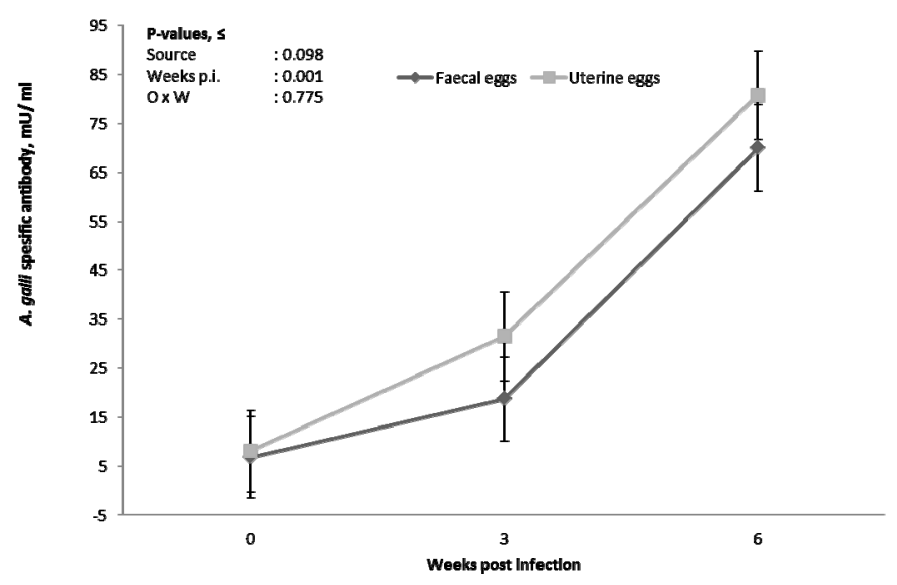

Figure 3: Specific antibody responses from two different sources of isolated eggs

\subsubsection{In ovo embryonic development}

Under natural environmental conditions, faecal eggs will complete an in ovo larval development (embryonation) to reach infectivity (Permin et al., 1998). This duration may vary from 1 to 8 weeks depending on various environmental factors (Ackert, 
1931; Onyirioha, 2011; Ramadan and Abou Znada, 1991; Tarbiat et al., 2015). In this study, isolated eggs from both origins reached the embryonated stage in almost two weeks, which is very similar to a study conducted by Onyirioha (2011). The first study, which used an entire worm uterus to embryonate came to the same results as Tiersch et al. (2014) who, in comparison, used the first two-thirds of a uterus (proximal to vulva) of intact worms of $C$. obsignata. This shows the lesser embryonation ability of uterine eggs when compared to faecal eggs. It has been demonstrated that the vast majority of the faecal eggs $(\approx 90 \%)$ are able to complete embryonation, whereas less than $40 \%$ of uterine eggs completed embryonation. This result is in close agreement with the result for C. obsignata eggs, with $95 \%$ of embryonated faecal eggs compared to $32.6 \%$ of uterine eggs (Norton and Joyner, 1965) and is probably due to the high proportion of undeveloped/ immature eggs in worm uteri (Graybill, 1924; Püllen U, 2007).

\subsubsection{Different stages of in ovo embryonic development}

Starting from the second day of incubation, a higher percentage of uterine eggs was found in the undeveloped stage in the current study. The high speed of in ovo embryonic development for faecal eggs was demonstrated by starting development $(7 \%)$ within a certain time period for the collection of fresh faeces samples $(<24 \mathrm{hrs})$. This is faster than Cruz et al. (2012), who reported results for two or more cells of Ascaris suum eggs after 48 hours. Apparently, daily temperature cycles will cause earlier embryonation in eggs compared to constant temperatures (Saunders et al., 2000) 
Todd et al. (1952) monitored fully embryonated eggs for 14 days at room temperature. In addition, $25 \%$ of uterine eggs completed embryonation in 15 days at fluctuating $\left(18-25^{\circ} \mathrm{C}\right)$ temperatures (Onyirioha, 2011). Another study (Katakam et al., 2014) at a constant temperature of $20^{\circ} \mathrm{C}$ showed early development stages and embryonated faecal eggs from one to six days and 30 days respectively. Based on the results of the first study, the developing eggs (faecal/ uterine) completed early development, vermiform stage and embryonation within eight, 14 and 14 days respectively, with no time shift. Apparent cumulative mortality was calculated by the differences between percentages of developing/ viable eggs on d2 (day two) (highest embryonation potential) and fully embryonated eggs on the last day of incubation (d28). This cumulative mortality was higher in uterine eggs $(52.7 \%-38.4 \%=14.3 \%)$ than $(88.4 \%-88.2 \%=0.2 \%)$ in faecal eggs. Embryonic death at very early developmental stages is easy to diagnosis because of darkened and dead eggs, whereas death at later stages may remain unnoticed unless they decompose. Although undeveloped stages in faecal eggs was constant from day two to the end (28th day) of incubation, there was an increase (11.2\%) in undeveloped stages that is shows that the vast majority of egg deaths must have occurred at the very early stages of embryonic development. Thus, mortality for uterine eggs may have been even higher than the present estimate due to non-recognized dead eggs over the incubation time. As discussed before, egg integrity was not influenced by the isolation procedure and egg maturity is lower in uterine eggs. Thus egg mortality may mainly be associated with egg maturation. No time-shift between faecal and uterine eggs was observed. 


\subsection{Passive immunity induced by Ascaridia galli}

It has been shown that transferred IgG from dams to offspring induce passive immunity (Brambell, 1970) as a form of primary specific protection (Hamal et al., 2006). Transfer of a portion of IgG antibodies to offspring and the stimulation of a strong immune response in the host was demonstrated in the study by MarcosAtxutegi et al. (2009). Mondal and Naqi (2001) investigated the transfer of maternal bronchitis virus antibodies to offspring and the transfer of plasma antibodies against viruses (Newcastle and bronchitis) to meat line eggs was studied by Hamal et al. (2006). IgY was reported as mainly immunoglobulin in egg yolk and that the presence of IgY in egg whites may be attributed to the transfer of egg yolk antibodies to egg whites (Hamal et al., 2006). In the second study (Paper 2), 36-week-old dams (Lohmann white LSL) were chosen due to the possibility of the age effect on nematode resistance. This was investigated by (Gauly et al., 2005; Idi et al., 2004) who aimed to uncover whether $A$. galli has a reasonable immune response and whether egg yolk was considered to be a source of IgY antibodies (Sharma, 1997). In agreement with the above mentioned studies the strong correlation shown $(r=0.89$, $P<0.001)$ in the current study investigated successfully transferring antibodies from dam plasma to egg yolk. Transferring a portion of specific plasma antibodies to egg yolk is in close agreement with the results of Hamal et al. (2006). Our results suggest that the amount of antibody present in egg yolk is dependent on dam antibody levels (Brierley and Hemmings, 1956).

\subsubsection{Infection dose on worm load and worm phenotypic association}

Significantly $(P \leq 0.001)$ correlated higher infection rates by higher infection doses of A. galli eggs were obtained in the current study and among all challenged chickens. 
After six weeks of study four challenged chickens infected with a +100 infection dose were not infected. Gauly et al. (2001) showed higher harvested worms, female worms and less male worms at higher infection doses of $A$. galli eggs. In the current study chickens infected with higher infection doses $(+1000)$ of $A$. galli eggs hosted 3.4 times more worms $(19.2 \pm 1.7)$ and 3.6 with 3 times more female $(11.8 \pm 1.05)$ and male worms $(7.5 \pm 0.75)$. This data is in agreement with higher harvested worms and larvae in Tongson and McCraw (1967) and Ferdushy et al. (2012), who assessed higher infection doses. In all study groups, harvested worms reached a size corresponding to their fertile stage $(5.1-7.6$ and $7.2-11.6 \mathrm{~cm}$ for males and females, respectively) (Ackert, 1931), which is higher than results reported by Ferdushy et al. (2013). Parasitological parameters in the current study were higher than those of other studies, independent of study conditions (Daş et al., 2010; Gauly et al., 2001; Tongson and McCraw, 1967), and were similar to those of the Abdelqader et al. (2007), who studied one-day-old chicks challenged with German $A$. galli. There was a significant difference in worm weights, with heavier worms occurring at lower chick infection doses, which is different from the results obtained by Gauly et al. (2001). Additionally, the current results showed an inverse correlation between worm burden and the phenotypic association of worms, which may be attributed to favorable environmental conditions, as demonstrated by (Gauly et al., 2001). Figure 4 (a-d) shows a negative correlation of worm loads for both genders with their length/ weight with a more negative correlation of worm weight compared to the length in both genders (data not shown in the paper). 


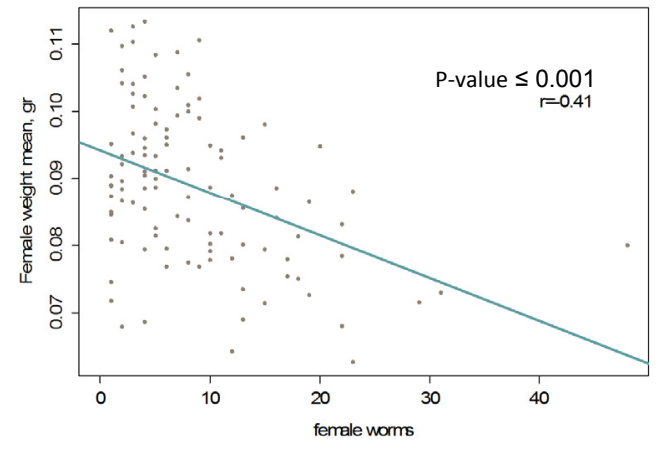

A.

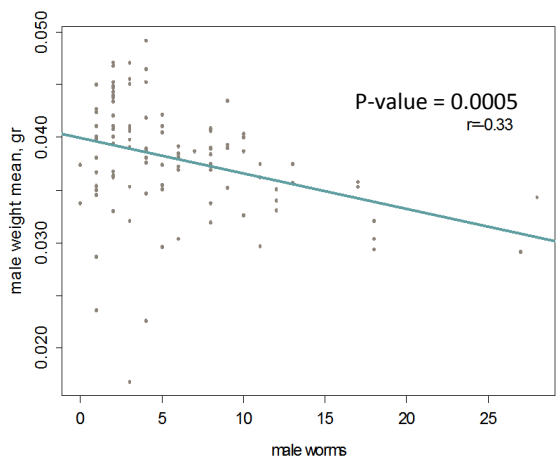

C.

Figure 4. Correlation between number of worms from both genders and worm characteristics

Correlation between female worms with female worm weights in grams (A); Female worms with female length in centimetre (B); Male worms with male worm weights in grams (C); Male worms with male length in centimetre (D)

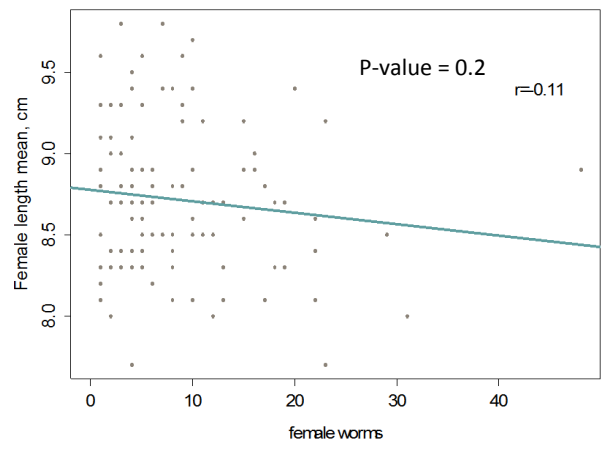

B.

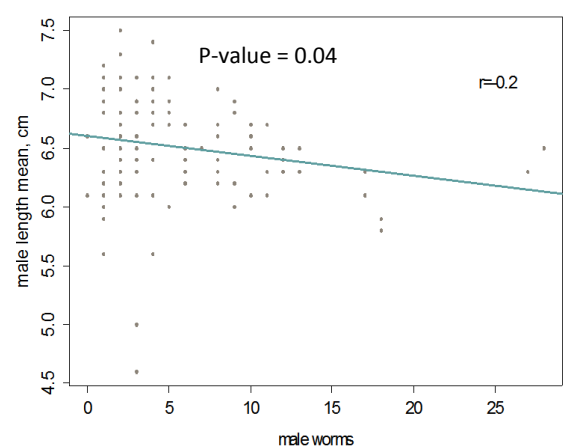

D. 


\subsubsection{Host gender on immune response and worm load}

Bettridge et al. (2014) investigated higher antibody levels in female chickens challenged by bacterial (Salmonella and Pasteurella) infections, which was also investigated in the Johnston et al. (2012) study. Here, a decrease in the lymphocyte population involved in cell-mediated immunity ( $T$ lymphocytes) was shown. There was no corresponding change in humoral immunity (B lymphocytes) after the sexual maturity of birds and it was concluded that female chickens are more resistant to infection. Based on obtained result in this study, higher (1.4 times) antibody concentrations, independent of dam infection were shown in female chickens when compared to male chickens. All chickens were necropsied at 42 days of age and heavier/ longer female worms were harvested from female chickens. The significant difference by gender may be due to the reproductive demands placed on females and to the behavioral traits of females (Bettridge et al., 2014). There is no significant difference in the effect of chicken gender on worm load in the current study. However, based on a negative association between phenotypic characteristics and number of worms in infrapopulation, it is assumed that female chickens with higher antibody concentration and heavier/ longer female worms hosted fewer female worms due to competition and favourable environmental condition in infrapopulation.

\subsubsection{Maternal protection}

Kringel and Roepstorff (2007) investigated positive but poor associations between antibody levels and worm burden in pigs infected with T.suis. No significant correlations between specific offspring antibody plasma titres and worm burden were observed in the current study, which is in line with observed very weak correlations between plasma antibody concentrations and worm burden in the study by Marcos- 
Atxutegi et al. (2009). An inverse relationship between epg and antibody level has been investigated (Marcos-Atxutegi et al., 2009; Norup et al., 2013), which shows the possibility of humoral immunity involved in protection (Norup et al., 2013). Based on current results of the transferred maternal antibodies to egg yolk, by correlation between egg yolk and plasma antibodies concentrations, lower infection rates in maternal antibody positive (mab+) chickens compared to maternal antibody negative (mab-) chickens were expected. Unexpectedly, our results reflected higher infection rates in mab+ chickens than mab- chickens in interaction between dams and offsprings, which suggest the absence of humoral immunity to the $A$. galli nematode in experimental infected chickens. By comparing the interaction results obtained from different infection doses in both mab+/ - groups, we observed that worm burden increased (2.6 times) at higher infection doses $(+1000)$ in mab+ chickens, whereas this increase was 5 times at the same infection dose in mab- chickens. This result demonstrates lower worm burden in mab- chicks against the $A$. galli pathogen, although Andersen et al. (2013) did not observe protection against $A$. galli.

\subsection{Host genotype in immune response of free-range chickens}

It has been demonstrated that immunity is strongly controlled by chicken genotype (Kaufmann et al., 2011b; Wongrak et al., 2015a). Brown chicken genotypes are genetically more resistant to parasites than white genotypes (Gauly et al., 2002; Sloss MW et al., 1994; Wakelin, 1965) and the two examined genotypes (LB plus and LB classic) share a very similar genetic background (Lohmann Tierzucht Gmbh, 2011). Time period of the third study (Paper 3) in the free-range system fulfilled the prepatent period of prevalent nematodes (Wongrak et al., 2014). The prepatent period for A.galli in young chicken is between four and six weeks (Anderson, 1992). 
This period is one week less for $H$. gallinarum (Fine, 1975). Cappilaria spp, dependant on the species (Permin and Hansen, 1998), has a three week prepatent period. Thus, the vast majority of chickens were reported as infected due to the presence of the three nematode species on the day of necropsy. Results from the current investigation show significantly $(P \leq 0.008)$ less susceptibly for LB plus genotype chickens. Norup et al. (2013) investigated the significant difference for a specific $A$. galli serum antibody titer in two lines of chicken. This variation was then simulated for the different genetical potential of genotypes, leading to the producion of a stronger IgG stimulation. In the current study, the number of LB classic chickens was lower at necropsy than LB plus and LB classic chicken slaughtered nine weeks later than LB plus. The LB plus genotype had a higher total specific antibodies concentration (TsAb) at necropsy compared to LB classic, which is in line with the negative association between $T W b$ and $T s A b$ shown. This result shows the independence of genotypes in older chickens with lower TsAb at necropsy and that they were more susceptible to infection, despite higher releases of specific antibodies for the LB classic genotype before necropsy was shown in the current study.

\subsubsection{Chickens seroconversion}

Investigated helminth parasites effect on chicken vaccinations against Newcastle disease in free-range chicken was shown by the Horning et al. (2003) study. Combined nematodes in free-range chickens increased the immune capacity of the infected hens based on the results obtained by the current study, which were similar to an A.galli nematode infection (Ackert et al., 1935; Idi et al., 2004; Kaufmann et al., 
2011a). Furthermore, there was a low total specific antibody concentrations (TsAb) at the beginning of the current study, which has been increasing fluctuations until week 68 and continuing a rapid rise until week 78 . This date was one week and 10 weeks before the necropsy day for LB plus and LB classic genotypes respectively. Horning et al. (2003) showed the fluctuated increase in the Newcastle antibody concentration which was susceptible to deworming in the free-range chicken system. Ferdushy et al. (2014) also showed fluctuated antibody response against A.galli. Hormonal changes throughout the laying activities of laying hens will make chickens more susceptible to infection (Ferdushy et al., 2014; Gauly et al., 2005). Recent infections may not induce the specific antibodies required within the serum, due to previous parasite exposure and can persist for a long time (Kringel et al., 2015). It is assumed that the lower TsAb titer for the beginning of the current study was due to hormonal changes during laying activities although there is a lack of continuous total worm burden (TWb) data aligns to obtained TsAb before necropsy.

\subsubsection{Phenotypic associations}

Based on the obtained results, there is positive but weak association between total nematode eggs per gram (Tepg) and TsAb before necropsy, which is not in close agreement with the results of Kaufmann et al. (2011a). These simulate the obtained low FEC of two chicken lines in the free-range system after six months of developing host immunity to release higher antibodies. Wongrak et al. (2014) discussed very low Tepg for the first 3 months of the study at the beginning of the laying period towards the final three months, which is in line with this study's TsAb before necropsy. Obtained inverse relationships between the antibody level and intensity of eggs 
showed by Marcos-Atxutegi et al. (2009) and Norup et al. (2013) stimulate immune protection by humoral immunity, although the high antibody titers neither prevent continued infection nor are they associated with protection. This conclusion is not in agreement with the current study, which might be because of the different study system (free-range) as well as the use of different nematode species. Also, negative $(P=0.1, r=-0.13)$ association between TWb and TsAb at necropsy was showed by the current study, which is not in line with Kringel and Roepstorff (2007) who investigated the positive but poor associations between antibody level and T.suis worm burden in pigs. The obtained association is similar to Horning et al. (2003) study against Newcastle disease virus and is in agreement with Kringel et al. (2015). This showed a poor association between specific antibody levels, egg excretion and the presence of macroscopic worms.

\subsubsection{Possibility of infectivity diagnosis by antibody detection}

Kringel et al. (2015) showed that antibody detection may be very useful for identifying pigs exposed to infection because FEC may underestimate the prevalence of infection. This study investigated antibodies responses at the beginning of laying period although Tepg was not reliable enough to estimate the infectivity (Wongrak et al., 2015a). A low phenotypic correlation between Tepg and TWb, combination of nematode eggs (Wongrak et al., 2014), problematic collecting suitable faeces samples and diurnal fluctuations in egg excretion (Wongrak et al., 2015b), the freshness effect of faecal samples and species of parasites of interest on epg technique (Cringoli et al., 2010), ability of chickens to host and expel worm populations in A. galli infection (Permin et al., 1999), and low reliability for detection 
$H$. gallinarum infections (Das et al., 2011) make the identification of free-range chicken infectivity difficult and show the need to find alternatives ways of doing so. As far as we know, there is no published information about infection identification using $T s A b$ in free-range chickens. Hosts may have the same mechanism(s) to resist against reported nematodes, especially between $H$. gallinarum and $A$. galli descended from the same family, the Ascaridiae. Higher contributions of $H$. gallinarum (80\%) in TWb is reported by (Wongrak et al., 2015a), which may be the cause of higher heritability. Strong genetic correlation between A.galli and $H$. gallinarum $(r G=0.88+0.34)$ showed in their study confirms the susceptibility of hosts to all nematodes and the production of antibodies against all nematodes. Positively obtained associations between Tepg and TsAb before necropsy in the current study are being investigated to find successful possibilities to help infectivity diagnosis by measuring antibodies in free-range chickens.

\subsection{General conclusion}

Possibly due to the maturation ability of faecal $A$. galli eggs, isolated $A$. galli eggs from host faeces have a higher embryonation capacity than uterine eggs. In experimental infection studies the specific $A$. galli transferred antibody is generally not protective. Furthermore, independent of dam's infection status and offspring infection dose, challenged female offspring with $A$. galli eggs produced more specific antibodies with no effect of host gender on parasite burden chickens. In a free-range system, the LB plus genotype is less susceptible to gastro-intestinal issues with higher TsAb concentrations at necropsy and less TsAb before necropsy. By investigating an association between macroscopic worm load (infection levels) and TsAb at necropsy, estimating continues to assess TsAb before necropsy in free- 
range systems. This study has demonstrated that repeated infection in free-range chickens leads to high rate of infection rather than complete protection against reinfection. It seems possible to identify chicken lines that are less susceptible to gastrointestinal problems and infectivity diagnosis of chickens in free-range systems by immune response. 


\section{References}

Abdelqader, A., M. Gauly and C. B. Wollny 2007. Response of two breeds of chickens to Ascaridia galli infections from two geographic sources. Vet Parasitol 145: 176180. doi: 10.1016/j.vetpar.2006.11.004

Ackert, J.E., D.A. Porter and T.D. Beach 1935. Age resistanceof chickens to the nematodo Ascaridia lineada (Scheider). J. Parasitol 21: 205-213.

Ackert, James E. 1931. The Morphology and Life History of the Fowl Nematode Ascaridia lineata (Schneider). Parasitology 23: 360-379. doi:

doi:10.1017/S0031182000013731

Andersen, J. P., L. R. Norup, T. S. Dalgaard, L. Rothwell, P. Kaiser, A. Permin, T. W. Schou, D. R. Fink, G. Jungersen, P. Sorensen and H. R. Juul-Madsen 2013. No protection in chickens immunized by the oral or intra-muscular immunization route with Ascaridia galli soluble antigen. Avian pathology : journal of the W.V.P.A 42: 276-282. doi: 10.1080/03079457.2013.783199

Anderson, R.C. 1992. Nematode Parasite of Vertebrates. Their Development and Transmission. CAB. International, Wallingford, UK, pp.578.

Bettridge, J. M., S. E. Lynch, M. C. Brena, K. Melese, T. Dessie, Z. G. Terfa, T. T. Desta, S. Rushton, O. Hanotte, P. Kaiser, P. Wigley and R. M. Christley 2014. Infectioninteractions in Ethiopian village chickens. Preventive Veterinary Medicine 117: 358-366. doi: 10.1016/j.prevetmed.2014.07.002

Brambell, F. W. R. 1970. Transmition of immunity in birds. Page 20-41 in Transmition of Passive Immunity from Mother to Young. Elsevier, New York, NY 18. A. Neuberger and E.L. Tatum, ed.

Brierley, Joan and W. A. Hemmings 1956. The Selective Transport of Antibodies from the Yolk Sac to the Circulation of the Chick. Development 4: 34-41.

Cringoli, G., L. Rinaldi, M. P. Maurelli and J. Utzinger 2010. FLOTAC: new multivalent techniques for qualitative and quantitative copromicroscopic diagnosis of 
parasites in animals and humans. Nat Protoc 5: 503-515. doi:

10.1038/nprot.2009.235

Cruz, Ligia M., Michael Allanson, Boo Kwa, Azliyati Azizan and Ricardo Izurieta 2012. Morphological Changes of Ascaris spp. Eggs During Their Development Outside the Host. Journal of Parasitology 98: 63-68. doi: 10.1645/ge-2821.1

Dahl, C., A. Permin, J. P. Christensen, M. Bisgaard, A. P. Muhairwa, K. M. D. Petersen, J. S. D. Poulsen and A. L. Jensen 2002. The effect of concurrent infections with Pasteurella multocida and Ascaridia galli on free range chickens. Veterinary Microbiology 86: 313-324. doi: http://dx.doi.org/10.1016/S0378-1135(02)00015-9

Das, G., T. Savas, F. Kaufmann, A. Idris, H. Abel and M. Gauly 2011. Precision, repeatability and representative ability of faecal egg counts in Heterakis gallinarum infected chickens. Vet Parasitol 183: 87-94.

Daş, Gürbüz, Falko Kaufmann, Hansjörg Abel and Matthias Gauly 2010. Effect of extra dietary lysine in Ascaridia galli-infected grower layers. Veterinary Parasitology 170: 238-243. doi: http://dx.doi.org/10.1016/j.vetpar.2010.02.026

Ferdushy, T., L. A. Luna-Olivares, P. Nejsum, A. K. Roepstorff, S. M. Thamsborg and N. C. Kyvsgaard 2013. Population dynamics of Ascaridia galli following single infection in young chickens. Parasitology 140: 1078-1084. doi: doi:10.1017/S0031182013000401

Ferdushy, T., P. Nejsum, A. Roepstorff, S. M. Thamsborg and N. C. Kyvsgaard 2012. Ascaridia galli in chickens: intestinal localization and comparison of methods to isolate the larvae within the first week of infection. Parasitol Res 111: 2273-2279. doi: $10.1007 / s 00436-012-3079-3$

Ferdushy, T., T. W. Schou, L. R. Norup, T. S. Dalgaard, S. M. Thamsborg, P. Nejsum, A. Permin, H. R. Juul-Madsen and N. C. Kyvsgaard 2014. Acquisition of resistance after continuous infection with Ascaridia galli in chickens. Parasitology 141: 1603-1610. doi: doi:10.1017/S0031182014000742 
Fine, Paul E. M. 1975. Quantitative studies on the transmission of Parahistomonas wenrichi by ova of Heterakis gallinarum. Parasitology 70: 407-417.

Gauly, M., C. Bauer, C. Mertens and G. Erhardt 2001. Effect and repeatability of Ascaridia galli egg output in cockerels following a single low dose infection. Vet Parasitol 96: 301-307.

Gauly, M., C. Bauer, R. Preisinger and G. Erhardt 2002. Genetic differences of Ascaridia galli egg output in laying hens following a single dose infection. Vet Parasitol 103: 99-107.

Gauly, M., T. Homann and G. Erhardt 2005. Age-related differences of Ascaridia galli egg output and worm burden in chickens following a single dose infection. Veterinary Parasitology 128: 141-148. doi: http://dx.doi.org/10.1016/j.vetpar.2004.11.023

Graybill, HW 1924. Capillaria columbae (Rud.) from the chicken and turkey. J Parasitol 10: 205-207.

Hamal, K. R., S. C. Burgess, I. Y. Pevzner and G. F. Erf 2006. Maternal antibody transfer from dams to their egg yolks, egg whites, and chicks in meat lines of chickens. Poult Sci 85: 1364-1372.

Hansen, L.R. Cruthers;Robert W. Weise;F. 1974. Topography of Ascaridia galli eggs exposed to low temperatures or cryoprotectants as shown by scanning electron microscopy. Journal of Parasitology 60: 632-635.

Hauck, R. and H. M. Hafez 2013. Experimental infections with the protozoan parasite Histomonas meleagridis: a review. Parasitology research 112: 19-34. doi: $10.1007 / \mathrm{s} 00436-012-3190-5$

Herd, R. P. and D. J. McNaught 1975. Arrested development and the histotropic phase of Ascaridia galli in the chicken. Int J Parasitol 5: 401-406.

Horning, G., S. Rasmussen, A. Permin and M. Bisgaard 2003. Investigations on the influence of helminth parasites on vaccination of chickens against Newcastle disease virus under village conditions. Trop Anim Health Prod 35: 415-424. 
Idi, A., A. Permin and K. D. Murrell 2004. Host age only partially affects resistance to primary and secondary infections with Ascaridia galli (Schrank, 1788) in chickens. Vet Parasitol 122: 221-231. doi: 10.1016/j.vetpar.2004.04.006

Johnston, Claire E., Catherine Hartley, Anne-Marie Salisbury and Paul Wigley 2012. Immunological Changes at Point-of-Lay Increase Susceptibility to $<$ italic $>$ Salmonella enterica</italic $>$ Serovar Enteritidis Infection in Vaccinated Chickens. PLoS ONE 7: e48195. doi: 10.1371/journal.pone.0048195

Johnston, Wendy L. and James W. Dennis 2012. The eggshell in the C. elegans oocyte-toembryo transition. Genesis 50: 333-349. doi: 10.1002/dvg.20823

K.H. Yusuf, O.J. Ajanusi, A.I. Lawal, L. Saidu and I.D. Jatau 2016. Effects of Ascaridia galli Infection in Two Breeds of Broilers. International Journal of Poultry Science 15: 72-75. doi: 10.3923/ijps.2016.72.75

Katakam, Kiran Kumar, Helena Mejer, Anders Dalsgaard, Niels Christian Kyvsgaard and Stig Milan Thamsborg 2014. Survival of Ascaris suum and Ascaridia galli eggs in liquid manure at different ammonia concentrations and temperatures. Veterinary Parasitology 204: 249-257. doi: http://dx.doi.org/10.1016/j.vetpar.2014.05.017

Kaufmann, Falko, Gürbüz Daş, Rudolf Preisinger, Matthias Schmutz, Sven König and Matthias Gauly 2011a. Genetic resistance to natural helminth infections in two chicken layer lines. Veterinary Parasitology 176: 250-257. doi: http://dx.doi.org/10.1016/j.vetpar.2010.11.007

Kaufmann, Falko, Gürbüz Daş, Birgit Sohnrey and Matthias Gauly 2011b. Helminth infections in laying hens kept in organic free range systems in Germany. Livestock Science 141: 182-187. doi: http://dx.doi.org/10.1016/j.livsci.2011.05.015

Kringel, H. and A. Roepstorff 2007. Trichuris suis excretory/secretory antigen-specific antibodies in serum from single-inoculated pigs. Parasite Immunol 29: 327-330. doi: 10.1111/j.1365-3024.2007.00943.x 
Kringel, Helene, Stig Milan Thamsborg, Heidi Huus Petersen, Harald Heinz Herbert Göring, Per Skallerup and Peter Nejsum 2015. Serum antibody responses in pigs trickleinfected with Ascaris and Trichuris: Heritabilities and associations with parasitological findings. Veterinary Parasitology 211: 306-311. doi: http://dx.doi.org/10.1016/j.vetpar.2015.06.008

Marcos-Atxutegi, C., B. Gandolfi, T. Arangüena, R. Sepúlveda, M. Arévalo and F. Simón 2009. Antibody and inflammatory responses in laying hens with experimental primary infections of Ascaridia galli. Veterinary Parasitology 161: 69-75. doi: http://dx.doi.org/10.1016/j.vetpar.2008.12.011

Mondal, S. P. and S. A. Naqi 2001. Maternal antibody to infectious bronchitis virus: its role in protection against infection and development of active immunity to vaccine. Vet Immunol Immunopathol 79: 31-40.

Norton, C. C. and L. P. Joyner 1965. Experiment chemotherapy of infection with capilaria obsignata. J Comp Pathol 75: 137-145.

Norup, Liselotte Rothmann, Tina S. Dalgaard, Janne Pleidrup, Anders Permin, Torben W. Schou, Gregers Jungersen, Dorte R. Fink and Helle R. Juul-Madsen 2013. Comparison of parasite-specific immunoglobulin levels in two chicken lines during sustained infection with Ascaridia galli. Veterinary Parasitology 191: 187190. doi: http://dx.doi.org/10.1016/j.vetpar.2012.07.031

Onyirioha, J.N.N. 2011. Effects of varying temperatures on the ex-uterine development and incubation period of eggs of Ascaridia galli. new york science journal 4: 61-63.

Permin, A., J. P. Christensen and M. Bisgaard 2006. Consequences of concurrent Ascaridia galli and Escherichia coli infections in chickens. Acta Vet Scand 47: 43-54.

Permin, A. and J.W. Hansen 1998. Epidemiology, Diagnosis and Control of Poultry Parasites. FAO Handbook. Rome, Italy. Food and Agricultutre Organisation of the United Nations: pp 22-23. 
Permin, A., P. Nansen, M. Bisgaard, F. Frandsen and M. Pearman 1998. Studies on Ascaridia galli in chickens kept at different stocking rates. Avian Pathology 27: 382-389. doi: 10.1080/03079459808419355

Permin, A., H. Ranvig and P. Nansen 1999. Difference in parasite burdens between Danish Landrace chickens and Lohman Brown chickens infected with Ascaridia galli. In: Proceeding of the 17th International Conference of the World Association for the Advancement of Veterinary Parasitology Copenhagen: c.6.74.

Püllen U, Cheat S, Moors E, Gauly M., 2007. The role of preparation technique, culture media and incubation time for embryonation of Heterakis gallinarum eggs. Deut. Tierarztl. Woch 115.

Ramadan, H.H. and N.Y. Abou Znada 1991. Morphology and life history of Ascaridia galli in the domestic fowl that are raised in jeddah. J.K.A.U. Sci 4: 87-99.

Saunders, L. M., D. M. Tompkins and P. J. Hudson 2000. The role of oxygen availability in the embryonation of Heterakis gallinarum eggs. International Journal for Parasitology 30: 1481-1485. doi: 10.1016/s0020-7519(00)00139-9

Sharma, J. M. 1997. The structure and function of the avian immune system. Acta Vet Hung 45: 229-238.

Sloss MW, Kemp RL and Zajac AM 1994. Fecal examination: dogs and cats. Veterinary clinical parasitology Sixth Ed.

Tarbiat, B., D. S. Jansson and J. Höglund 2015. Environmental tolerance of free-living stages of the poultry roundworm Ascaridia galli. Veterinary Parasitology. doi: http://dx.doi.org/10.1016/j.vetpar.2015.01.024

Thienpoint, D., Rochette, F., Vanparis, O.F.J., 1986. Diagnosis Helminthiasis by Coprological Examination, 2nd. Janson Research Foundation, Beerse.

Tiersch, K. M., G. Daş, G. Samson-Himmelstjerna and M. Gauly 2013a. The role of culture media on embryonation and subsequent infectivity of Capillaria obsignata eggs. Parasitology research 112: 357-364. 
Tiersch, K. M., G. Das, G. V. Samson-Himmelstjerna and M. Gauly 2013b. The role of culture media on embryonation and subsequent infectivity of Capillaria obsignata eggs. Parasitol Res 112: 357-364. doi: 10.1007/s00436-012-3143-z

Tiersch, K. M., G. Daş, G. von Samson-Himmelstjerna and M. Gauly 2014. Artificial infection of chickens with Capillaria obsignata eggs embryonated in different media. Veterinary Parasitology 200: 139-146. doi: http://dx.doi.org/10.1016/j.vetpar.2013.11.024

Todd, A. C., D. H. Crowdus and Z. N. Wyant 1952. Experimental embryonation of the egg and development of Ascaridia galli in its chicken host. Experimental Parasitology 1: 176-183. doi: http://dx.doi.org/10.1016/0014-4894(52)90008-8

Tongson, Mario S. and Bruce M. McCraw 1967. Experimental ascaridiasis: Influence of chicken age and infective egg dose on structure of Ascaridia galli populations. Experimental Parasitology 21: 160-172. doi: http://dx.doi.org/10.1016/0014$\underline{4894(67) 90078-1}$

Wakelin, D. 1965. Experimental Studies on the Biology of Capillaria obsignata Madsen, 1945, a Nematode Parasite of the Domestic Fowl. Journal of Helminthology 39: 399-412.

Wongrak, K., G. Das, E. Moors, B. Sohnrey and M. Gauly 2014. Establishment of gastrointestinal helminth infections in free-range chickens: a longitudinal on farm study. Berl Munch Tierarztl Wochenschr 127: 314-321.

Wongrak, K., G. Das, U. K. von Borstel and M. Gauly 2015a. Genetic variation for worm burdens in laying hens naturally infected with gastro-intestinal nematodes. British Poultry Science 56: 15-21. doi: 10.1080/00071668.2014.981147

Wongrak, K., M. Gauly and G. Das 2015b. Diurnal fluctuations in nematode egg excretion in naturally and in experimentally infected chickens. Vet Parasitol 208: 195-203. doi: 10.1016/j.vetpar.2015.01.020 


\section{Curriculum Vitae}

\begin{tabular}{|c|c|}
\hline \multicolumn{2}{|c|}{ Personal Information } \\
\hline Name & Shayan Rahimian, B.Sc, M.Sc \\
\hline Email & shayan.rahimian@agr.uni-goettingen.de \\
\hline \multicolumn{2}{|l|}{ Education } \\
\hline \multirow[t]{5}{*}{2012 to 2016} & Ph.D. studies at Georg-August-University Göttingen, Germany \\
\hline & Title: Studies on the Ascaridia galli embryonal stages, potential \\
\hline & maternal \\
\hline & protection and immune response in chicken \\
\hline & Fund: Erasmus mundus \\
\hline \multirow[t]{2}{*}{2007 to 2009} & Study M.Sc. Agricultural Sciences at the Islamic Azad University, Qaesmshahr, Iran \\
\hline & $\begin{array}{l}\text { Title: Effect of Sex ratio with male permanent or interim attendance in Spanish } \\
\text { and white Japanese quail to estimate fertility rate }\end{array}$ \\
\hline \multirow[t]{2}{*}{1998 to 2002} & Study B.Sc. Agricultural Sciences at the Sari Agricultural Sciences and Natural \\
\hline & Resources University, Sari, Iran \\
\hline \multicolumn{2}{|l|}{ Experiences } \\
\hline 2010 to 2012 & Ramsar Toyour Producing Group Ramsar, Iran \\
\hline 2009 & Ministry of agriculture, Ramsar, Iran \\
\hline \multirow{2}{*}{2002 to 2006} & Iran Mayeh (Yeast producing factory) Company Tehran, Iran \\
\hline & Internship and collaboration \\
\hline 2015 & $\begin{array}{l}\text { 3-months internship: Swedish University of Agricultural Science, Department of } \\
\text { biomedical science and veterinary public health (BVF), SLU, Uppsala, Sweden } \\
\text { Project: Optimum storage for Ascaridia galli eggs under laboratory condition }\end{array}$ \\
\hline \multicolumn{2}{|l|}{ Publications } \\
\hline \multirow[t]{2}{*}{2016} & $\begin{array}{l}\text { Rahimian, Shayan, Matthias Gauly and Gürbüz Daş 2016. Embryonation ability of } \\
\text { Ascaridia galli eggs isolated from worm uteri or host faeces. Veterinary Parasitology } \\
\text { 215: 29-34. doi: http://dx.doi.org/10.1016/j.vetpar.2015.10.026 }\end{array}$ \\
\hline & $\begin{array}{l}\text { Rahimian, Shayan, Matthias Gauly and Gürbüz Daş 2016. Maternal protection } \\
\text { against Ascaridia galli? Veterinary Parasitology 233 } \\
\text { http://dx.doi.org/10.1016/j.vetpar.2016.11.014 }\end{array}$ \\
\hline \multicolumn{2}{|c|}{ Posters and Presentations } \\
\hline \multicolumn{2}{|c|}{ Shayan Rahimian, Matthias Gauly, Gurbuz Das: } \\
\hline \multicolumn{2}{|c|}{$\begin{array}{l}\text { "Ascaridia galli eggs harvested from host faeces or worm uteri have different embryonation abilities". } 3^{\text {rd }} \\
\text { International Symposium on Parasite Infections in Poultry. } \\
\text { Vienna, Austria. } 2016\end{array}$} \\
\hline
\end{tabular}




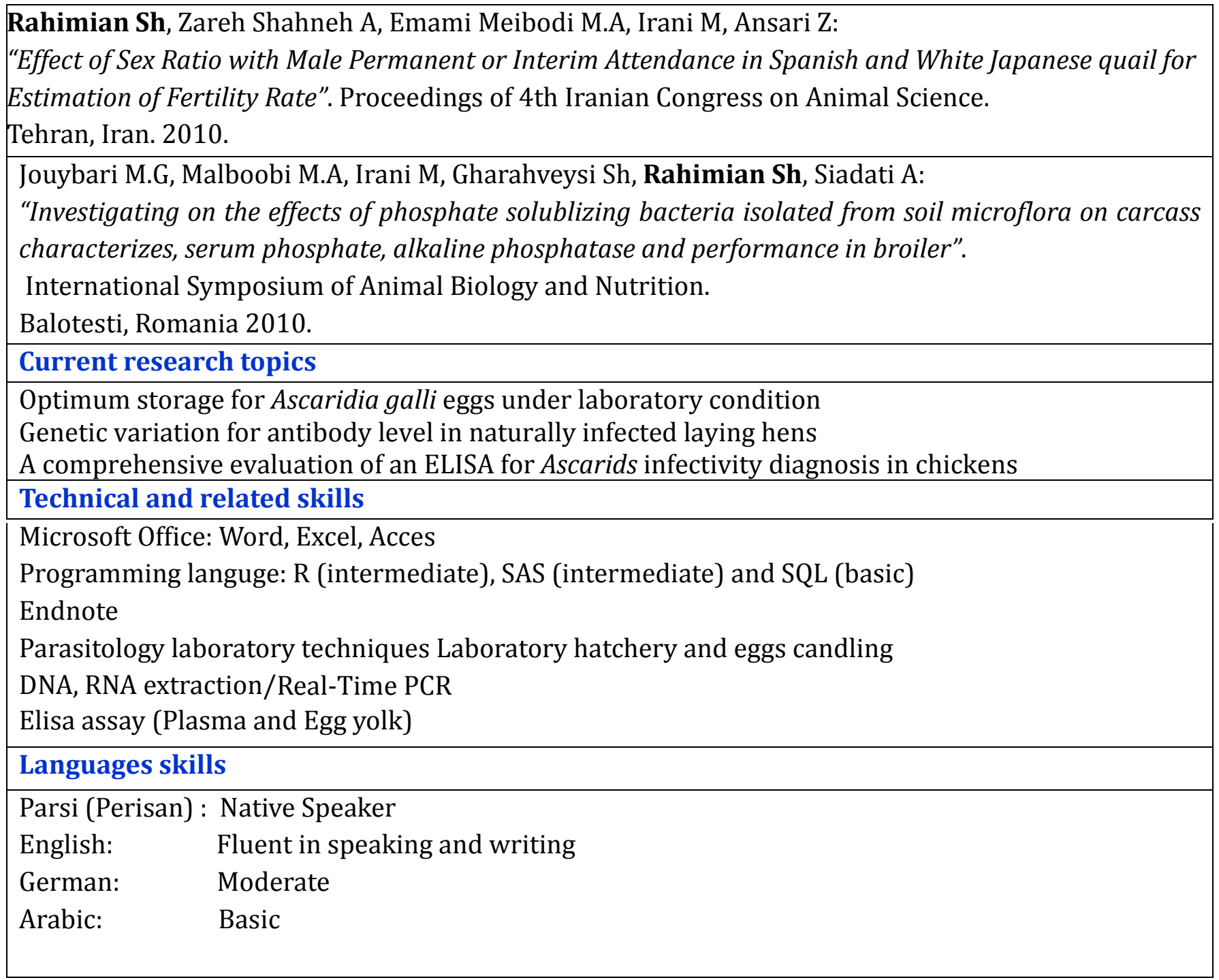

